Prepared in cooperation with the Metropolitan Sewer District of St. Louis

\title{
An Initial Abstraction and Constant Loss Model, and Methods for Estimating Unit Hydrographs, Peak Streamflows, and Flood Volumes for Urban Basins in Missouri
}
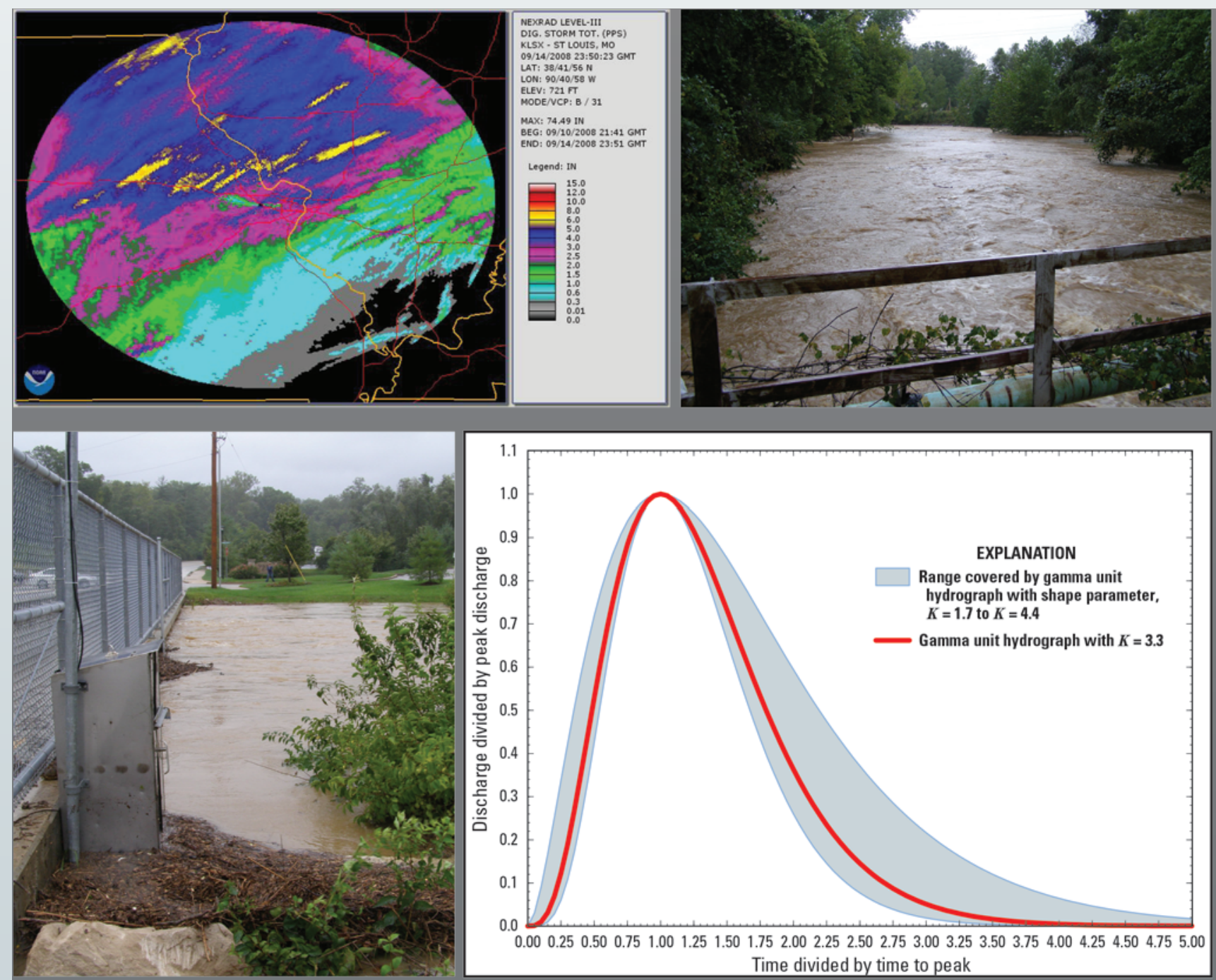

Scientific Investigations Report 2014-5193

U.S. Department of the Interior

U.S. Geological Survey 
Cover. Upper left: Digital storm total precipitation for storms of September 10-14, 2008, as viewed in the National 0ceanic and Atmospheric Administration (NOAA) Weather and Climate Toolkit.

Upper right: Fishpot Creek downstream from Hanna Road in Valley Park, Missouri, September 14, 2008.

Bottom left: Grand Glaize Creek streamflow-gaging station on downstream side of Big Bend Road bridge, near Valley Park, Missouri, September 14, 2008.

Bottom right: Shape of the dimensionless gamma unit hydrograph for selected shape parameter values. 


\section{An Initial Abstraction and Constant Loss Model, and Methods for Estimating Unit Hydrographs, Peak Streamflows, and Flood Volumes for Urban Basins in Missouri}

By Richard J. Huizinga

Prepared in cooperation with the Metropolitan Sewer District of St. Louis

Scientific Investigations Report 2014-5193 


\title{
U.S. Department of the Interior SALLY JEWELL, Secretary
}

\section{U.S. Geological Survey \\ Suzette M. Kimball, Acting Director}

\author{
U.S. Geological Survey, Reston, Virginia: 2014
}

For more information on the USGS - the Federal source for science about the Earth, its natural and living resources, natural hazards, and the environment, visit http://www.usgs.gov or call 1-888-ASK-USGS.

For an overview of USGS information products, including maps, imagery, and publications, visit http://www.usgs.gov/pubprod

To order this and other USGS information products, visit http://store.usgs.gov

Any use of trade, firm, or product names is for descriptive purposes only and does not imply endorsement by the U.S. Government.

Although this information product, for the most part, is in the public domain, it also may contain copyrighted materials as noted in the text. Permission to reproduce copyrighted items must be secured from the copyright owner.

Suggested citation:

Huizinga, R.J., 2014, An initial abstraction and constant loss model, and methods for estimating unit hydrographs, peak streamflows, and flood volumes for urban basins in Missouri: U.S. Geological Survey Scientific Investigations Report 2014-5193, 59 p., http://dx.doi.org/10.3133/sir20145193.

ISSN 2328-031X (print) ISSN 2328-0328 (online) ISBN 978-1-4113-3863-0 


\section{Acknowledgments}

The author gratefully acknowledges the assistance of Jeff Shiner at Metropolitan Sewer District of St. Louis, who provided rain gage information and interpretation that was useful in the verification of the values obtained from next generation weather radar data. Several people at the National Oceanic and Atmospheric Administration provided valuable insight on the usefulness and applicability of the various next generation weather radar products; most notable are Daniel Berkowitz and David Kitzmiller.

The author also gratefully acknowledges Rodney Southard of the U.S. Geological Survey Missouri Water Science Center, whose prior analysis of urban flood frequency and low flow in Missouri were foundational to this study, and who was instrumental in developing the proposal and guiding the current study. Several U.S. Geological Survey Missouri Water Science Center student employees who helped through the course of this study are Zachary Martin, Lisa Holtmann, and Kristopher Johnston; their contributions to the project are gratefully acknowledged. 


\section{Contents}

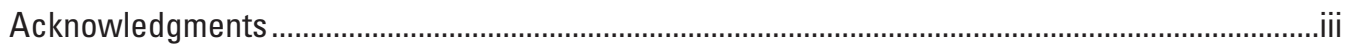

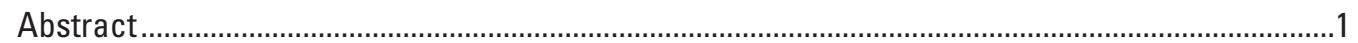

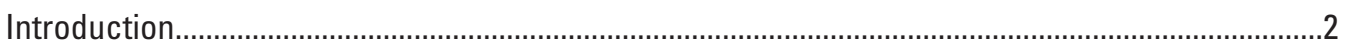

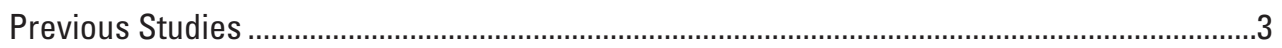

Definition of the Gamma Unit Hydrograph..................................................................................

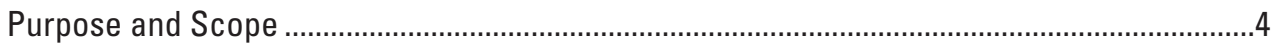

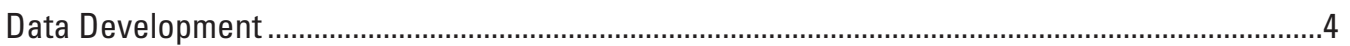

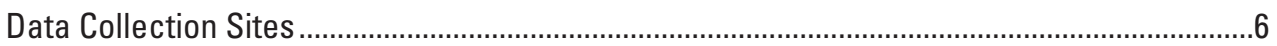

Determination of Basin Characteristics..................................................................................6

Brief Explanation of Next Generation Weather Radar Data Availability and Use ....................9

An Initial Abstraction and Constant Loss Model for Urban Basins in Missouri................................14

Analysis of Storm-Specific Data for Initial Abstraction, Constant Loss, and

Gamma Unit Hydrograph Parameters.................................................................... 14

Estimation of Initial Abstraction ........................................................................................ 16

Estimation of Constant Loss ................................................................................................17

Methods for Estimating Unit Hydrographs for Urban Basins in Missouri .......................................18

Development of Gamma Unit Hydrograph Parameters for Urban Basins in Missouri............18

Testing of Modeled Hydrographs..................................................................................................19

Testing of Gamma Unit Hydrograph Regressions ..........................................................19

Testing of Initial Abstraction and Constant Loss with Gamma Unit Hydrograph ............23

Verification of Modeled Hydrographs ........................................................................................24

Comparison with Previous Studies ......................................................................................26

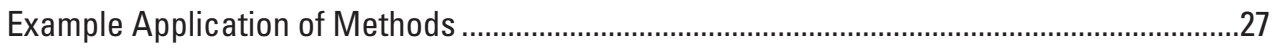

Gamma Unit Hydrograph Parameter Determination Example .......................................27

Effective Rainfall Hyetograph Development Example ......................................................29

Example Application of the Gamma Unit Hydrograph to the Effective Rainfall

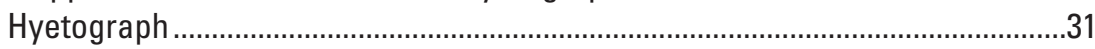

Method for Estimating Peak Streamflow from Rainfall for Urban Basins in Missouri....................31

Methods for Estimating Flood Volume for Urban Basins in Missouri ................................................44

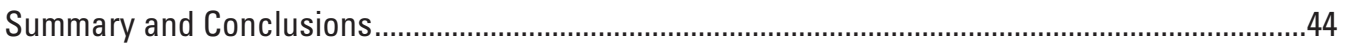

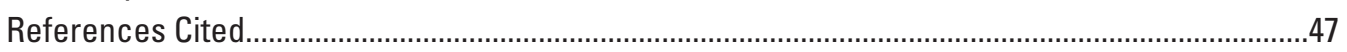

Appendix 1. Procedure for Determining Shape Parameter Using the Numerical

Root Solver in Microsoft ${ }^{\circledR}$ Excel........................................................................................52

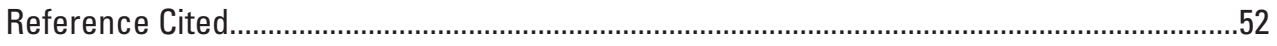

Appendix 2. Methods Used to Estimate Basin Composite Curve Number .................................53

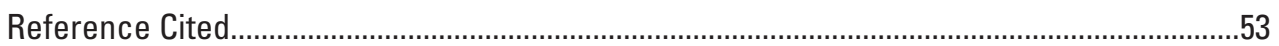

Appendix 3. Procedure for Obtaining Rainfall Hyetograph and Other Rainfall-Related

Values from NEXRAD Radar Data........................................................................................56

Obtaining the NEXRAD Data and Converting to a Table in Microsoft ${ }^{\circledR}$ Excel...........................56

Obtaining Hyetograph from the NEXRAD Tabular Data in Microsoft ${ }^{\circledR}$ Excel............................58

Obtaining Basin-Average Rainfall and Centroid of Rainfall-Digital Storm Product

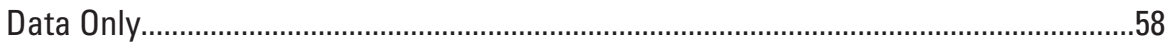

Obtaining Standard Deviation of Rainfall—Digital Storm Product Data Only .........................59

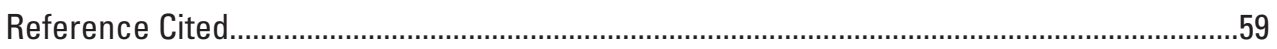




\section{Figures}

1. Map showing location of U.S. Geological Survey streamgages in and adjacent to Missouri used in this study

2. Map showing approximate coverage of next generation weather radar sites in and adjacent to Missouri

3. Map showing urban streamgages and associated upstream basins in the St. Louis, Missouri, area used for this study, and the distribution of Digital Precipitation Array and Digital Storm Product data available from the next generation weather radar station KLSX located near St. Louis, Missouri.

4. Graphs showing comparison of rainfall derived from next generation weather radar near basin centroids and measured rainfall at Metropolitan Sewer District rain gage locations near basin outlets in St. Louis, Missouri, showing comparison and residuals with time

5. Graphs showing examples of final match between direct runoff hydrographs that were uniform and non-uniform and the modeled hydrographs using optimized storm-specific values.

6. Graph showing comparison of storm-specific and modeled values of initial abstraction for all of the storm-specific events used from the 39 streamgages in urban areas in and adjacent to Missouri.

7. Graph showing relation between basin-specific peak streamflow and fitted values of basin-depth peak streamflow by regression from equation 7 for a gamma unit hydrograph developed using data from 39 streamgages in urban areas in and adjacent to Missouri

8. Graph showing relation between basin-specific unit hydrograph time to peak and fitted values of time to peak by regression from equation 8 for a gamma unit hydrograph developed using data from 39 streamgages in urban areas in and adjacent to Missouri

9. Whisker diagrams showing distribution of error statistics for both of the constant loss models for storms before 2011 (primary dataset) and after 2011 (verification dataset) from numerical values listed in tables 5 and 6

10. Graphs showing the shape of the dimensionless gamma unit hydrograph for selected shape parameter values along with the previous dimensionless unit hydrograph developed for Missouri by Becker (1990) and dimensionless unit hydrographs developed in various other studies

11. Graph showing comparison of observed and estimated peak streamflow from the peak streamflow regression equation for streamgages in urban areas in and adjacent to Missouri

12. Graph showing comparison of observed and estimated flood volume from the flood volume regression equation for streamgages in urban areas in and adjacent to Missouri. 


\section{Tables}

1. Description and basin characteristics of selected U.S. Geological Survey streamgages in urban areas in and adjacent to Missouri.

2. Generalized and specific regional mean values of constant loss determined from analysis of storm-specific values at streamgages in urban areas in and adjacent to Missouri.

3. Listing and summary statistics of the basin-specific and regressed values of the unit hydrograph time to peak and associated 5-minute time interval, the basin-depth peak streamflow, and the basin shape parameter for 39 streamgages in urban areas in and adjacent to Missouri

4. Common summary statistics for five forms of error in comparisons of observed and modeled runoff hydrographs for the 39 streamgages in urban areas in and adjacent to Missouri, using an optimized storm-specific excess rainfall hyetograph and the storm-specific or regressed gamma unit hydrograph parameters...

5. Common summary statistics for five forms of error in comparisons of observed and modeled runoff hydrographs for the 39 streamgages in urban areas in and adjacent to Missouri, using a modeled excess rainfall hyetograph and regressed gamma unit hydrograph parameters.

6. Common summary statistics for five forms of error in comparisons of observed and modeled runoff hydrographs for storms after 2011 on the 39 streamgages in urban areas in and adjacent to Missouri, using a modeled excess rainfall hyetograph and regressed gamma unit hydrograph parameters.

7. Range of basin- and rainfall-characteristic values used to develop selected basin-loss and gamma unit hydrograph regression equations from streamgages in urban areas in and adjacent to Missouri.

8. Example application of the method to convert a total rainfall hyetograph to an effective rainfall hyetograph for U.S. Geological Survey streamgage Coldwater Creek near Black Jack, Missouri.

9. Example conversion of unit hydrograph to runoff hydrograph using effective rainfall hyetograph at U.S. Geological Survey streamgage Coldwater Creek near Black Jack, Missouri, for the storm of June 26, 2000

\section{Appendix Tables}

2-1. Land use and land cover classifications and descriptions used to develop runoff curve numbers for streamgages in urban areas in and adjacent to Missouri, from the National Land Cover Dataset.

2-2. Runoff curve numbers for various land use and land cover classifications and soil group types for streamgages in urban areas in and adjacent to Missouri, from tables 9-1 and 9-5 of Chapter 9, National Engineering Handbook Part 630. 


\section{Conversion Factors}

\begin{tabular}{|c|c|c|}
\hline Multiply & By & To obtain \\
\hline \multicolumn{3}{|c|}{ Length } \\
\hline inch (in.) & 2.54 & centimeter $(\mathrm{cm})$ \\
\hline foot $(\mathrm{ft})$ & 0.3048 & meter $(\mathrm{m})$ \\
\hline mile (mi) & 1.609 & kilometer (km) \\
\hline \multicolumn{3}{|c|}{ Area } \\
\hline square mile $\left(\mathrm{mi}^{2}\right)$ & 2.590 & square kilometer $\left(\mathrm{km}^{2}\right)$ \\
\hline \multicolumn{3}{|c|}{ Flow rate } \\
\hline foot per second (ft/s) & 0.3048 & meter per second $(\mathrm{m} / \mathrm{s})$ \\
\hline cubic foot per second $\left(\mathrm{ft}^{3} / \mathrm{s}\right)$ & 0.02832 & cubic meter per second $\left(\mathrm{m}^{3} / \mathrm{s}\right)$ \\
\hline
\end{tabular}

Vertical coordinate information is referenced to the North American Vertical Datum of 1988 (NAVD 88).

Horizontal coordinate information is referenced to the North American Datum of 1983 (NAD 83).

\section{Abbreviations and Symbols}

$A$

$\operatorname{Adj}-R^{2}$

AEP

ASTORAGE

$C_{L}$

${ }^{4} C_{L}$

$C N$

CSL1085LFP

$\delta$

DEM

DPA

DRNAREA drainage area (generic) in square miles

adjusted $R$-squared, a measure of the goodness of fit of a regression equation

annual exceedance probability

the percent of the basin area in storage (ponds, lakes, wetlands)

constant loss, the capacity of a basin to remove rainfall at some constant rate after the initial abstraction amount, $I_{A^{\prime}}$ is satisfied. Analogous (but not equal) to an infiltration rate.

storm-specific value of constant loss based on analysis described in this report composite Natural Resources Conservation Service curve number computed based on land use and soil types in the basin (see appendix 2)

the main-channel slope based on the 10- and 85-percent length method in feet per mile

the integer time step used to round the time to peak of the gamma unit hydrograph $\left(T_{p}\right)$ to the nearest valid time step of the unit hydrograph

digital elevation model

Level III Digital Precipitation Array, a 1-hour rolling accumulation of precipitation, mosaicked and displayed on the approximately 4- by 4-kilometer Hydrologic Rainfall Analysis Project (HRAP) grid

drainage area of the basin in square miles 


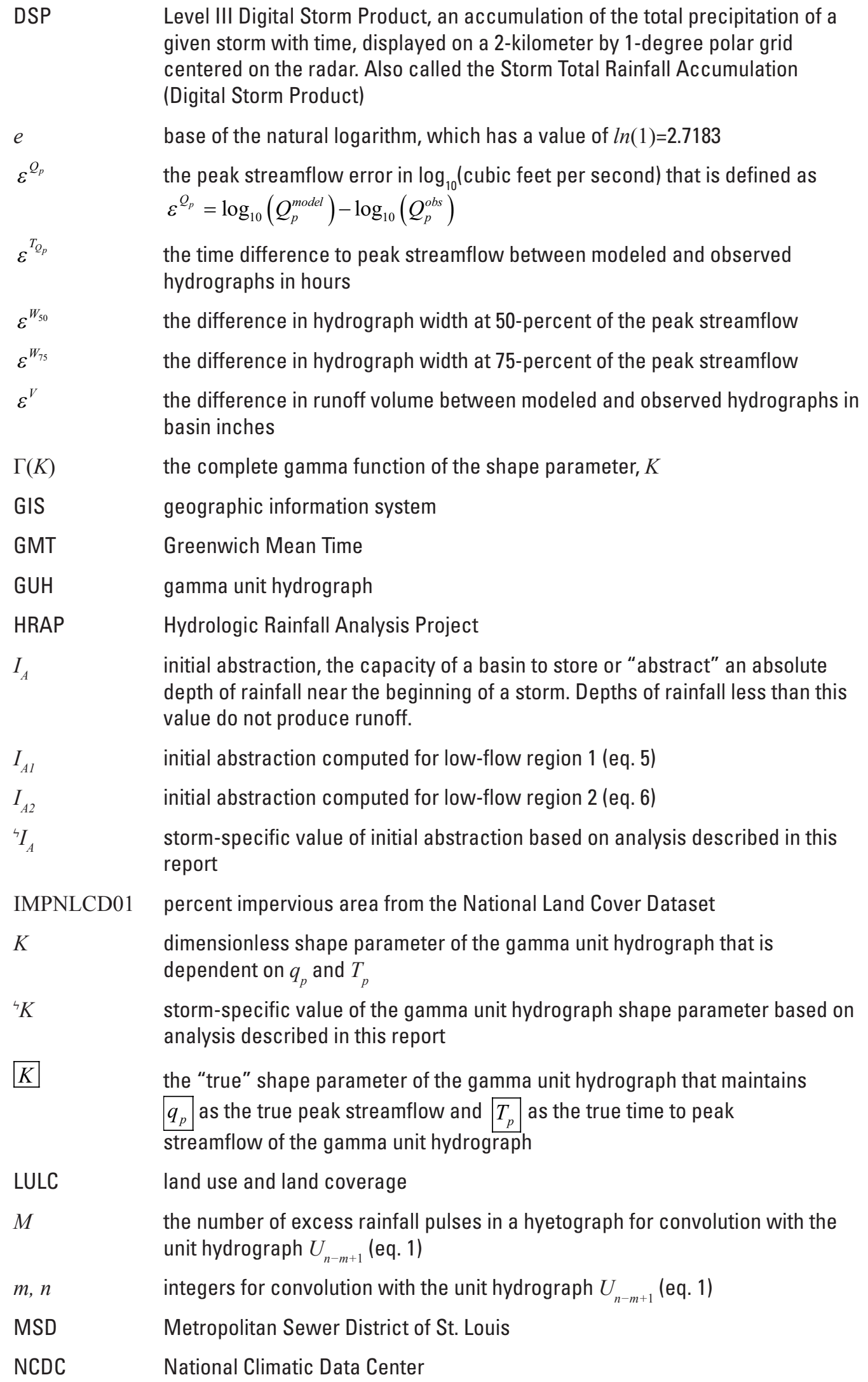


NEH

NEXRAD

NLCD

NOAA

NRCS

NTP

NWIS

NWS

OLS

$P_{m}$

$q(t)$

$q_{p}$

${ }^{4} q_{p}$

$q_{p}$

$Q_{n}$

$Q_{p}$

$\hat{Q}_{p}$

${ }^{4} Q_{p}$

$Q_{p}^{\text {model }}$

$Q_{p}^{\mathrm{obs}}$

RAIN $_{14 \text {-day }}$

RAIN $_{5 \text {-day }}$

RAIN $_{\text {Cent }}$
National Engineering Handbook

next generation weather radar, a network of 160 Weather Surveillance

Radar-1988 Doppler (WSR-88D) units operated by the National Oceanic and Atmospheric Administration's National Weather Service, the Federal Aviation Administration, and the U.S. Air Force

National Land Cover Dataset

National Oceanic and Atmospheric Administration

Natural Resources Conservation Service, formerly the Soil Conservation Service

Level III Storm Total Precipitation, an accumulation of the total precipitation for a given storm with time, displayed on a 2-kilometer by 1-degree polar grid centered on the radar. Similar to the DSP data, but for storms before about 2008 in Missouri and having a less-refined data gradation. Also called the Storm Total Rainfall Accumulation Product (STP) in the literature

National Water Information System

National Weather Service

ordinary least-squares

the $m$ th value of excess rainfall in basin inches for convolution with the unit hydrograph $U_{n-m+1}$ (eq. 1)

the basin-depth peak streamflow of the gamma unit hydrograph in basin inches per hour at time $t$ in hours

basin-depth peak streamflow of the gamma unit hydrograph, in basin inches perhour

storm-specific value of basin-depth peak streamflow of the gamma unit hydrograph based on analysis described in this report

the "true" basin-depth peak streamflow of the gamma unit hydrograph

the $n$th value of streamflow in cubic feet per second from convolution of the unit hydrograph with excess rainfall (eq. 1)

the peak or maximum instantaneous streamflow in cubic feet per second

estimated peak streamflow in cubic feet per second from given storm-specific parameters (eq. 10)

the peak streamflow of a modeled hydrograph using optimized storm-specific GUH parameters (the optimized storm-specific GUH convolved with the stormspecific excess rainfall hyetograph)

the peak streamflow from a context-specific modeled hydrograph (the GUH developed for each basin convolved with either the storm-specific or modeled excess rainfall hyetograph)

the peak streamflow of the observed runoff hydrograph

the 14-day antecedent rainfall in the area in inches

the 5-day antecedent rainfall in the area in inches

the total rainfall at the basin centroid from NEXRAD data, in inches 


\begin{tabular}{|c|c|}
\hline RAIN $_{\text {Storm }}$ & $\begin{array}{l}\text { the total rainfall in the storm in question from the NEXRAD rainfall hyetograph } \\
\text { in inches. This is rainfall immediately before and during the runoff hydrograph, } \\
\text { ignoring rainfall from some time period (usually } 2 \text { hours) before runoff begins. }\end{array}$ \\
\hline SSURGO & Natural Resources Conservation Service Soil Survey Geographic database \\
\hline$t$ & time in hours from inception of streamflow of the gamma unit hydrograph \\
\hline$T_{\text {Lag }}$ & basin lag time \\
\hline$T_{p}$ & time to peak of the gamma hydrograph in hours \\
\hline${ }^{`} T_{p}$ & $\begin{array}{l}\text { storm-specific value of time to peak of the gamma unit hydrograph based on } \\
\text { analysis described in this report }\end{array}$ \\
\hline$T_{p}$ & $\begin{array}{l}\text { the "true" time to peak streamflow of the gamma unit hydrograph with a valid } \\
\text { time step based on an integer value of } \delta \text { and maintaining } q_{p} \text { as the true peak } \\
\text { streamflow of the unit hydrograph }\end{array}$ \\
\hline$T^{Q_{p}}$ & time of the peak streamflow of the runoff hydrograph \\
\hline$T^{Q_{p}^{\text {obs }}}$ & time to peak streamflow of the observed runoff hydrograph \\
\hline${ }^{4} T^{Q_{p}}$ & $\begin{array}{l}\text { time to peak streamflow of the modeled hydrograph using optimized storm- } \\
\text { specific GUH parameters (the optimized storm-specific GUH convolved with } \\
\text { the storm-specific excess rainfall hyetograph) }\end{array}$ \\
\hline $\mathrm{U}_{n-m+1}$ & $\begin{array}{l}\text { the } n-m+1 \text { th value of the unit hydrograph in cubic feet per second for } \\
\text { convolution with excess rainfall } P_{m} \text { (eq. 1) }\end{array}$ \\
\hline USGS & U.S. Geological Survey \\
\hline$V$ & $\begin{array}{l}\text { volume in basin depth of a runoff hydrograph or hyetograph. For a unit } \\
\text { hydrograph, } V=1 \text {. }\end{array}$ \\
\hline$\hat{V}$ & $\begin{array}{l}\text { estimated flood volume in basin inches from given storm-specific parameters } \\
\text { (eq. 11) }\end{array}$ \\
\hline$V_{\text {excess rain }}^{\text {model }}$ & volume of the excess rainfall hyetograph \\
\hline$V^{\text {obs }}$ & volume of the observed runoff hydrograph \\
\hline$V_{\text {runoff }}^{\text {obs }}$ & $\begin{array}{l}\text { volume of the observed runoff hydrograph in basin-depth terms (volume under } \\
\text { the hydrograph divided by the basin area) }\end{array}$ \\
\hline WLS & weighted least-squares \\
\hline WSR-88D & Weather Surveillance Radar-1988 Doppler \\
\hline
\end{tabular}




\title{
An Initial Abstraction and Constant Loss Model, and Methods for Estimating Unit Hydrographs, Peak Streamflows, and Flood Volumes for Urban Basins in Missouri
}

\author{
By Richard J. Huizinga
}

\section{Abstract}

Streamflow data, basin characteristics, and rainfall data from 39 streamflow-gaging stations for urban areas in and adjacent to Missouri were used by the U.S. Geological Survey in cooperation with the Metropolitan Sewer District of St. Louis to develop an initial abstraction and constant loss model (a time-distributed basin-loss model) and a gamma unit hydrograph (GUH) for urban areas in Missouri. Study-specific methods to determine peak streamflow and flood volume for a given rainfall event also were developed.

Distinct basin characteristics were evaluated and selected for use on the basis of their theoretical relation to flow, results from previous studies, and the ability to reliably measure the basin characteristic using digital datasets and geographic information system (GIS) technology. The key basin characteristics determined or computed for each of the 39 basins upstream from the streamflow-gaging stations were drainage area, percent impervious area, main-channel slope based on the 10- and 85-percent length method, percentage of the basin area in storage (lakes, ponds, reservoirs, wetlands), the composite Natural Resources Conservation Service curve number estimated from a combination of the soil type data and land-use characteristics, and the streamflow variability index developed for the recently completed study of low-flow regression in Missouri.

Characteristics of spatial and temporal rainfall distribution came from the next generation weather radar (NEXRAD) network. Procedures were developed for this study to convert the variable radar sweep rate into a 5-minute total rainfall hyetograph using data from the radar bin at the centroid of a given basin. Additional characteristics determined for each storm on the basin included the 5-day and 14-day antecedent rainfall, estimated from the mean of daily rainfall values from various rain gages in the area.

The database of observed rainfall and runoff events for the 39 basins upstream from the streamflow-gaging stations was analyzed to compute the optimal storm-specific initial abstraction and constant loss values, as well as the time to peak, peak streamflow, and shape factor values of the GUH. The optimal storm-specific values were used to develop a regional regression equation for initial abstraction; conversely, the constant loss was estimated not by regression but from either a generalized or specific regional mean value. The optimal storm-specific values of GUH time to peak, GUH peak streamflow, and GUH shape factor were used to develop regression equations for the GUH.

The regression equations for the GUH initially were tested alone, and then were combined with the appropriate regional regression equation for initial abstraction and both the generalized regional and specific regional mean constant loss values. For the GUH regression equations, the interquartile range was substantially smaller than the range spanned by the minimum and maximum values, which indicates most of the errors have much smaller variation, and the minimum and maximum values may be extreme outliers. The central tendency of the regressed errors for peak streamflow and runoff hydrograph volume were both approximately zero, which implies a generally unbiased estimation of these values. The mean and median of the regressed errors for time to peak streamflow were both small but greater than zero, which implies the GUH regression equations create a hydrograph that has a peak that is later in time than observed. Specifically, the regressed times indicate an offset of about 10 minutes, on average, from observed. The mean and median of the regressed errors for widths of the runoff hydrograph at 50 and 75 percent were less than zero, which implies the GUH tends to slightly underestimate these widths compared to the observed.

The appropriate regional initial abstraction regression equation was combined with both the generalized and the specific regional mean constant loss values and the GUH regression equations. Both the generalized regional mean constant loss and specific regional mean constant loss forms of the basin-loss model worked equally well to model the observed runoff hydrograph based on the error analysis, and neither model seems to make a consistently better approximation. 
Both initial abstraction and constant loss models combined with the GUH regression equations were further validated using several storms available after the start of the project in early 2011 with similar but consistently higher error results. If these methods are used in an urban area in Missouri other than those examined in this study, advice to the user is given to consider using the generalized regional mean values. If these methods are used in an urban area that is a subbasin of one of the basins in this study, advice to the user is given to consider using the specific regional mean values.

The rainfall-runoff pairs from the storm-specific GUH analysis were further analyzed against various basin and rainfall characteristics to develop equations to estimate the peak streamflow and flood volume based on a quantity of rainfall on the basin.

\section{Introduction}

Streamflow is used by government agencies, engineers, scientists, and environmental groups for purposes of water management, permitting, and design. The primary source of streamflow data is streamflow-gaging stations (hereinafter referred to as "streamgages") operated by the U.S. Geological Survey (USGS; U.S. Geological Survey, 2014). Streamflow data collected at streamgages inherently reflect unique characteristics of the basin upstream. Characteristics of a basin include magnitude of peak streamflow $\left(Q_{p}\right)$, time to peak $\left(T^{Q_{p}}\right)$ or basin lag time $\left(T_{\text {Lag }}\right)$, flow volume, and base flow. Understanding the flow characteristics of a basin provides a means for estimating a unit hydrograph as part of the process of basin modeling or design of stormwater-management structures. A unit hydrograph is considered unique for a given basin, and may be used to derive the runoff hydrograph from any amount of excess rainfall on the basin (Chow and others, 1988). The runoff hydrograph can be used to determine the water-surface elevation and duration of inundation at and upstream from roadways and drainage structures (Hjelmsfelt and Cassidy, 1975). Unit hydrographs also can be used to estimate flood volumes for combined sewer systems (Hjelmsfelt and Cassidy, 1975).

Estimation of a runoff hydrograph by the unit hydrograph method requires a method to convert a total rainfall hyetograph into an appropriate excess rainfall hyetograph that represents the rainfall that runs off from the basin. A hyetograph is analogous to the more widely known hydrograph but represents a time series of rainfall intensity during a storm event as opposed to a time series of streamflow. The conversion of the total rainfall hyetograph into an excess rainfall hyetograph is accomplished by means of a basin-loss model that is time distributed and consistent with the hypothesized processes (such as loss to surface depressions, infiltration, and evaporation) that prevent rainfall from becoming runoff. Starting in 2011, the USGS, in cooperation with the Metropolitan Sewer District of St. Louis (MSD), examined streamflow data and basin characteristics to develop an initial abstraction $\left(I_{A}\right)$ and constant loss $\left(C_{L}\right)$ model (a time-distributed basin-loss model, hereinafter referred to as " $I_{A}-C_{L}$ model") and unit hydrograph for urban areas in Missouri with particular emphasis on the St. Louis area.

A unit hydrograph is defined as the runoff hydrograph that results from a unit pulse of excess rainfall for a specific duration that also is uniformly distributed over a basin (Chow and others, 1988, p. 213). The basin is assumed to function as a linear system in which the concepts of superposition, proportionality, and time invariance are fundamental (Asquith and Roussel, 2007; Chow and others, 1988):

\section{Superposition.-The runoff hydrograph resulting from two consecutive pulses is computed using the addition of two unit hydrographs, separated by the effective duration of the first pulse. The duration of the unit hydrograph is equal to the time step of the rainfall pulses (that is, a 5-minute unit hydro- graph must be used for rainfall data in 5-minute increments).}

Proportionality.-The runoff hydrograph resulting from a two unit pulse of rainfall of a specific duration has ordinates that are twice as large as those resulting from a single unit pulse of rainfall of the same duration.

Time invariance.-A unit hydrograph has a specified time period (step), and this time step is the duration of the time-invariant (uniform-intensity) excess rainfall. As a result, the magnitude of runoff within each time step is uniform and the temporal input-response relation is constant for a given basin. The duration of the unit hydrograph often is specified in the name of the unit hydrograph. For this study, a 5-minute time step exclusively was used because it is identical to the recording interval at most of the sites used in this study, and is a small finite interval that is sufficiently small to capture salient characteristics of the runoff hydrograph without being computationally complex. Conversion of a 5-minute unit hydrograph to a longer duration requires uncomplicated mathematics.

Computing the runoff hydrograph from an excess rainfall hyetograph using the unit hydrograph requires a process called discrete convolution. The discrete convolution equation (Chow and others, 1988) is

$$
Q_{n}=\sum_{m=1}^{n \leq M} P_{m} U_{n-m+1}
$$

where

$\begin{aligned} Q_{n} & \text { is streamflow, in cubic feet per second; } \\ P_{m} & \text { is the excess rainfall, in basin inches; } \\ U_{n-m+1} & \text { are the ordinates of the unit hydrograph, in } \\ & \quad \text { cubic feet per unit time; } \\ M & \text { is the number of excess rainfall pulses; and } \\ m, n & \text { are integers. }\end{aligned}$


The discrete convolution process applies the unit hydrograph to the incremental pulses of the excess rainfall hyetograph and combines the incremental runoff hydrographs into a total runoff hydrograph.

\section{Previous Studies}

There have been various studies on the estimation of $Q_{p}$, determination of $T_{L a g}$ or $T^{Q_{p}}$, and development of unit hydrographs. Techniques presented by Stricker and Sauer (1982)

and the Natural Resources Conservation Service (2014b) have broad application to urban and rural basins in a variety of locations and terrain. Stricker and Sauer (1982) in particular included 25 urban sites in St. Louis County, Missouri, but Becker (1990) found the methods of Stricker and Sauer (1982) to be less useful than the general approach used by Inman (1987) for Missouri. The methods of the Natural Resources Conservation Service (NRCS, formerly the Soil Conservation Service) were developed using data from relatively small drainage basins, and are presented with no definition of the inherent error that may be expected in their results (Dillow, 1998).

There also have been a number of unit hydrograph studies by the USGS in other nearby states and urban areas (Inman, 1987 [Georgia]; Bohman, 1990, 1992 [rural and urban South Carolina, respectively]; Mason and Bales, 1996 [urban North Carolina]; Dillow, 1998 [Maryland]; Weaver, 2003 [Mecklenburg County, North Carolina]). All of these studies used the O'Donnell (1960) method to develop the dimensionless unit hydrograph, which extracts the unit hydrograph from the direct runoff hydrograph using harmonic analysis of the rainfall excess and runoff data to derive a series of harmonic coefficients. Each increment of rainfall (having a duration equal to the data recording interval) is treated as an individual storm, and an instantaneous unit hydrograph that reproduces the direct runoff hydrograph is computed from the harmonic coefficients (Mason and Bales, 1996). The determination of these harmonic coefficients is not mathematically trivial, and was accomplished by means of specially developed computer programs available or contemporaneously developed at the time of these studies.

Similarly, Becker (1990) applied the method developed by Inman (1987) based on the O'Donnell (1960) method to compute a dimensionless hydrograph for small (less than 40 square miles) rural and urban basins in Missouri. Data for 24 rural and 17 urban streamgages in Missouri were analyzed. The basin lag time could be estimated using one of three equations for urban basins and using one of two equations for rural basins. Peak streamflow for an event could be estimated using equations from Becker's earlier study for estimating $Q_{p}$ from urban basins (Becker, 1986). In the earlier study, Becker (1986) recognized the effects of urbanization on rural basins such as increasing $Q_{p}$ and decreased response times, but only limited urban streamgage data were available in Missouri in 1990.
Several advances have been made in recent years to improve the determination of $Q_{p}$ and unit hydrographs in Missouri, due to increased availability of digital geospatial datasets and other data. Southard (2010) has revised the flood-frequency equations for urban basins based on more than 25 years of additional streamflow data. These equations are used to determine the magnitude and frequency of floods in urban basins in Missouri for the flood annual exceedance probabilities (AEPs) of 50, 20, 10, 4, 2, 1, and 0.2 percent (recurrence intervals of 2, 5, 10, 25, 50, 100, and 500 years, respectively). More recently, Southard (2013) has computed statistics at 532 streamgages in and adjacent to Missouri, and developed regional regression equations for estimating the magnitude and frequency of the annual N-day, 10-year low-flow statistic for gaged and ungaged streams. The N-day durations selected for the regression equations were the 1-, 2-, 7-, 10-, 30-, and 60-day periods. As part of the study, Southard (2013) tabulated values for 32 different basin characteristics determined from a variety of digital geospatial data sources, which are useful for a variety of ancillary studies.

Additionally, the gamma unit hydrograph (GUH) recently was rigorously used to model runoff hydrographs for urban and rural basins in Texas (Asquith and others, 2011; Asquith and Roussel, 2007; Asquith and others, 2005). The GUH has been documented to attain a shape that mimics the general shape of many observed runoff hydrographs (unit or otherwise) with three parameters (it is mathematically convenient to consider three parameters but only two are required), and can be applied to incremental rainfall in an excess rainfall hyetograph in a "forward" approach (as opposed to the O'Donnell [1960] method, which involves determining the unit hydrograph shape from the direct runoff hydrograph in a "backward" approach). Two GUH parameters that are shown to be related to physical characteristics of the basin are basin-depth peak streamflow $\left(q_{p}\right)$ in inches over the basin per hour (basin inches per hour) and time to peak $\left(T_{p}\right)$ in hours. The third parameter is a shape parameter $(K)$ that is uniquely dependent on $q_{p}$ and $T_{p}$. Expression and analysis of unit hydrographs in terms of $q_{p}$ and $T_{p}$ are important because the magnitude and timing of $Q_{p}$ are critical for many designs. Previous studies (Asquith and others, 2003; Asquith and others, 2004; Williams-Sether and others, 2004) of rainfall hyetographs were completed ahead of the $I_{A}-C_{L}$ model study of Asquith and Roussel (2007) for Texas GUH application.

\section{Definition of the Gamma Unit Hydrograph}

The equation (Asquith and others, 2005; Asquith and Roussel, 2007; Asquith and others, 2011) defining a dimensionless gamma hydrograph (unit or otherwise) is

$$
\frac{q(t)}{q_{p}}=\left[\frac{t}{T_{p}} \mathrm{e}^{1-\left(\frac{t}{T_{p}}\right)}\right]^{K}
$$


where

$$
\begin{array}{cl}
q(t) & \text { is streamflow, in basin inches per hour, at time } \\
& t, \text { in hours; } \\
q_{p} & \text { is basin-depth peak streamflow, in basin } \\
& \text { inches per hour; } \\
T_{p} & \text { is gamma hydrograph time to peak, in hours; } \\
& \text { and } \\
K & \text { is a dimensionless shape parameter that is } \\
& \text { dependent on } q_{p} \text { and } T_{p} .
\end{array}
$$

This equation produces streamflow ordinates, $q(t)$, of a GUH for a given time step, $t$. Dividing $q(t)$ by $q_{p}$ and $t$ by $T_{p}$ makes these terms dimensionless. The relation between $q_{p}$ or $q(t)$ (in basin inches per hour) and $Q_{p}$ or $Q_{n}$ (in cubic feet per second) is

$$
Q=645.33 \times q \times A
$$

where

$$
\begin{aligned}
Q & \text { is streamflow, in cubic feet per second; } \\
q & \text { is streamflow, in basin inches per hour; } \\
A & \text { is drainage area, in square miles; and } \\
645.33 & \text { is a units conversion factor. }
\end{aligned}
$$

Although the gamma hydrograph equation is defined by three parameters $\left(q_{p}, T_{p}\right.$, and $\left.K\right)$, any two of the parameters will yield the third if the runoff volume $(V)$ is known (Asquith and others, 2005; Asquith and Roussel, 2007; Asquith and others, 2011). The $V$ of a gamma hydrograph is computed by

$$
V=q_{p} T_{p} \Gamma(K)\left(\frac{\mathrm{e}^{(1)}}{K}\right)^{K}
$$

where

$$
\begin{array}{cc}
V & \begin{array}{c}
\text { is volume of a gamma hydrograph, in basin } \\
\text { inches; }
\end{array} \\
q_{p} & \begin{array}{c}
\text { is basin-depth peak streamflow, in basin } \\
\text { inches per hour; }
\end{array} \\
T_{p} & \begin{array}{c}
\text { is time to peak of the gamma hydrograph, in } \\
\text { hours; }
\end{array} \\
\Gamma(K) \quad \begin{array}{l}
\text { is the complete gamma function (Abramowitz } \\
\text { and Stegun, 1964) for } K \text {; and }
\end{array} \\
K \quad \begin{array}{l}
\text { is a dimensionless shape parameter that is } \\
\text { dependent on } q_{p} \text { and } T_{p} .
\end{array}
\end{array}
$$

Because $V=1$ for a unit hydrograph (a unit volume), equation 4 can be written such that any of the parameters is determined from the other two using a numerical root solver or function minimizer (appendix 1).

For clarity, two notes concerning nomenclature in this report are needed. First, synonymous use of $q$ and $Q$ for "streamflow" (with attendant modifiers) is made throughout this report; the two differ only in context-dependent units. Second, the unit hydrograph time to peak $\left(T_{p}\right)$ is a distinct parameter for the GUH. There also is a hydrograph time of peak, which represents the real time that the peak streamflow of the runoff hydrograph ( $Q_{p}^{\text {obs }}$ ) occurs, and is denoted as $T^{Q_{p}}$.

\section{Purpose and Scope}

The purpose of this report is to present techniques for estimating an $I_{A}-C_{L}$ model (as a time-distributed basin-loss model), a unit hydrograph based on the gamma distribution function (a GUH), and event-specific values of peak streamflow and flood volume for urban areas in Missouri. Statistical relations from regression were developed for estimating (1) parameters of a $I_{A}-C_{L}$ model as a basin-loss model to estimate the excess rainfall hyetograph from a total rainfall hyetograph, (2) parameters for a GUH to estimate the runoff hydrograph for an ungaged basin from an excess rainfall hyetograph, and (3) peak streamflow $\left(\hat{Q}_{p}\right)$ and (4) flood volume $(\hat{V})$ for a particular storm event solely based on rainfall and basin characteristics. Streamflow data and basin characteristics at 39 streamgages in urban areas in and around Missouri were combined with rainfall data from a number of storm events, resulting in a database of discrete storm events used in developing the various statistical relations. This report is intended to supersede previous USGS urban unit hydrograph reports for Missouri (such as Becker [1990]).

Although the various parts of this study are discussed in discrete sections of this report, the development of the various parts occurred concurrently and iteratively because of interdependency. Although the report organization is motivated by continuity, the reader is advised to keep this in mind.

\section{Data Development}

The study area included several urban areas in and adjacent to the state of Missouri (fig. 1). In particular, the study area covers the City of St. Louis and St. Louis County, Kansas City, Springfield, and Columbia in Missouri, as well as Fayetteville, Arkansas. The two sites from Arkansas included in this study are considered for purposes herein to be geologically, topographically, and hydrologically similar to other urban areas in Missouri.

The State of Missouri is located in the Midwest region of the continental United States, and has a continental type of climate with strong seasonality (Missouri Climate Center, 2014). No topographic barriers hinder cold air masses from the northern plains and Canada or warm air masses from the Gulf of Mexico. Thunderstorms develop and redevelop along fronts that separate these contrasting air masses, which sometimes leads to copious amounts of precipitation or brief but intense precipitation. For example, thunderstorms on August 12 and 13, 1982, in the Kansas City area resulted in a 24-hour rainfall report of 12.6 inches and widespread flash flooding (Becker and Alexander, 1983). Substantial amounts of precipitation 


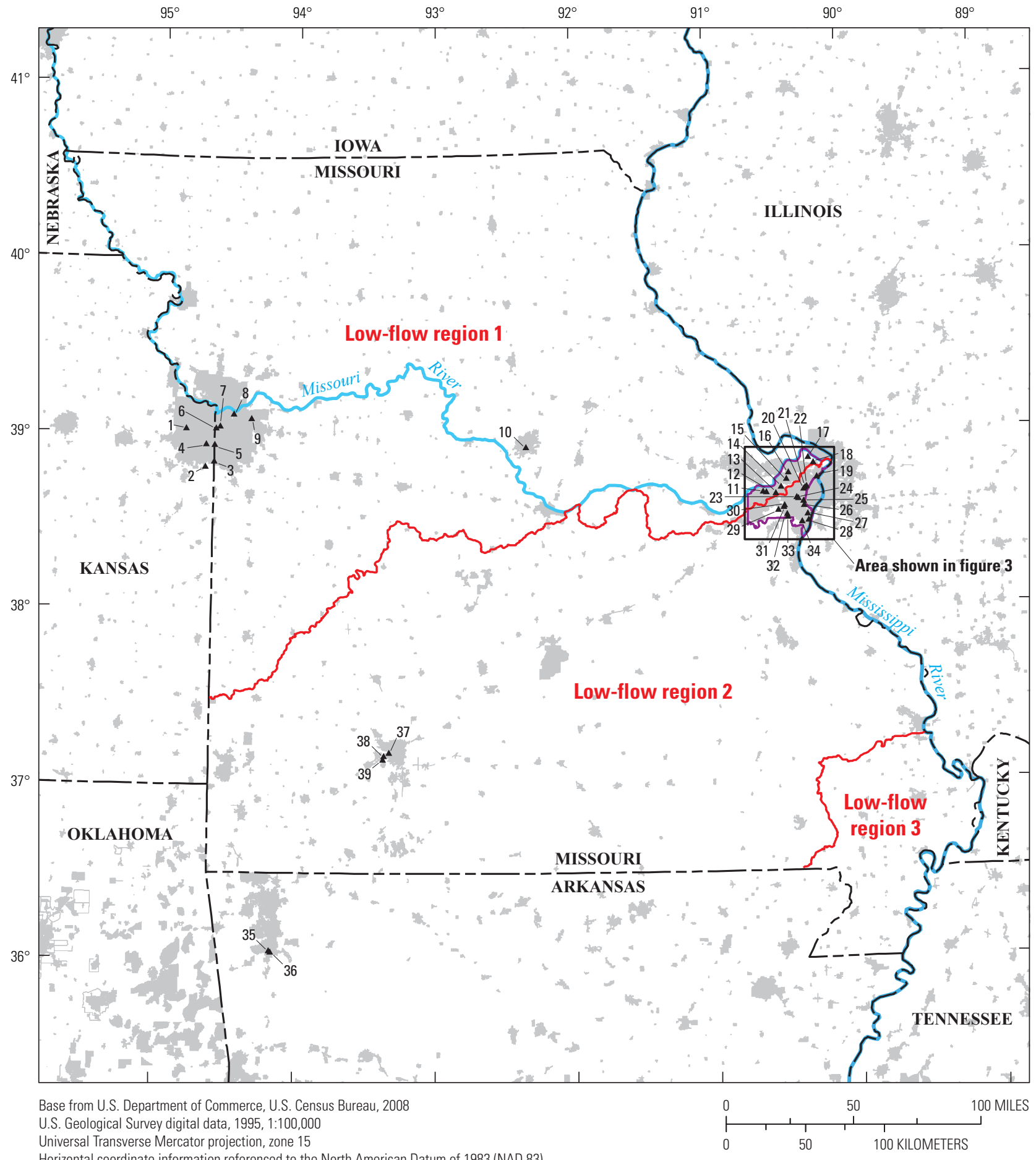

Horizontal coordinate information referenced to the North American Datum of 1983 (NAD 83)

EXPLANATION

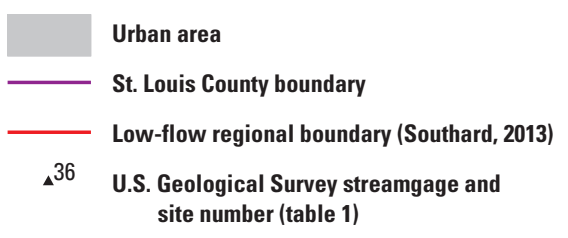

Figure 1. Location of U.S. Geological Survey streamgages in and adjacent to Missouri used in this study. 
An Initial Abstraction and Constant Loss Model, and Methods for Estimating Urban Unit Hydrographs in Missouri

also result from tropical systems from the Gulf of Mexico. Whereas these tropical systems typically do not have the same rainfall intensity as frontal type thunderstorms, they are capable of producing substantial amounts of rainfall over large areas. Mean annual rainfall rates vary from 34 inches in the northwest to 50 inches in the southeast part of the State (Missouri Climate Center, 2014).

\section{Data Collection Sites}

To provide continuity with Southard's (2010) work to estimate the magnitude and frequency of floods in urban areas of Missouri, the list of urban sites in and adjacent to Missouri from that study was the starting point for this study. Whereas Southard (2010) was able to use data from all urban streamgages with 9 years or more of record including sites with historic record (as opposed to recent data), an emphasis of this study was to develop regression equations based partly on rainfall data available from the next generation weather radar (NEXRAD) system, which began in the early 1990s. As such, only streamgages with more recent data records could be used for this study; however, streamgages with less than 9 years of record also were useable. Southard (2010) had started with a list of 70 streamgages and pared it down to 35 for analysis. The original list of 70 streamgages by Southard (2010) also served as a starting point for this study, and reduced to a final list of 39 streamgages upon further evaluation and exploratory analysis. The fundamental criteria used for the selection of streamgages were similar to Southard (2010), including (1) urbanization with development resulting in an increase in impervious area, but relatively stable during the data analysis period; (2) no major diversions into or out of the basin upstream from the streamgage; and (3) minimal storage effects from retention, detention structures, or road crossings.

Three basins with drainage area greater than 183 square miles were present in the initial list of 70 streamgages and were not removed by the fundamental criteria. Two of the three basins had been used in the analysis of flood-frequency equations for urban areas in Missouri (Southard, 2010), and as a result, these three basins were included in early stages of this study; however, two of the three basins had results that were noticeably different from the majority of the other basins in this study. One had a percent area of storage that was slightly larger than the other basins in the analysis, which may account for part of the unusual behavior, but had been used by Southard (2010). It is possible that these three basins are large enough to behave more like rural basins, despite their high percentage of impervious area. Ultimately, the three large basins were removed from the analysis, as application of a unit hydrograph is more appropriate on smaller drainage areas because the assumption of uniform rainfall distribution in space and time becomes tenuous for larger drainage areas (Chow and others, 1988).
The spatial distribution of the 39 USGS streamgages is shown in figure 1. For continuity with Southard (2010), the two streamgages in Fayetteville, Ark., were included because the basins upstream from the streamgages were similar to basins in Missouri and could potentially improve the range of independent variables in the regression equations. Key information about the streamgages is listed in table 1 .

Streamflow data for discrete storm events at each of the 39 streamgages were compiled in two datasets (U.S. Geological Survey, 2014). Data available through December 2010 were compiled early in the study, and were used for the development of the regression equations; this streamflow dataset was combined with NEXRAD rainfall data (as described in subsequent sections) and is referred to as the "primary dataset." An additional dataset (the "verification dataset") was compiled towards the end of the study from several additional discrete storm events after January 2011. Much of the streamflow data for both datasets were in 5-minute increments; however, nearly all of the streamgages in the Kansas City area had data that were collected at 15-minute increments. The Kansas City data were linearly interpolated to 5 -minute increments to be consistent with the other streamgage data available, and to permit the development of a 5-minute unit hydrograph from the data for all urban areas in Missouri. For each observed hydrograph, the base flow was removed by linear interpolation between the start of the rise of the hydrograph (the first substantial increase of streamflow) and the end of the recession, taken as the point where the rate of decreasing discharge generally became constant (indicating the end of the direct runoff segment in the observed hydrograph; Weaver, 2003; Rutledge, 1998).

\section{Determination of Basin Characteristics}

As noted in Southard (2010), drainage patterns and hydraulic characteristics often are altered in urban areas through anthropomorphic influences. Stream channels may be enlarged and straightened, whereas numerous road crossings may cause localized constrictions. Stream channels may be routed underground in long culverts and conduits. Retention ponds may alter the characteristics of the runoff hydrograph for an area, affecting the time to peak and the magnitude of $Q_{p}$ (Feaster and Guimaraes, 2004).

Several distinct basin characteristics were evaluated as predictor variables for estimation of $\hat{Q}_{p}$ and $\hat{V}$, as well as the estimation parameters for the GUH and the $I_{A}-C_{L}$ model. The basin characteristics were selected for use as potential variables on the basis of their theoretical relation to flow, results from previous studies referred to in the "Previous Studies" section, and the ability to measure the basin characteristic using digital datasets and geographic information system (GIS) technology. Measurement of the characteristic using GIS methods was important to facilitate the process of measuring the basin characteristics and solving the regression equations for ungaged sites. For consistency with recent 


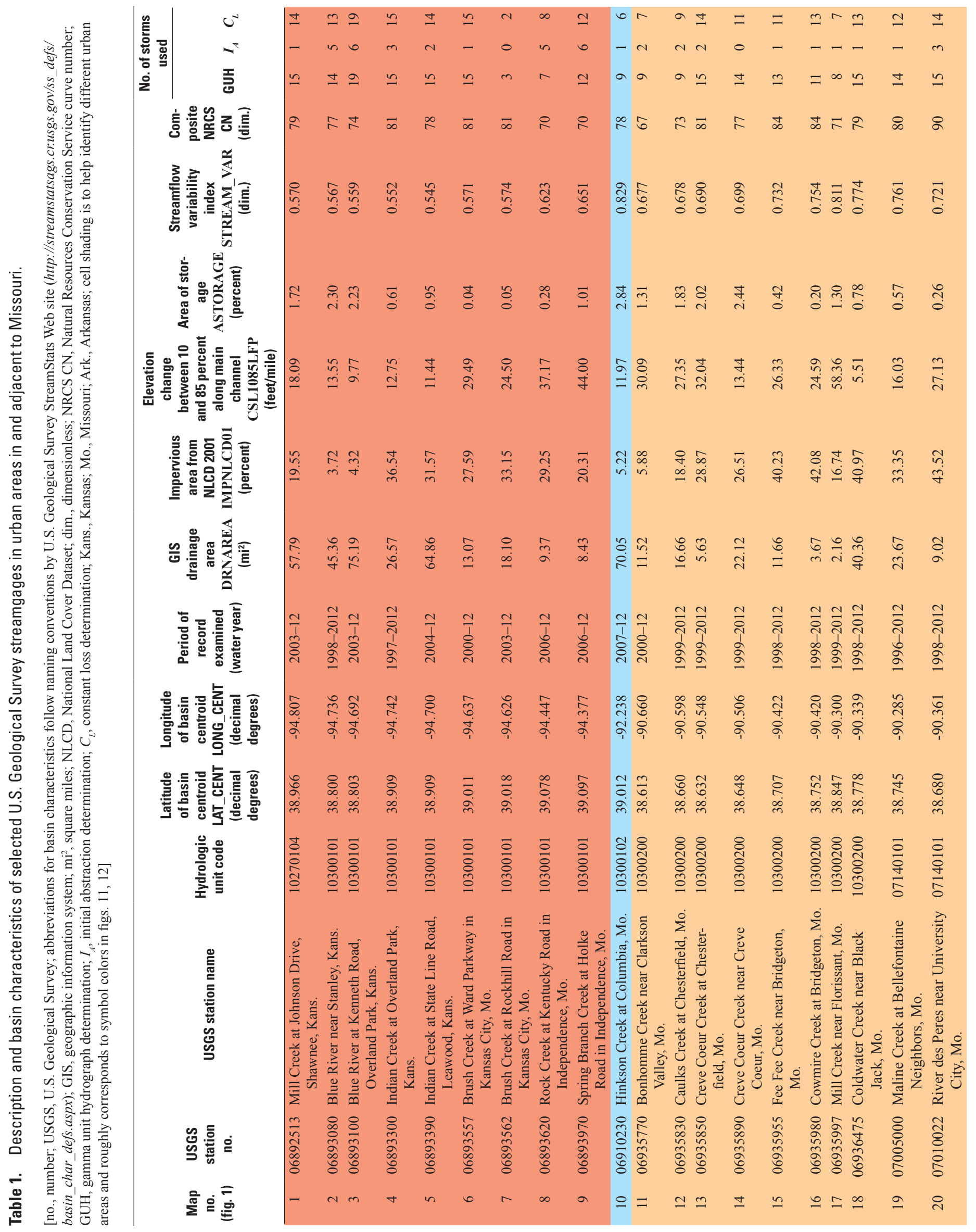




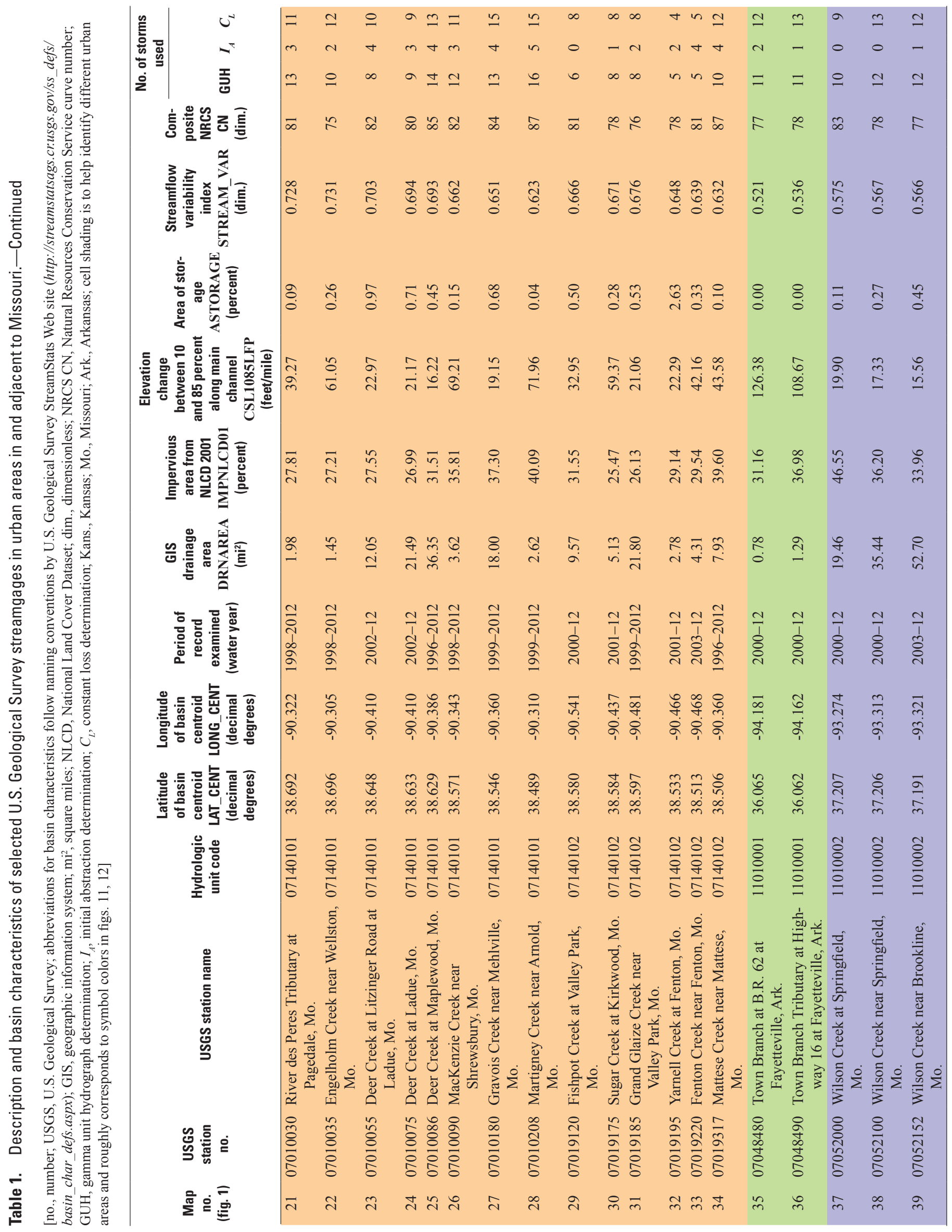


work done in Missouri by Southard $(2010,2013)$, the variable names used herein match Southard's nomenclature, which follow naming conventions established by the USGS StreamStats Web site (http://streamstatsags.cr.usgs.gov/ss_defs/ basin_char_defs.aspx). The basin characteristics determined or computed for each of the basins upstream from the 39 streamgages are as follows:

1. Drainage area is a common basin characteristic present in most flood-frequency and unit hydrograph equations. Each of the basins used in this study had been delineated for the low-flow study by Southard (2013) from a digital elevation model (DEM) using GIS algorithms and other techniques detailed therein. The variable "DRNAREA" will hereinafter describe the drainage area.

2. Percent impervious area is another common basin characteristic present in most flood-frequency and unit hydrograph equations. The impervious area for each of the basins used in this study had been determined for the urban flood-frequency study by Southard (2010) from the National Land Cover Dataset (NLCD) 2001 impervious area (Multi-Resolution Land Characteristics Consortium, 2014) at the following Web site: http://www.mrlc. gov/index.php. Southard (2010) modified some of the impervious area values for older basins that had undergone substantial development during the timespan of that basin's historic $Q_{p}$ data. In contrast, the unmodified values of the impervious area determined directly from the NLCD 2001 dataset were used in this study because only comparatively recent storm data were used. The variable "IMPNLCD01" will hereinafter describe the percent impervious area.

3. Main-channel slope was computed as the difference in elevation between the 10- and 85-percent points along a stream channel divided by the length between those two points, and recorded in feet per mile. Data were obtained from a DEM using GIS algorithms and other techniques detailed in both the urban flood-frequency and low-flow studies by Southard (2010, 2013). The variable "CSL1085LFP" will hereinafter describe the main-channel slope. This slope definition often is seen in statistical studies, but differs from the specific definition of main-channel slope used by Asquith and Roussel (2007) for Texas.

4. The percentage of the basin area in storage (lakes, ponds, reservoirs, wetlands) was determined from the NLCD 2001 coverage using techniques detailed in the low-flow study by Southard (2013). The variable "ASTORAGE" will hereinafter describe the percent storage.

5. The composite NRCS curve numbers, $C N$, were estimated from a combination of the soil type data from NRCS Soil Survey Geographic (SSURGO) database (Natural Resources Conservation Service, 2014a) and the land-use characteristics from the NLCD 2001 dataset
(Multi-Resolution Land Characteristics Consortium, 2014), as detailed in appendix 2 (the digital data layer from which the $C N \mathrm{~s}$ were determined for this report is included as a digital attachment [http://pubs.usgs.gov/ sir/2014/5193/downloads/soil_lulc_mo.zip] for use with ungaged basins).

6. The streamflow variability index from the Missouri low-flow study by Southard (2013) is a measure of the steepness of the slope of the flow duration curve of the basin, and is inversely related to the capacity of the basin to sustain base flow in a stream. Detailed discussion of the variable and a digital data layer of the values for ungaged basins in Missouri are available in Southard (2013). The variable "STREAM_VAR" will hereinafter describe the streamflow variability index.

7. The 5-day and 14-day antecedent rainfall for each urban area was determined from the mean of daily rainfall values from various rain gages maintained by the National Oceanic and Atmospheric Administration (NOAA), obtained for each of the urban areas in the study from the National Climatic Data Center's (NCDC) Climate Data Online portal (National Oceanic and Atmospheric Administration, 2014b). The variables "RAIN 5 -day " and "RAIN ${ }_{14-\text { day }}$ " will hereinafter describe the 5-day and 14-day antecedent rainfall values, respectively.

Various other basin and soil characteristics detailed in Southard (2013) were examined, such as overall stream length; basin shape factor; mean basin slope; mean basin elevation; saturated hydraulic conductivity; and percentage of area of surficial geologic units of large, moderate, or minimal permeability. The 7-day and 10-day antecedent rainfall values also were examined; however, these additional characteristics were not determined to be statistically significant in any of the analyses subsequently described, and are not discussed further in this report.

\section{Brief Explanation of Next Generation Weather Radar Data Availability and Use}

In the fall of 1990, the first high-resolution Weather Surveillance Radar-1988 Doppler (WSR-88D) system was installed near Oklahoma City, Oklahoma (Crum and Alberty, 1993). Since that time, the NEXRAD weather radar network has grown to nearly $160 \mathrm{WSR}-88 \mathrm{D}$ units operated by the NOAA's National Weather Service (NWS), the Federal Aviation Administration, and the U.S. Air Force (National Oceanic and Atmospheric Administration, 2011, 2014a). WSR-88D detects precipitation and atmospheric movement, which when processed can be displayed to show patterns of precipitation and its movement. Approximate precipitation amounts and distribution can be determined from Level III processed data available from the NCDC at http://www.ncdc.noaa.gov/ nexradinv/. The distribution of NEXRAD radar sites covering Missouri with various levels of coverage (dependent on 
distance from the radar site and topography) is shown in figure 2 . The area apparently not covered (beyond the area indicating coverage at 10,000 feet above ground; fig. 2) is in fact covered by the 230-kilometer (142.9-mile) maximum range of the various radar sites, so all of Missouri is fully covered by the NEXRAD system.

Of particular interest in this study were the Level III Digital Precipitation Array (DPA) and the Level III Digital Storm Product (DSP) datasets. The DPA data represent a rolling 1-hour accumulation of precipitation, mosaicked and displayed on the approximately 4- by 4-kilometer Hydrologic Rainfall Analysis Project (HRAP) grid (fig. 3), and are available for most storms from about 1994 through 2008 for Missouri. The DSP data represent an accumulation of the total precipitation in a given storm with time, are displayed on a 2-kilometer by 1-degree polar grid centered on the radar (fig. 3), and are available since 2008 in Missouri. Each of the datasets can be viewed for a given radar sweep, or all radar sweeps for a given storm event can be downloaded from NCDC and viewed or queried (see appendix 3 for detailed instructions).

The NEXRAD data available from NCDC for storm events are collected when the radar is in precipitation mode, in which the system is scanning at a variable rate (between 4 and 5 minutes per sweep) to accommodate the greatest number of elevation angles, thus sampling the full radar volume to detect precipitation in all its forms (National Oceanic and Atmospheric Administration, 2006b). The variable radar sweep rate was interpolated to a 5-minute hyetograph, using data from the radar bin at the centroid of the basin with techniques detailed in appendix 3. For data after 2008 (from the DSP dataset), the hyetograph obtained at the basin centroid was scaled such that the total rainfall in the hyetograph was equal to the average rainfall on the entire basin. The average rainfall on the basin was determined from the DSP rainfall data distribution using techniques detailed in appendix 3. Mass was conserved using this method, such that the total volume of rainfall from each DSP cell in the basin (from the final radar sweep of a given storm) was equal to the volume under the scaled hyetograph.

When estimating $\hat{Q}_{p}$ (see section titled "Method for Estimating Peak Streamflow from Rainfall for Urban Basins in Missouri"), only the total precipitation of a given storm is needed. For more recent storms (any time after 2008), the DSP data for a single radar sweep near the end of the storm can be viewed, and the storm total for a given radar bin can be queried directly. For a storm before 2008, the Level III Storm Total Precipitation (NTP) dataset must be used rather than the 1-hour rolling accumulation of the DPA dataset. The NTP dataset uses the 2-kilometer by 1-degree polar grid centered on the radar like the DSP data, but the data gradation is less refined, having only 16 levels (gradations at $0,0.3,0.5,1,1.5$, $2,2.5,3,4,5,6,7,9,10,12$, and 15 inches) rather than the 256 levels (approximately 0.01-inch increments) in the DPA and DSP datasets. This reduced resolution is not expected to diminish the usefulness of the NTP dataset for these storms, but analysts are cautioned that the coarse gradation may over- or underestimate the rainfall of a given storm. The total rainfall as determined from the total storm hyetograph also can be used (appendix 3).

A brief discussion is warranted regarding the potential bias of the NEXRAD data compared to observed rainfall. According to the Federal Meteorological Handbook 11, Part C, Chapter 3, the DPA dataset is not adjusted for potential bias compared to measured rainfall, whereas the DSP dataset may have a bias correction applied (National Oceanic and Atmospheric Administration, 2006a). Although the potential for bias exists, both of these datasets generally are more widely available with a higher spatial and temporal resolution than measured rain gage information. Radar-derived estimates of precipitation corrected for observed rainfall are readily available only as daily totals, making storm-specific analysis more difficult (a daily total may reflect only part of or more than one storm event on a given day). Furthermore, data for individual radar sweeps are not maintained in the corrected estimate datasets, which was considered essential to create the 5-minute rainfall hyetographs for this study. Numerous studies compare NEXRAD estimates with rain gage observations (Feaster and others, 2012; Jayakrishnan and others, 2004; Westcott and others, 2008; Young and Brunsell, 2008), and all indicate a tendency for the NEXRAD-derived estimate to underestimate the observed rainfall, with noticeable improvement in the correlation with time as the algorithms used to estimate rainfall from radar data are refined. Young and Brunsell (2008) indicate a bias of less than 20 percent by 2004 for Kansas City and St. Louis (down from nearly 40 percent in 1998); Westcott and others (2008) indicate a bias of less than 25 percent for Kansas City, St. Louis, Columbia, and Springfield during the growing season (March-August) of 2002-2005. All the studies acknowledge the superiority of the spatial and temporal resolution of the NEXRAD data compared to rain gage observation data and conclude that NEXRAD-derived rainfall data are a good alternative to measured rainfall data. Ultimately, observed time-series data from a rain gage can be used in lieu of the NEXRAD data described in this section, if available and preferred.

An indirect comparison was made between the NEXRAD-derived storm total and data from the extensive rain gage network maintained by MSD (fig. 4). Data from the MSD rain gages nearest to the streamgages in St. Louis had been compiled for each storm early in the study, but were used for only rough comparison with the NEXRAD-derived storm totals. Although the comparison shown in figure 4 is not direct (the MSD data are near the outlet of each basin, whereas the NEXRAD data are near the basin centroid, which may introduce some bias based on the spatial variation of rainfall in a given storm), it is nonetheless beneficial to show the low apparent bias between the NEXRAD and observed rainfall totals. There are several instances for which the nearest MSD rain gage did not record any rainfall and there are several for which the NEXRAD data seem to substantially overestimate the MSD rain gage value; however, the NEXRAD-derived rainfall seems to be biased about 20 percent lower than the MSD rain gage values (fig $4 A$ ), which is consistent with Young 


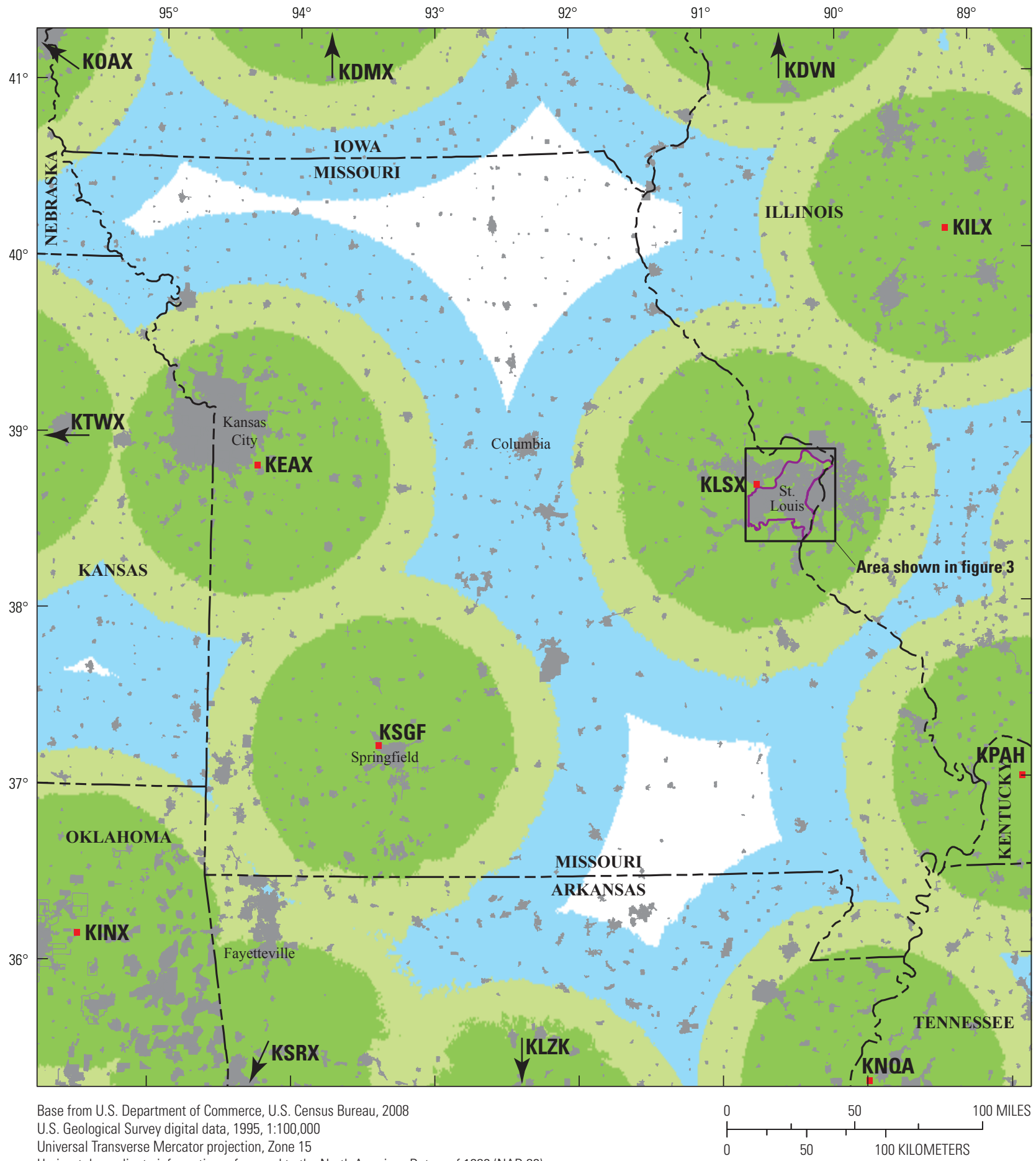

Universal Transverse Mercator projection, Zone 15

Horizontal coordinate information referenced to the North American Datum of 1983 (NAD 83)

\section{EXPLANATION}

Coverage at 4,000 feet above ground at radar

Coverage at 6,000 feet above ground at radar

Coverage at 10,000 feet above ground at radar

\section{Urban area}

St. Louis County boundary

- KEAX NEXRAD weather radar site and identifier

Figure 2. Approximate coverage of next generation weather radar (NEXRAD) sites in and adjacent to Missouri. Coverage exists beyond the "10,000 feet above ground at radar" extent to a maximum 230 kilometers (142.9 miles) from the various radar sites. 


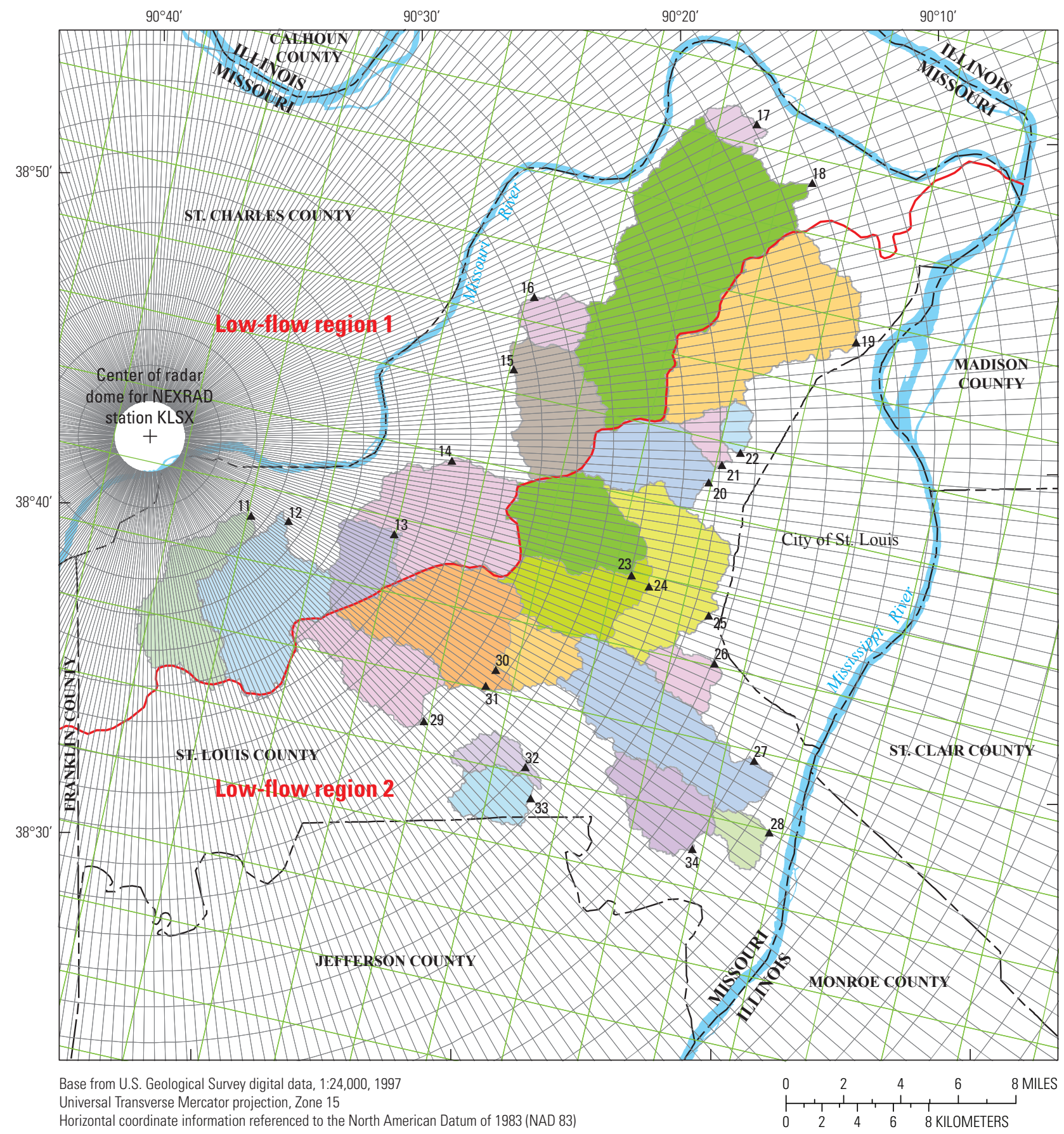

Horizontal coordinate information referenced to the North American Datum of 1983 (NAD 83)

\section{EXPLANATION}

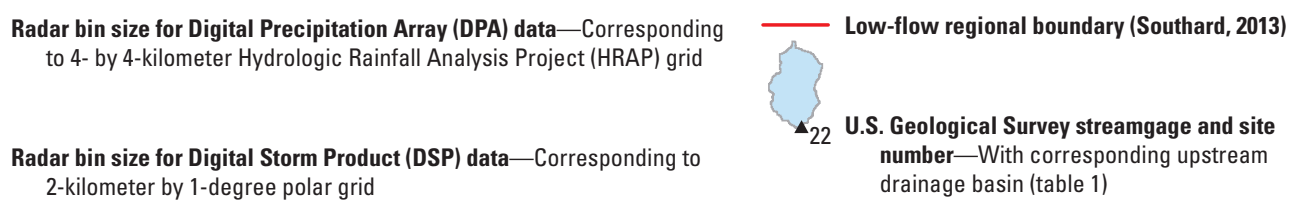

Figure 3. Urban streamgages and associated upstream basins in the St. Louis, Missouri, area used for this study, and the distribution of Digital Precipitation Array (DPA) and Digital Storm Product (DSP) data available from the next generation weather radar (NEXRAD) station KLSX located near St. Louis, Missouri. 

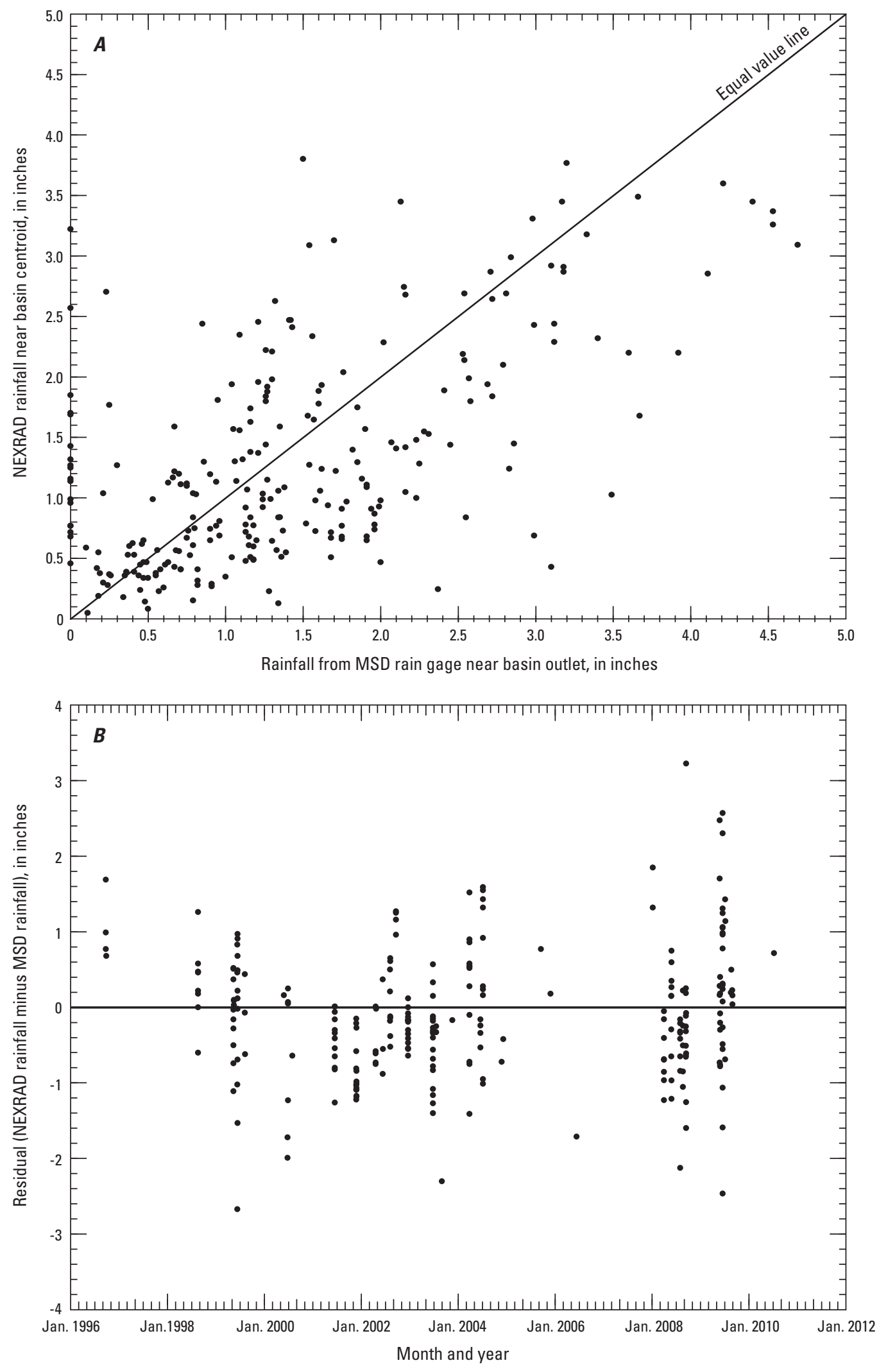

Figure 4. Comparison of rainfall derived from next generation weather radar (NEXRAD) near basin centroids and measured rainfall at Metropolitan Sewer District (MSD) rain gage locations near basin outlets in St. Louis, Missouri, showing $A$, comparison and $B$, residuals with time. 
and Brunsell (2008) and Westcoff and others (2008). Also, there is no discernable trend with time (fig. $4 B$ ), except from 1996 to 2002 where the NEXRAD rainfall overestimated the MSD rainfall for the storm in September 1996, and routinely underestimated the MSD rainfall for the storms from June 2001 to May 2002. For most storms from May 2002 onward, there is no consistent, discernible trend in the residuals. Ultimately, any apparent trend in the residuals in figure $4 B$ may be the result of spatial and temporal variations in rainfall as much as bias.

\section{An Initial Abstraction and Constant Loss Model for Urban Basins in Missouri}

Estimation of a runoff hydrograph by the unit hydrograph method requires a method to convert a total rainfall hyetograph into an appropriate excess rainfall hyetograph that represents the rainfall that runs off from the basin. This conversion is accomplished by means of a time-distributed basin-loss model that is consistent with the hypothesized processes (such as losses to surface depressions, infiltration, and evaporation) that prevent rainfall from becoming runoff. For the current (2014) study, a combined $I_{A}-C_{L}$ model was developed.

Conceptually, $I_{A}$ is the capacity of a basin to store or "abstract" an absolute depth of rainfall near the beginning of a storm. Accumulated depths of rainfall less than $I_{A}$ do not produce runoff. Constant loss is the capacity of a basin to remove rainfall at some constant rate after the $I_{A}$ amount is satisfied, and is analogous (but not equal) to an infiltration rate. Additional rainfall inputs to the basin after the $I_{A}$ is satisfied will contribute to runoff if the rainfall rate (intensity) is larger than the $C_{L}$. Initial abstraction has units of length, measured in basin inches (inches per square area of basin). Constant loss has units of length per unit time, measured in basin inches per hour. Asquith and Roussel (2007) provide substantial detail of an $I_{A}-C_{L}$ model for a study of Texas basins germane to the current (2014) study in Missouri.

\section{Analysis of Storm-Specific Data for Initial Abstraction, Constant Loss, and Gamma Unit Hydrograph Parameters}

The primary dataset of observed rainfall and runoff events through December 2010 for the basins upstream from the 39 streamgages was analyzed using Microsoft ${ }^{\circledR}$ Excel spreadsheets. Rainfall data from NEXRAD and runoff data from the USGS National Water Information System (NWIS; U.S. Geological Survey, 2014) database were processed at a 5-minute time step; rainfall and runoff data were linearly interpolated to 5-minute increments as needed. The observed rainfall and runoff data were used to compute the optimal storm-specific ( $\left(^{4}\right)$ parameter values for ${ }^{4} I_{A}$ and ${ }^{4} C_{L}$, as well as storm-specific values for the GUH parameters of ${ }^{4} q_{p},{ }^{h} T_{p}$, and ${ }^{`} K$.

Optimization of the five parameters was an iterative process involving several steps:

1. An initial value of ${ }^{4} C_{L}$ was chosen, based on knowledge of the basin characteristics and local infiltration rates.

2. A value of ${ }^{\natural} I_{A}$ was computed that resulted in an excess rainfall hyetograph with the same volume as the observed runoff hydrograph, expressed in basin inches (volume under hydrograph divided by basin area), or $V_{\text {excess rain }}^{\text {mode }}=V_{\text {runoff }}^{\text {obs }}$.

3. A value of ${ }^{\natural} T_{p}$ was chosen that resulted in an approximate match of the 5-minute time interval of the observed runoff hydrograph and the modeled hydrograph (the GUH convolved with the modeled excess rainfall) hyetograph, or ${ }^{4} T^{Q_{p}} \cong T^{Q_{p}^{\text {obs }}}$.

4. A value of ${ }^{\iota} K$ was determined by the numeric root solver (appendix 1) of equation 4 with $V=1$ and the value of ${ }^{4} T_{p}$ such that the peak streamflow of the observed runoff hydrograph was matched by the modeled hydrograph (again, the GUH convolved with the modeled excess rainfall hyetograph), or ${ }^{4} Q_{p}=Q_{p}^{\text {obs }}$. This step also resulted in the determination of ${ }^{\iota} q_{p}$, by default, because ${ }^{\iota} T_{p}$ and ${ }^{\iota} K$ are now known.

5. The modeled hydrograph was visually examined with respect to shape and appearance compared to the observed runoff hydrograph, and returned to step 1 or 3 to adjust ${ }^{4} C_{L}$ and ${ }^{4} T_{p}$ (and consequently, ${ }^{4} I_{A},{ }^{4} K$, and ${ }^{4} q_{p}$ ).

This process was iterated until the modeled hydrograph reasonably mimicked the observed runoff hydrograph in shape and appearance. The principle metric of fit is a minimized residual sum of squares (Helsel and Hirsch, 2002) between the hydrographs and a minimum percent difference between the observed and modeled hydrograph widths (in hours) at 50 and 75 percent of $Q_{p} \cdot{ }^{4} I_{A}$ and ${ }^{4} C_{L}$ were further constrained to be physically meaningful (that is, greater than or equal to zero), such that excess rainfall was less than total rainfall. This method worked for direct runoff hydrographs that were both uniform and non-uniform in appearance (fig. 5).

The analysis described successfully processed 440 storms in the primary dataset through December 2010 (table 1). Some rainfall events as extracted from the NEXRAD data did not input sufficient volume to match the observed runoff, and were removed from further consideration. Although this practice represents a form of observational bias correction, it is necessary to make physically meaningful computations. The most ready explanation for the discrepancy is simply fundamental errors in the conceptualization of the rainfall-runoff process that are divergent from those required when unit hydrographs are used for synthetic hydrograph computation by design practitioners. 


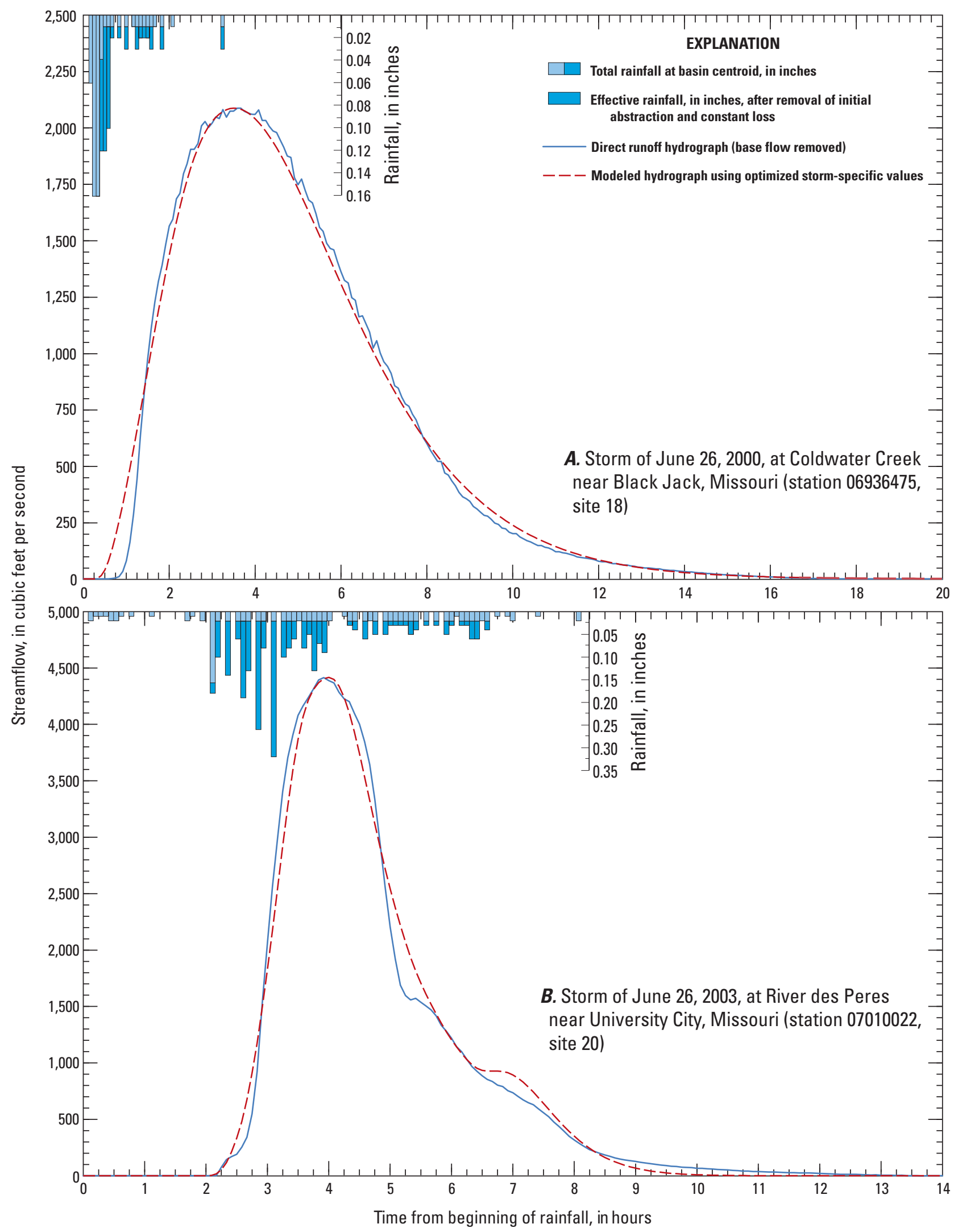

Figure 5. Examples of final match between direct runoff hydrographs that were $A$, uniform and $B$, non-uniform and the modeled hydrographs using optimized storm-specific values. 
For example, occasionally, a volume difference between rainfall and runoff was observed after periods of belowfreezing conditions, which implied that the additional runoff may have been from melting of accumulated snow or ice. Further examination of other events that occurred after periods of below-freezing conditions revealed the runoff hydrographs often were unusual in shape, or the ${ }^{4} I_{A}$ and ${ }^{4} C_{L}$ values were unusually low. Therefore, it was assumed that below-freezing conditions cause atypical runoff conditions either by freezing the ground and causing more impermeability, or appreciably altering the time response of the runoff. All storms that occurred after periods of below-freezing conditions were removed from further analysis. In a few instances, either the rainfall or the runoff data for a storm on a basin did not exist, or both existed but simply did not match in time for some unknown reason; these storms also were removed from further analysis.

\section{Estimation of Initial Abstraction}

Several attempts were made to model the $I_{A}$ using the storm-specific values and the mean and median values for each basin, initially with minimal success. In a study of $I_{A}$ and $C_{L}$ in Central Texas, Asquith and Roussel (2007) used a combination of (1) the overall mean of the basin-specific values weighted by the number of storms in a basin, (2) the overall median of the basin-specific values, (3) values obtained based on a regression, and (4) values obtained based on a regression tree model (also called "recursive partitioning," a regression tree is constructed such that partitions [branches of the tree] are determined by an algorithm that seeks to split and minimize the residual sum of squares [Faraway, 2006]); Asquith and Roussel (2007) indicated that any of these values (or the combined arithmetic mean of all four-their "combined $I_{A} \&$ $C_{L}$ model") could be expected to provide a reasonable estimate of $I_{A}$ and $C_{L}$ in the basins in Central Texas.

A similar approach initially was attempted in this study, and although the adjusted $R$-squared (Adj- $R^{2}$ ) of the regression equation for Missouri was higher than that from Asquith and Roussel (2007) (Adj- $R^{2}$ of 0.590 for Missouri compared to 0.345 for Central Texas), the residual standard error of the equation was 0.493 (compared to 0.302 in Texas). Furthermore, it was reasonably assumed for this study that $I_{A}$ should be somehow dependent on antecedent moisture conditions, which was not intrinsic to a basin-average value of $I_{A}$. The data available to Asquith and Roussel (2007) did not consist of radar estimates or temporally long rainfall time series, rendering it impossible for Asquith and Roussel (2007) to include antecedent moisture conditions as a model parameter.

Therefore, another approach was adopted for this study wherein a prerequisite of uniform distribution of rainfall over the basin was used to isolate suitable storms for the analysis. The condition of uniform distribution of rainfall is fundamental to unit hydrograph theory - the condition logically should apply as a basis for development of storm-specific $I_{A}$ values.
The standard deviation of the NEXRAD rainfall data in the various radar bins that covered a basin were analyzed to get a sense of the distribution of the rainfall over the basin. This process only worked with the DSP data, because the resolution of the DPA data is too coarse to provide a meaningful sense of the rainfall distribution (fig. 3). In figure 3, some basins are small enough to be covered by only one or two DPA data bins. Using the standard deviation of the rainfall data, 89 storms were isolated as being reasonably uniformly distributed over the various basins as indicated by a standard deviation of 0.4 or less (determined empirically) combined with a visual confirmation of the relative uniformity of the storm distribution using GIS. The ${ }^{4} I_{A}$ values from these storms were evaluated by their relations to various basin and rainfall characteristics to develop an equation to estimate $I_{A}$ by ordinary least-squares (OLS) regression. Regional analysis using the low-flow regions established by Southard (2013) also was done, and determined to be helpful to improve the estimation of $I_{A}$ for the basins in Missouri.

The regression equation for estimation of $I_{A}$ in low-flow region 1 is

$$
I_{A 1}=52.626\left(\frac{\text { RAIN }_{\text {Storm }}}{\text { RAIN }_{14-\text { day }}}\right)^{0.6743}(10)^{-0.0242(C N)-0.0090(\text { IMPNLCD } 1)}
$$

and for low-flow region 2 is

$$
\begin{gathered}
I_{A 2}=14.381\left(\frac{\mathrm{RAIN}_{\text {Storm }}}{\mathrm{RAIN}_{14 \text {-day }}}\right)^{1.0155} \times \\
(10)^{0.3387\left(\mathrm{RAIN}_{5 \text {-day }}\right)-0.0252(C N)+0.0142(\mathrm{IMPNLCD} 01)}
\end{gathered}
$$

where

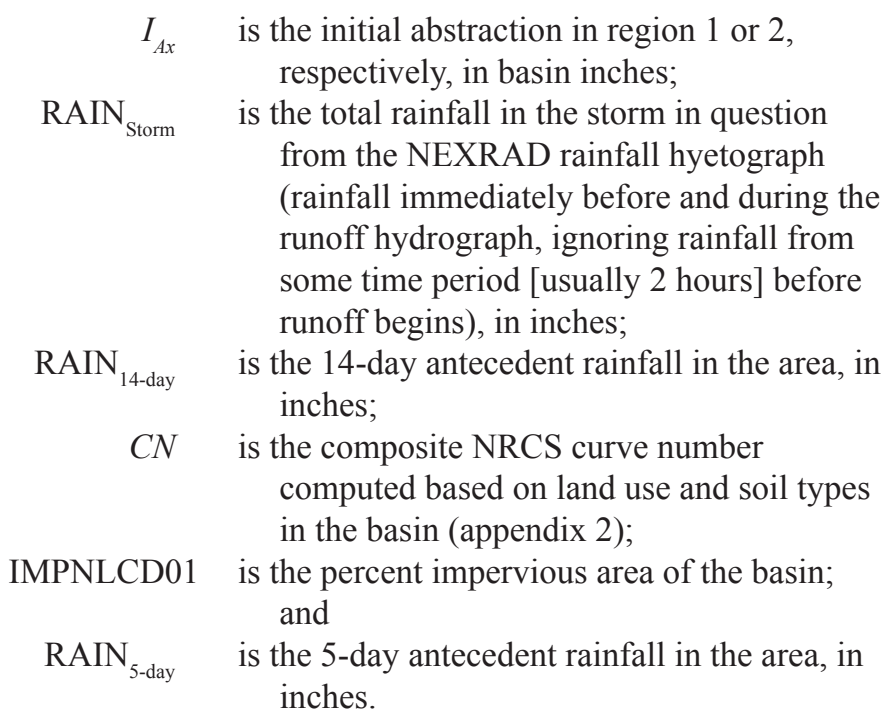

Equation 5 has 36 degrees of freedom, a residual standard error of about $0.252 \log _{10}$ (basin inch), and an Adj- $R^{2}$ of 0.604 (see Helsel and Hirsch [2002] for description of statistical 
criteria). Equation 6 has 44 degrees of freedom, a residual standard error of about $0.249 \log _{10}$ (basin inch), and an Adj- $R^{2}$ of 0.710 .

Although equations 5 and 6 were developed from a limited subset of the ${ }^{4} I_{4}$ values, the equations are eminently useful for prediction, recognizing the fundamental condition of uniform distribution of rainfall over the basin. A comparison of storm-specific and modeled values of $I_{A}$ is shown in figure 6 for all of the storm-specific events, with the values used to establish the regressions highlighted.

The ratio of RAIN Storm $_{\text {to }}$ RAIN ${ }_{14 \text {-day }}$ is the most important variable in both equations 5 and 6 , accounting for 40 to 50 percent of the variability of the equations (Adj- $R^{2}$ was 0.39 and 0.50 for that variable alone for regions 1 and 2 , respectively). Whereas a value for this ratio can be obtained from the various sources indicated herein, this variable conceptually is a measure of the antecedent moisture conditions for the storm. If the volume of the storm is large compared with the antecedent conditions in the prior 14 days such that the ratio is large, the computed $I_{A}$ value will be larger; however, if there has been a substantial amount of rainfall in the prior 14 days (or the volume of the storm is small in comparison) such that the ratio is small, the computed $I_{A}$ value will be smaller. For computation purposes, a practical upper limit of 3 for this ratio is advised so that the computed $I_{A}$ does not become unreasonably large. A "large" value of $I_{A}$ is about 2.5 inches based on ad hoc analysis (see upper limit of storm-specific $I_{A}$ values in figure 6). Limiting the ratio of RAIN Storm $_{\text {to }}$ RAIN ${ }_{14-\text { day }}$ to 3 maintains the $I_{A}$ below 2.5 inches for the storms used in this study.

\section{Estimation of Constant Loss}

Because it is analogous to infiltration, it was assumed that $C_{L}$ might not be as variable as $I_{A}$ across the basins in a particular urban area. Initially, the procedure followed by Asquith and Roussel (2007) was followed with $C_{L}$, but the resulting regression equation (not listed in this report) seemed to be substantially more variable than the one shown by Asquith and Roussel (2007) for Central Texas in predicting the value (Adj- $R^{2}$ of 0.215 for Missouri [compared to 0.301 for Central Texas], which implies that only 21 percent of the variability of the data is estimated by the equation). Further analyses with the overall mean and median of the storm-specific ${ }^{4} C_{L}$ values, the regression equation of the basin-mean $C_{L}$ values, and a regression tree model (Faraway, 2006) of the $C_{L}$ values indicated that the overall mean $C_{L}$ value $(0.240$ basin inches

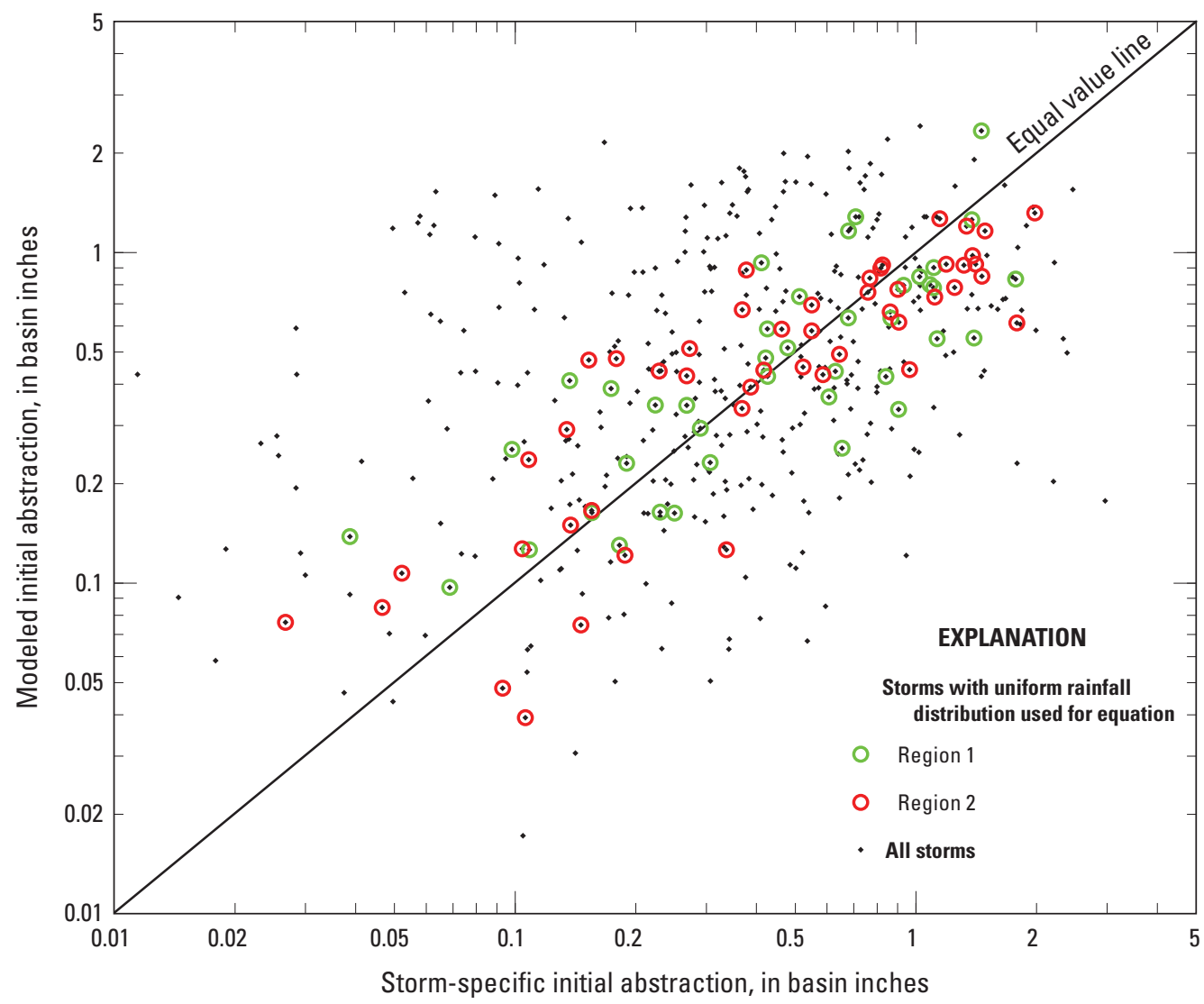

Figure 6. Comparison of storm-specific and modeled values of initial abstraction $\left(I_{A}\right)$ for all of the storm-specific events used from the 39 streamgages in urban areas in and adjacent to Missouri. 
per hour) did no worse than any of the other values at predicting the $C_{L}$ of a basin; however, the overall mean was rejected based on additional regional analysis.

The storm-specific ${ }^{4} C_{L}$ values were further examined for possible regional trends. Generalized regions were established based on similar topography, geology, soil types, and $C_{L}$ values; St. Louis, Springfield, and Fayetteville were combined as one generalized region roughly following the low-flow regions identified in Southard (2013) but without subdividing St. Louis, and Kansas City and Columbia were combined as another (table 2). Each urban area subsequently was examined individually in a specific regionalization. St. Louis was divided into two specific regions, using the divide between the Missouri River (basins with station numbers starting with "069"; table 1) and the Mississippi River (basins with station numbers starting with " 070 "; table 1 ), which correspond to low-flow regions 1 and 2, respectively, of Southard (2013). Although there is not a substantial difference between the topography, geology, and soils of the St. Louis area, a difference was noted in the specific regional mean $C_{L}$ value (table 2). Southard (2013) also noted differences between these basins in St. Louis, and ultimately concluded that St. Louis should be divided into two different low-flow regions along the Missouri-Mississippi River divide (fig. 1).

Table 2. Generalized and specific regional mean values of constant loss $\left(C_{L}\right)$ determined from analysis of storm-specific values at streamgages in urban areas in and adjacent to Missouri.

[Kansas City and Columbia were combined as one "Generalized region," and St. Louis, Fayetteville, and Springfield were combined as another; each urban area was examined as its own "specific region," and St. Louis was divided into two along the divide between the Missouri River and the Mississippi River (Southard, 2013; fig. 3); in/hr, basin inches per hour; cell shading is to help identify different urban areas and roughly corresponds to symbol colors in figs. 11, 12]

\begin{tabular}{|c|c|c|}
\hline Urban area & $\begin{array}{c}\text { Generalized } \\
\text { regional mean } \\
\text { constant loss, } C_{L} \\
\text { (in/hr) }\end{array}$ & $\begin{array}{c}\text { Specific } \\
\text { regional mean } \\
\text { constant loss, } C_{L} \\
\text { (in/hr) }\end{array}$ \\
\hline Kansas City, Missouri & 0.33 & 0.31 \\
\hline Columbia, Missouri & 0.33 & 0.75 \\
\hline $\begin{array}{l}\text { St. Louis, Missouri, } \\
\text { Missouri River side }^{\mathrm{a}}\end{array}$ & 0.20 & 0.17 \\
\hline $\begin{array}{l}\text { St. Louis, Missouri, } \\
\text { Mississippi River side }^{\mathrm{b}}\end{array}$ & 0.20 & 0.22 \\
\hline Fayetteville, Arkansas & 0.20 & 0.20 \\
\hline Springfield, Missouri & 0.20 & 0.20 \\
\hline
\end{tabular}

aThose streamgages with station numbers starting with " 069 " (table 1) (Southard, 2013).

'Those streamgages with station numbers starting with "070" (table 1) (Southard, 2013).
As described in the section titled "Testing of Modeled Hydrographs," both forms of the regional $C_{L}$ value worked nearly equally well at developing a reasonably shaped runoff hydrograph. The specific regional $C_{L}$ has only slight variability throughout the urban areas examined in this study with the exception of Columbia (table 2). A substantial part of the basin at Columbia is rural with about 5 percent impervious area (table 1), which may contribute to the larger $C_{L}$ value. If these methods are used in an urban area in Missouri other than those examined in this study, the user is advised to consider using the generalized regional values. If these methods are used in an urban area that is a subbasin of one of the basins in this study, the user is advised to consider using the specific regional values.

\section{Methods for Estimating Unit Hydrographs for Urban Basins in Missouri}

In Central Texas, Asquith and Roussel (2007) used a GUH model that was dependent on $K$ and $T_{p}$. The $K$ and $T_{p}$ form of the GUH was deemed appropriate for their study of a basin-loss model based on prior work in the area (Asquith and others, 2005) and conclusions from independent modeling techniques described in by Cleveland and others (2006); however, in their study of urban basins in Houston, Asquith and others (2011) used a GUH model that was dependent on the $T_{p}$ and $q_{p}$, because the magnitude and timing of $Q_{p}$ are critical for many designs. As described in the "Introduction" section, any two of the GUH parameters will yield the third if $V$ is known (Asquith and others, 2005; Asquith and Roussel, 2007; Asquith and others, 2011). Because of the importance of $Q_{p}$ in the estimation of hydrographs in urban areas in Missouri, the $q_{p}$ and $T_{p}$ form of the GUH was developed for this study.

\section{Development of Gamma Unit Hydrograph Parameters for Urban Basins in Missouri}

As described in the section titled "Analysis of Storm-Specific Data for Initial Abstraction, Constant Loss, and Gamma Unit Hydrograph Parameters," the optimal storm-specific values of $q_{p}$ and $T_{p}$ were determined for each rainfall-runoff pair. These values were optimized such that the modeled hydrograph reasonably matched the observed runoff hydrograph in shape and appearance (thus ensuring ${ }^{4} T^{Q_{p}} \cong T^{Q_{p}^{\text {obs }}}$ and $\left.{ }^{4} Q_{p}=Q_{p}^{\text {obs }}\right)$. Furthermore, the metric to assess quality of fit was a minimized residual sum of squares between the hydrographs and a minimum percent difference between the observed and modeled hydrograph widths (in hours) at 50 and 75 percent of $Q_{p}$. 
For each basin, mean values of $q_{p}$ and $T_{p}$ were computed from the optimal storm-specific values. These basin-specific values of $q_{p}$ and $T_{p}$ were used to compute, through numerical root solving of equation 4 (appendix 1), basin-specific values of $K$. Summary statistics for each of the three parameters for the 39 basins are listed in table 3 . The basin-specific values of $q_{p}$ and $T_{p}$ then were analyzed to develop an equation to estimate each based on various basin characteristics.

The equation for the estimation of $q_{p}$, computed using weighted least-squares (WLS) regression, is

$$
\begin{gathered}
q_{p}=0.0560(\text { DRNAREA })^{-0.2857}(\text { CSL1085LFP })^{0.3269} \times \\
(10)^{0.0106(C N)-0.0914(\text { ASTORAGE })}
\end{gathered}
$$

where

$$
\begin{aligned}
& q_{p} \quad \text { is the basin-depth peak streamflow, in basin } \\
& \text { inches per hour; }
\end{aligned}
$$

DRNAREA is the basin drainage area, in square miles; CSL1085LFP is the main-channel slope based on the 10and 85-percent length method, in feet per mile;

$C N \quad$ is the composite NRCS curve number computed based on land use and soil types in the basin (appendix 2); and

ASTORAGE is the percent of the basin area in storage (ponds, lakes, wetlands).

Equation 7 has 34 degrees of freedom, a residual standard error of about $0.108 \log _{10}$ (basin inch), and an Adj- $R^{2}$ of 0.887 . The weighting factor in the regression analysis was the number of storms in each basin, normalized such that the sum of the weights equaled the sample size of 39. The relation between the basin-specific $q_{p}$ and the fitted value of $q_{p}$ from equation 7 is shown in figure 7 .

The equation for the estimation of $T_{p}$, computed using WLS regression, is

$$
T_{p}=4.7555(\text { DRNAREA })^{0.4336}(10)^{0.0983(\text { ASTORAGE })-0.0133(C N)}
$$

where

$\begin{aligned} & T_{p} \begin{array}{c}\text { is the unit hydrograph time to peak, in hours; } \\ \text { DRNAREA }\end{array} \\ & \text { is the basin drainage area, in square miles; } \\ & \text { is the percent of the basin area in storage } \\ & \text { (ponds, lakes, wetlands); and } \\ & \text { is the composite NRCS curve number } \\ & \text { computed based on land use and soil types } \\ & \text { in the basin (appendix 2). }\end{aligned}$

Equation 8 has 35 degrees of freedom, a residual standard error of about $0.100 \log _{10}$ (hours), and an Adj- $R^{2}$ of 0.900 . The weighting factor in the regression analysis was the number of storms in each basin, normalized such that the sum of the weights equaled the sample size of 39 . The relation between the basin-specific unit hydrograph time to peak and the fitted value of time to peak from equation 8 is shown in figure 8 .

A regression was not developed for the unit hydrograph shape factor, $K$, because it must be computed from the values of $q_{p}$ and $T_{p}$ from equations 7 and 8 , combined with equation 4 with $V=1$ for the unit hydrograph, using a numerical root solver (appendix 1). The computed $K$ values are shown in table 3 for each basin.

\section{Testing of Modeled Hydrographs}

Two levels of testing of the primary dataset were used in this study. First, the runoff hydrograph generated using the optimized storm-specific excess rainfall hyetograph and the regressed GUH parameters of $q_{p}$ and $T_{p}$ from equations 7 and 8 was compared to the observed runoff hydrograph to test the validity of the GUH regressions. A runoff hydrograph then was generated using an excess rainfall hyetograph developed from the observed total rainfall hyetograph from NEXRAD data and the regressed $I_{A}$ and various $C_{L}$ values combined with the regressed GUH parameters, and compared to the observed runoff hydrograph to test the validity of the combined $I_{A}$, $C_{L}$, and GUH regressions. The resultant modeled hydrographs were compared with the observed runoff hydrographs using five types of error. The error between the modeled and observed $Q_{p}$ is defined as

$$
\varepsilon^{Q_{p}}=\log _{10}\left(Q_{p}^{\mathrm{model}}\right)-\log _{10}\left(Q_{p}^{\mathrm{obs}}\right)
$$

where

$$
\begin{aligned}
& \varepsilon^{Q_{p}} \quad \text { is the peak streamflow error in } \log _{10} \text { (cubic feet } \\
& \text { per second); } \\
& Q_{p}^{\text {model }} \quad \text { is the peak streamflow for a context-specific } \\
& \text { modeled hydrograph; and } \\
& Q_{p}^{\text {obs }} \quad \text { is the observed peak streamflow. }
\end{aligned}
$$

The context-specific nature of $Q_{p}^{\text {model }}$ refers to the two levels of testing and subsequent validation in the following sections. The error for time of peak streamflow $\left(\varepsilon^{T_{Q_{p}}}\right)$ in hours, runoff volume $\left(\varepsilon^{V}\right)$ in basin inches, and hydrograph width at 50 and 75 percent of the peak streamflow ( $\varepsilon^{W_{50}}$ and $\varepsilon^{W_{75}}$, respectively) in hours are similarly defined, but $\log _{10}$ transformations are not used for the time, volume, or width errors.

\section{Testing of Gamma Unit Hydrograph Regressions}

In practice, the process of estimating the runoff hydrograph using the GUH can stand alone without a basin-loss model. For example, the excess rainfall hyetograph might be sourced from external information or from alternative loss models for a basin, or perhaps a simple, single-pulse (or multipulse with equal amounts in each pulse) rainfall event is assumed. 
Table 3. Listing and summary statistics of the basin-specific and regressed values of the unit hydrograph time to peak $\left(T_{p}\right)$ and associated 5-minute time interval, the basin-depth peak streamflow $\left(q_{p}\right)$, and the basin shape parameter $(K)$ for 39 streamgages in urban areas in and adjacent to Missouri.

[no., number; in/hr, basin inches per hour; dim., dimensionless; cell shading is to help identify different urban areas and roughly corresponds to symbol colors in figs. 11, 12]

\begin{tabular}{|c|c|c|c|c|c|c|c|c|c|}
\hline \multirow{2}{*}{$\begin{array}{l}\text { Map no. } \\
\text { (fig. 1) }\end{array}$} & \multirow[b]{2}{*}{ Station no. } & \multicolumn{4}{|c|}{ Basin-specific (mean) values } & \multicolumn{4}{|c|}{ Regressed values } \\
\hline & & $\begin{array}{c}T_{p} \\
\text { (hours) }\end{array}$ & $\begin{array}{c}\text { 5-minute } \\
\text { time interval }\end{array}$ & $\begin{array}{c}q_{p} \\
\text { (in/hr) }\end{array}$ & $\begin{array}{l}\text { Computed } K^{\text {a }} \\
\text { (dim.) }\end{array}$ & $\begin{array}{c}T_{p} \\
\text { (hours) }\end{array}$ & $\begin{array}{l}\text { 5-minute } \\
\text { time interval }\end{array}$ & $\begin{array}{c}q_{p} \\
\text { (in/hr) }\end{array}$ & $\begin{array}{l}\text { Computed } K^{\text {a }} \\
\text { (dim.) }\end{array}$ \\
\hline 1 & 06892513 & 3.167 & 38 & 0.200 & 2.67 & 3.667 & 44 & 0.217 & 4.13 \\
\hline 2 & 06893080 & 3.583 & 43 & 0.144 & 1.82 & 4.000 & 48 & 0.178 & 3.35 \\
\hline 3 & 06893100 & 5.000 & 60 & 0.137 & 3.12 & 5.333 & 64 & 0.131 & 3.21 \\
\hline 4 & 06893300 & 2.333 & 28 & 0.220 & 1.82 & 1.917 & 23 & 0.320 & 2.52 \\
\hline 5 & 06893390 & 2.833 & 34 & 0.203 & 2.24 & 3.333 & 40 & 0.207 & 3.16 \\
\hline 6 & 06893557 & 0.833 & 10 & 0.840 & 3.24 & 1.250 & 15 & 0.582 & 3.48 \\
\hline 7 & 06893562 & 1.333 & 16 & 0.489 & 2.83 & 1.417 & 17 & 0.498 & 3.28 \\
\hline 8 & 06893620 & 1.583 & 19 & 0.565 & 5.20 & 1.583 & 19 & 0.501 & 4.12 \\
\hline 9 & 06893970 & 1.833 & 22 & 0.370 & 3.06 & 1.750 & 21 & 0.468 & 4.38 \\
\hline 10 & 06910230 & 3.667 & 44 & 0.153 & 2.14 & 5.250 & 63 & 0.138 & 3.47 \\
\hline 11 & 06935770 & 2.583 & 31 & 0.334 & 4.85 & 2.333 & 28 & 0.330 & 3.90 \\
\hline 12 & 06935830 & 2.000 & 24 & 0.521 & 7.00 & 2.583 & 31 & 0.299 & 3.90 \\
\hline 13 & 06935850 & 1.833 & 22 & 0.419 & 3.87 & 1.333 & 16 & 0.501 & 2.97 \\
\hline 14 & 06935890 & 3.417 & 41 & 0.225 & 3.88 & 3.000 & 36 & 0.212 & 2.70 \\
\hline 15 & 06935955 & 1.333 & 16 & 0.438 & 2.30 & 1.167 & 14 & 0.576 & 2.99 \\
\hline 16 & 06935980 & 0.667 & 8 & 0.996 & 2.93 & 0.667 & 8 & 0.820 & 2.04 \\
\hline 17 & 06935997 & 0.917 & 11 & 0.756 & 3.18 & 1.000 & 12 & 0.731 & 3.52 \\
\hline 18 & 06936475 & 2.917 & 35 & 0.224 & 2.83 & 2.500 & 30 & 0.198 & 1.70 \\
\hline 19 & 07005000 & 1.417 & 17 & 0.441 & 2.61 & 1.833 & 22 & 0.351 & 2.76 \\
\hline 20 & 07010022 & 0.833 & 10 & 0.914 & 3.81 & 0.833 & 10 & 0.748 & 2.60 \\
\hline 21 & 07010030 & 0.583 & 7 & 0.841 & 1.67 & 0.583 & 7 & 1.084 & 2.67 \\
\hline 22 & 07010035 & 0.750 & 9 & 0.895 & 2.99 & 0.583 & 7 & 1.139 & 2.93 \\
\hline 23 & 07010055 & 1.417 & 17 & 0.695 & 6.25 & 1.417 & 17 & 0.462 & 2.85 \\
\hline 24 & 07010075 & 1.667 & 20 & 0.488 & 4.32 & 1.833 & 22 & 0.384 & 3.27 \\
\hline 25 & 07010086 & 1.750 & 21 & 0.296 & 1.84 & 1.833 & 22 & 0.361 & 2.92 \\
\hline 26 & 07010090 & 0.500 & 6 & 1.444 & 3.44 & 0.667 & 8 & 1.110 & 3.60 \\
\hline 27 & 07010180 & 2.083 & 25 & 0.374 & 3.98 & 1.500 & 18 & 0.434 & 2.82 \\
\hline 28 & 07010208 & 0.583 & 7 & 1.104 & 2.76 & 0.500 & 6 & 1.427 & 3.36 \\
\hline 29 & 07019120 & 1.250 & 15 & 0.764 & 5.90 & 1.167 & 14 & 0.598 & 3.22 \\
\hline 30 & 07019175 & 1.500 & 18 & 0.430 & 2.77 & 0.917 & 11 & 0.843 & 3.92 \\
\hline 31 & 07019185 & 2.583 & 31 & 0.298 & 3.89 & 2.000 & 24 & 0.359 & 3.41 \\
\hline 32 & 07019195 & 1.500 & 18 & 0.495 & 3.62 & 1.250 & 15 & 0.446 & 2.11 \\
\hline 33 & 07019220 & 1.000 & 12 & 0.889 & 5.13 & 0.833 & 10 & 0.844 & 3.27 \\
\hline 34 & 07019317 & 0.583 & 7 & 1.104 & 2.76 & 0.833 & 10 & 0.871 & 3.48 \\
\hline 35 & 07048480 & 0.333 & 4 & 2.116 & 3.29 & 0.417 & 5 & 1.914 & 4.16 \\
\hline 36 & 07048490 & 0.333 & 4 & 2.092 & 3.22 & 0.500 & 6 & 1.618 & 4.28 \\
\hline 37 & 07052000 & 1.417 & 17 & 0.469 & 2.93 & 1.417 & 17 & 0.473 & 2.98 \\
\hline 38 & 07052100 & 3.000 & 36 & 0.299 & 5.21 & 2.167 & 26 & 0.325 & 3.29 \\
\hline 39 & 07052152 & 3.667 & 44 & 0.262 & 5.96 & 2.750 & 33 & 0.263 & 3.46 \\
\hline
\end{tabular}


Table 3. Listing and summary statistics of the basin-specific and regressed values of the unit hydrograph time to peak $\left(T_{p}\right)$ and associated 5-minute time interval, the basin-depth peak streamflow $\left(q_{p}\right)$, and the basin shape parameter $(K)$ for 39 streamgages in urban areas in and adjacent to Missouri.-Continued

[no., number; in/hr, basin inches per hour; dim., dimensionless; cell shading is to help identify different urban areas and roughly corresponds to symbol colors in figs. 11, 12]

\begin{tabular}{|c|c|c|c|c|c|c|c|c|}
\hline & \multicolumn{4}{|c|}{ Basin-specific (mean) values } & \multicolumn{4}{|c|}{ Regressed values } \\
\hline & $\begin{array}{c}T_{p} \\
\text { (hours) }\end{array}$ & $\begin{array}{c}\text { 5-minute } \\
\text { time interval }\end{array}$ & $\begin{array}{c}q_{p} \\
\text { (in/hr) }\end{array}$ & $\begin{array}{l}\text { Computed } K^{\mathrm{a}} \\
\text { (dim.) }\end{array}$ & $\underset{\text { (hours) }}{T_{p}}$ & $\begin{array}{c}\text { 5-minute } \\
\text { time interval }\end{array}$ & $\begin{array}{c}q_{p} \\
\text { (in/hr) }\end{array}$ & $\begin{array}{c}\text { Computed } K^{\text {a }} \\
\text { (dim.) }\end{array}$ \\
\hline First quartile & 0.875 & 10.50 & 0.297 & 2.76 & 0.875 & 10.50 & 0.323 & 2.89 \\
\hline Mean & 1.810 & 21.72 & 0.614 & 3.52 & 1.793 & 21.51 & 0.589 & 3.24 \\
\hline Maximum & 5.000 & 60.00 & 2.116 & 7.00 & 5.333 & 64.00 & 1.914 & 4.38 \\
\hline
\end{tabular}

a Shape parameter $K$ is computed from $T_{p}$ and $q_{p}$ using equation 4 with $V=1$, using a numerical root solver (appendix 1).

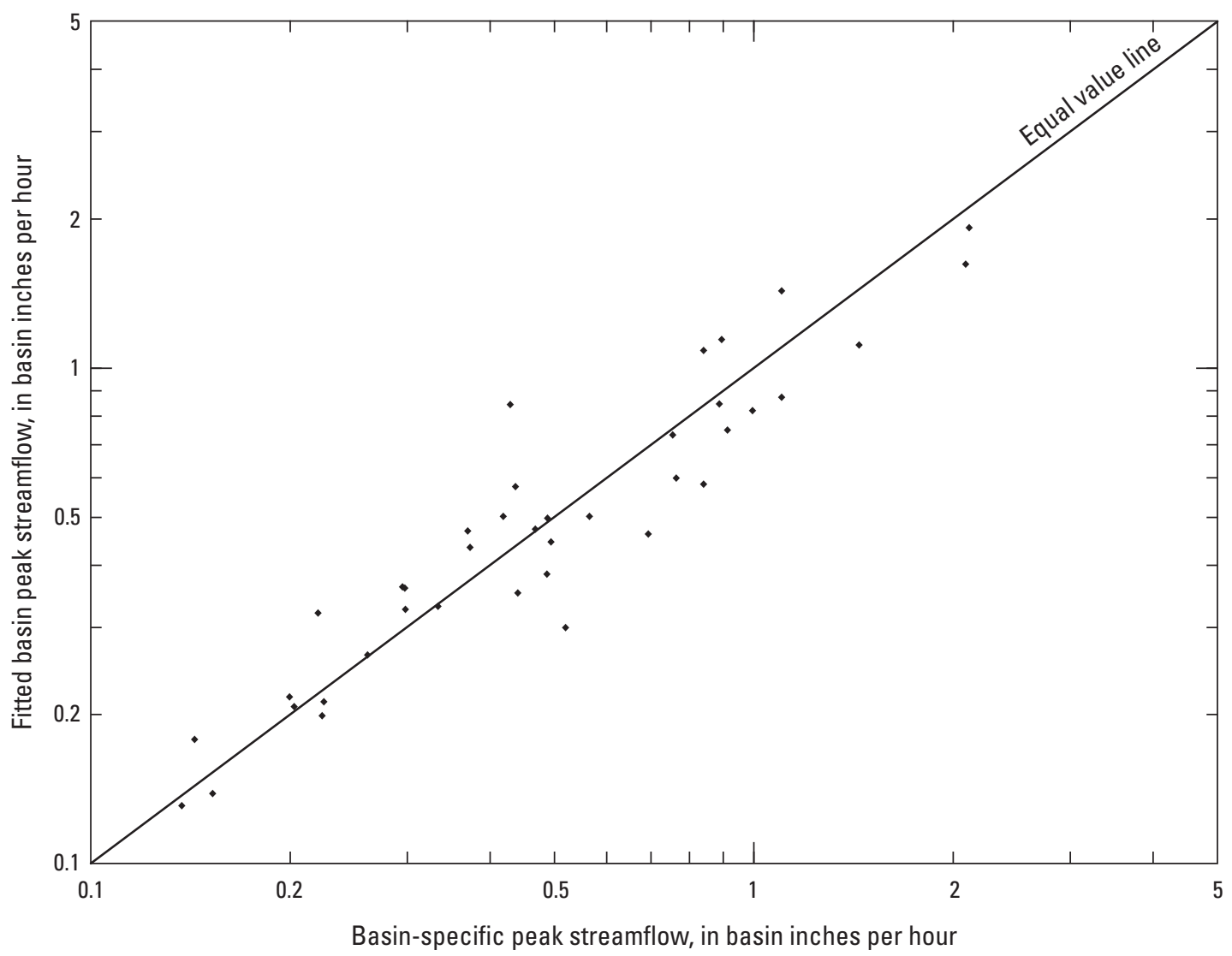

Figure 7. Relation between basin-specific peak streamflow and fitted values of basin-depth peak streamflow $\left(q_{p}\right)$ by regression from equation 7 for a gamma unit hydrograph developed using data from 39 streamgages in urban areas in and adjacent to Missouri. 


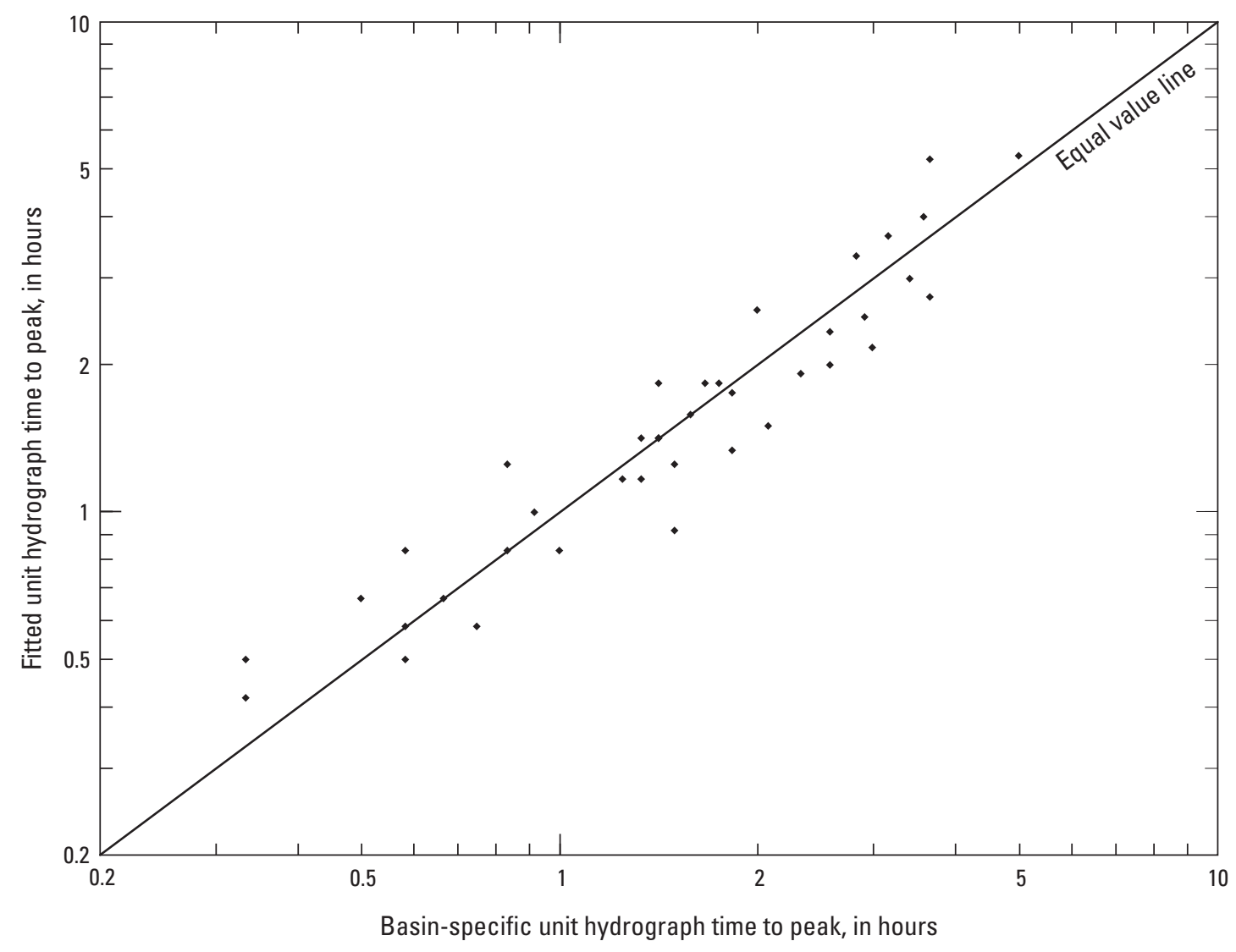

Figure 8. Relation between basin-specific unit hydrograph time to peak and fitted values of time to peak $\left(T_{p}\right)$ by regression from equation 8 for a gamma unit hydrograph developed using data from 39 streamgages in urban areas in and adjacent to Missouri.

The optimized storm-specific excess rainfall hyetographs were convolved (using eq. 1) with the GUH developed for each basin using the regression equations for $q_{p}$ (eq. 7) and $T_{p}$ (eq. 8), and the $\varepsilon^{T_{Q_{p}}}, \varepsilon^{Q_{p}}, \varepsilon^{V}, \varepsilon^{W_{50}}$, and $\varepsilon^{W_{75}}$ for each storm were computed. Common summary statistics for $\varepsilon^{T_{Q_{p}}}, \varepsilon^{Q_{p}}, \varepsilon^{V}$, $\varepsilon^{W_{50}}$, and $\varepsilon^{W_{75}}$ are listed in table 4 .

Although the minimum and maximum errors for the summary statistics shown in table 4 occasionally are large, all storms processed in the analysis were retained without regard to the specific nature of the rainfall and runoff data. Complex, non-uniform patterns and distributions of rainfall and runoff are in the dataset, which likely contribute to the magnitude of the minimum and maximum errors; however, the interquartile range (third-quartile minus first-quartile) is substantially smaller than the range spanned by the minimum and maximum values, which indicates most of the errors have much smaller variation, and the minimum and maximum values may be extreme outliers.

The central tendency (as indicated by the median and mean) of the storm-specific $\varepsilon^{T_{Q_{p}}}, \varepsilon^{Q_{p}}$, and $\varepsilon^{V}$ are all approximately zero. The central tendency being approximately zero was expected for the storm-specific results, because these were the constraints by which the quality of the modeled runoff hydrograph as compared to the observed hydrograph was measured. The mean and median of the storm-specific $\varepsilon^{W_{50}}$ and $\varepsilon^{W_{75}}$ were greater than zero, which implies that the GUH tends to slightly overestimate these widths compared to the observed when all other match constraints are met, even when specifically trying to match a given storm hydrograph. Ultimately, it is more important that the modeled hydrograph be a good match with the observed in terms of $Q_{p}, T^{Q_{p}}$, and $V$, and it is less important that the $\varepsilon^{W_{50}}$ and $\varepsilon^{W_{75}}$ be small.

The minimum and maximum values for the regressed GUH parameters are larger than for the storm-specific GUH parameters (table 4), which implies the regression introduces additional variation compared to the storm-specific analysis. The larger minimum and maximum for the regressed GUH parameters was expected, because the regressions are based on basin-averaged values for $q_{p}$ and $T_{p}$, which implicitly contain variability. The interquartile ranges are larger than for the storm-specific analysis. The central tendency of the regressed $\varepsilon^{Q_{p}}$ and $\varepsilon^{V}$ are both approximately zero, which implies a 
generally unbiased estimation of these values. The mean and median of the regressed $\varepsilon^{T_{Q_{p}}}$ were both small but greater than zero, which implies that the regressions create a hydrograph that has a peak that is later in time than observed by about 10 minutes, on average. The mean and median of the regressed $\varepsilon^{W_{50}}$ and $\varepsilon^{W_{75}}$ generally were less than zero, which implies that the GUH tends to slightly underestimate these widths compared to the observed hydrograph width.

\section{Testing of Initial Abstraction and Constant Loss with Gamma Unit Hydrograph}

The appropriate regional regression equations for $I_{A}$ (eq. 5 or 6), was combined with the generalized and specific regional mean values of $C_{L}$ to create two variations of a basin-loss model (the "generalize regional $C_{L}$ model" and the "specific regional $C_{L}$ model") to determine an excess rainfall hyetograph from a total rainfall hyetograph for each storm. Both variations of the excess rainfall hyetograph were convolved (using eq. 1) with the GUH developed for each basin using the regression equations for $q_{p}$ (eq. 7) and $T_{p}$ (eq. 8). The resultant modeled hydrographs for each storm were compared with the observed runoff hydrograph for that storm, and the $\varepsilon^{T_{Q_{p}}}, \varepsilon^{Q_{p}}$, $\varepsilon^{V}, \varepsilon^{W_{50}}$, and $\varepsilon_{T}^{W_{75}}$ were computed for each. Common summary statistics for $\varepsilon^{T_{Q_{p}}}, \varepsilon^{Q_{p}}, \varepsilon^{V}, \varepsilon^{W_{50}}$, and $\varepsilon^{W_{75}}$ for the two $C_{L}$ models are listed in table 5 .
There were 74 storms that had no modeled runoff because the combined losses of $I_{A}$ from the regression and the two regional mean $C_{L}$ values were greater than the observed rainfall, likely as a result of non-uniform spatial distribution of rainfall on the basin. The excluded storms generally are those on the upper side of and furthest from the equal value line in figure 6 (as well as furthest from the more uniform DSP data from which the regression equation was developed), which indicates a substantial overestimation of the modeled $I_{A}$ value compared to the storm-specific value. For storms with an irregular spatial distribution of rainfall, the rainfall at the basin centroid is not an accurate representation of the rainfall on the basin, resulting in a biased result for $I_{A}$. Results from these storms could not be included in the statistical summary.

A similar method had been used to test the validity of a computed regression equation and regression tree model for $C_{L}$, mentioned in the section titled "Estimation of Constant Loss." This analysis resulted in these two methods being abandoned, because the results were no better than those provided by the simple mean but were more computationally complex. The results of these earlier comparisons are not shown.

Both variations of the basin-loss model worked equally well to model the observed runoff hydrograph based on the summary statistics shown in table 5 , and neither model seems to make a consistently better approximation (fig. 9). The generalized regional $C_{L}$ model has the lowest standard deviation

Table 4. Common summary statistics for five forms of error in comparisons of observed and modeled runoff hydrographs for the 39 streamgages in urban areas in and adjacent to Missouri, using an optimized storm-specific excess rainfall hyetograph and the storm-specific or regressed gamma unit hydrograph parameters.

[E, times ten raised to the power of, or $\left.\left(\mathrm{x} 10^{\mathrm{a}}\right)\right]$

\begin{tabular}{|c|c|c|c|c|c|c|c|c|}
\hline Method & Storm count & Minimum & First quartile & Median & Mean & Third quartile & Maximum & Standard deviation \\
\hline \multicolumn{9}{|c|}{ Time of peak streamflow error, $\varepsilon^{T_{Q_{p}}}$, in hours } \\
\hline Storm specific & 440 & -2.167 & -0.083 & 0.000 & -0.048 & 0.083 & 0.917 & 0.276 \\
\hline Regressed & 440 & -3.417 & -0.250 & 0.167 & 0.191 & 0.833 & 3.750 & 1.093 \\
\hline \multicolumn{9}{|c|}{ Peak streamflow error, $\varepsilon^{Q_{p}}$, in $\log _{10}$ (cubic feet per second) } \\
\hline \multicolumn{9}{|c|}{ Runoff hydrograph volume error, $\varepsilon^{V}$, in basin inches } \\
\hline Storm specific & 440 & -0.431 & $-4.16 \mathrm{E}-5$ & $-3.91 \mathrm{E}-6$ & $-1.72 \mathrm{E}-3$ & $-2.28 \mathrm{E}-7$ & 0.052 & 0.023 \\
\hline Regressed & 440 & -0.106 & $-1.17 \mathrm{E}-3$ & $6.94 \mathrm{E}-4$ & $4.64 \mathrm{E}-3$ & $7.36 \mathrm{E}-3$ & 0.075 & 0.019 \\
\hline \multicolumn{9}{|c|}{ Width of runoff hydrograph at 50 percent of peak error, $\varepsilon^{W_{50}}$, in hours } \\
\hline \multicolumn{9}{|c|}{ Width of runoff hydrograph at 75 percent of peak error, $\varepsilon^{W_{75}}$, in hours } \\
\hline Storm specific & 440 & -2.035 & -0.123 & 0.078 & 0.059 & 0.270 & 2.152 & 0.430 \\
\hline Regressed & 440 & -4.008 & -0.651 & 0.005 & -0.110 & 0.525 & 2.909 & 1.068 \\
\hline
\end{tabular}


in three of the five errors (table 5); however, as mentioned in the section titled "Testing of Gamma Unit Hydrograph Regressions," the error on the widths is less important than the $Q_{p}, T^{Q_{p}}$, and $V$. The specific regional $C_{L}$ model has the lowest mean value for four of the five errors; however, it has a slightly higher mean value for $\varepsilon^{Q_{p}}$ (table 5).

\section{Verification of Modeled Hydrographs}

As stated earlier in the "Data Collection Sites" section, the current (2014) study was started in early 2011, and the regressions were developed using data through December 2010; however, more than 3 years have passed since the study began, providing several additional rainfall events that could be used for verification of the regression equations (the verification dataset).

As with the testing of the primary dataset, the appropriate regional regression equation for $I_{A}$ (eq. 5 or 6 ) was combined with the various regional mean values of $C_{L}$ to create two variations of a basin-loss model to determine an excess rainfall hyetograph from a total rainfall hyetograph for each storm after 2011, and both variations of the excess rainfall hyetograph were convolved (using eq. 1) with the GUH developed for each basin using the regression equations for $q_{p}$ (eq. 7) and $T_{p}$ (eq. 8). The resultant modeled hydrographs were once again compared with the observed runoff hydrographs and the $\varepsilon^{T_{Q_{p}}}, \varepsilon^{Q_{p}}, \varepsilon^{V}, \varepsilon^{W_{50}}$, and $\varepsilon^{W_{75}}$ for each storm were computed. Common summary statistics for $\varepsilon^{T_{Q_{p}}}, \varepsilon^{Q_{p}}, \varepsilon^{V}, \varepsilon^{W_{50}}$, and $\varepsilon^{W_{75}}$ for the storms after 2011 are listed in table 6 . And once again, storms with no modeled runoff occasionally occurred because the combined losses of $I_{A}$ from the regression and the two regional mean $C_{L}$ values were greater than the observed rainfall, and results from these storms were not included in the statistical summary.

The verification dataset also indicates that both variations of the $C_{L}$ model worked equally well to model the observed runoff hydrograph based on the summary statistics (table 6); however, the verification dataset errors consistently are higher than the errors from the primary dataset of before-2011 storms for $\varepsilon^{Q_{p}}, \varepsilon^{V}, \varepsilon^{W_{50}}$, and $\varepsilon^{W_{75}}$ (fig. 9), which implies that the modeled data consistently are overestimated compared to the observed data. The interquartile range is slightly larger for the verification dataset for almost all of the errors (tables 5 and 6 ; fig. 9).

A possible explanation for the overestimation of the verification dataset is that the after-2011 storms were of smaller magnitude than those before 2011. The median total storm rainfall of the after-2011 storms was 1.07 inches, which is slightly lower than the before-2011 storms of 1.16 inches. Furthermore, the maximum value of total storm rainfall of the after-2011 storms was 3.13 inches compared to 5.89 inches for the before-2011 storms.

Table 5. Common summary statistics for five forms of error in comparisons of observed and modeled runoff hydrographs for the 39 streamgages in urban areas in and adjacent to Missouri, using a modeled excess rainfall hyetograph and regressed gamma unit hydrograph parameters.

\begin{tabular}{|c|c|c|c|c|c|c|c|c|}
\hline $\begin{array}{c}\text { Model of constant loss, } \\
C_{L}\end{array}$ & $\begin{array}{l}\text { Storm } \\
\text { count }\end{array}$ & Minimum & $\begin{array}{c}\text { First } \\
\text { quartile }\end{array}$ & Median & Mean & $\begin{array}{l}\text { Third } \\
\text { quartile }\end{array}$ & Maximum & $\begin{array}{l}\text { Standard } \\
\text { deviation }\end{array}$ \\
\hline \multicolumn{9}{|c|}{ Time of peak streamflow error, $\varepsilon^{T_{Q_{p}}}$, in hours } \\
\hline Generalized regional $C_{L}$ & 366 & -9.000 & -0.500 & -0.042 & -0.152 & 0.250 & 3.833 & 1.104 \\
\hline Specific regional $C_{L}$ & 366 & -9.000 & -0.500 & 0.000 & -0.144 & 0.250 & 3.917 & 1.108 \\
\hline \multicolumn{9}{|c|}{ Peak streamflow error, $\varepsilon^{Q_{p}}$, in $\log _{10}$ (cubic feet per second) } \\
\hline Generalized regional $C_{L}$ & 366 & -1.571 & -0.196 & -0.002 & -0.006 & 0.234 & 1.493 & 0.398 \\
\hline Specific regional $C_{L}$ & 366 & -1.652 & -0.191 & -0.002 & -0.009 & 0.234 & 1.188 & 0.398 \\
\hline \multicolumn{9}{|c|}{ Runoff hydrograph volume error, $\varepsilon^{V}$, in basin inches } \\
\hline Generalized regional $C_{L}$ & 366 & -2.048 & -0.154 & 0.004 & 0.044 & 0.200 & 2.161 & 0.463 \\
\hline Specific regional $C_{L}$ & 366 & -2.078 & -0.166 & -0.003 & 0.039 & 0.213 & 2.176 & 0.455 \\
\hline \multicolumn{9}{|c|}{ Width of runoff hydrograph at 50 percent of peak error, $\varepsilon^{W_{50}}$, in hours } \\
\hline Generalized regional $C_{L}$ & 366 & -5.588 & -0.552 & 0.027 & -0.066 & 0.530 & 4.459 & 1.189 \\
\hline Specific regional $C_{L}$ & 366 & -5.618 & -0.539 & 0.030 & -0.057 & 0.531 & 4.459 & 1.200 \\
\hline \multicolumn{9}{|c|}{ Width of runoff hydrograph at 75 percent of peak error, $\varepsilon^{W_{75}}$, in hours } \\
\hline Generalized regional $C_{L}$ & 366 & -3.592 & -0.342 & 0.047 & -0.049 & 0.333 & 3.043 & 0.818 \\
\hline Specific regional $C_{L}$ & 366 & -3.592 & -0.316 & 0.053 & -0.040 & 0.332 & 3.857 & 0.837 \\
\hline
\end{tabular}




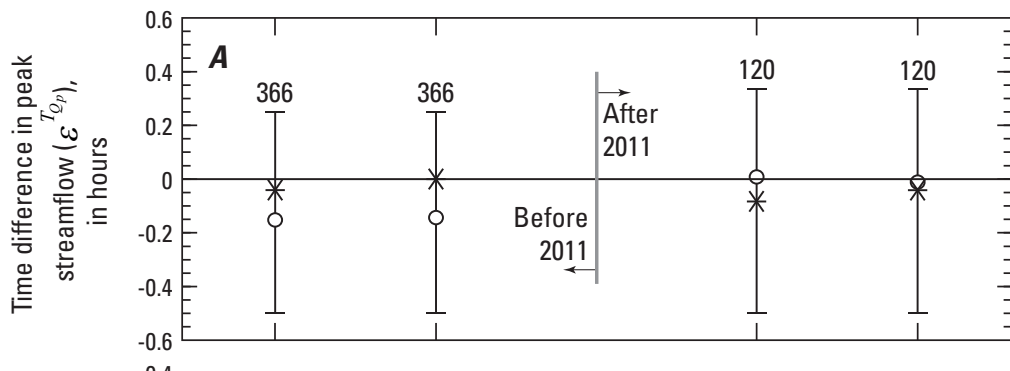

EXPLANATION

120 Number of storms

T Upper or third quartile of error statistic $\varepsilon$

* Median of error statistic $\varepsilon$

Mean of error statistic $\varepsilon$

Lower or first quartile of error statistic $\varepsilon$
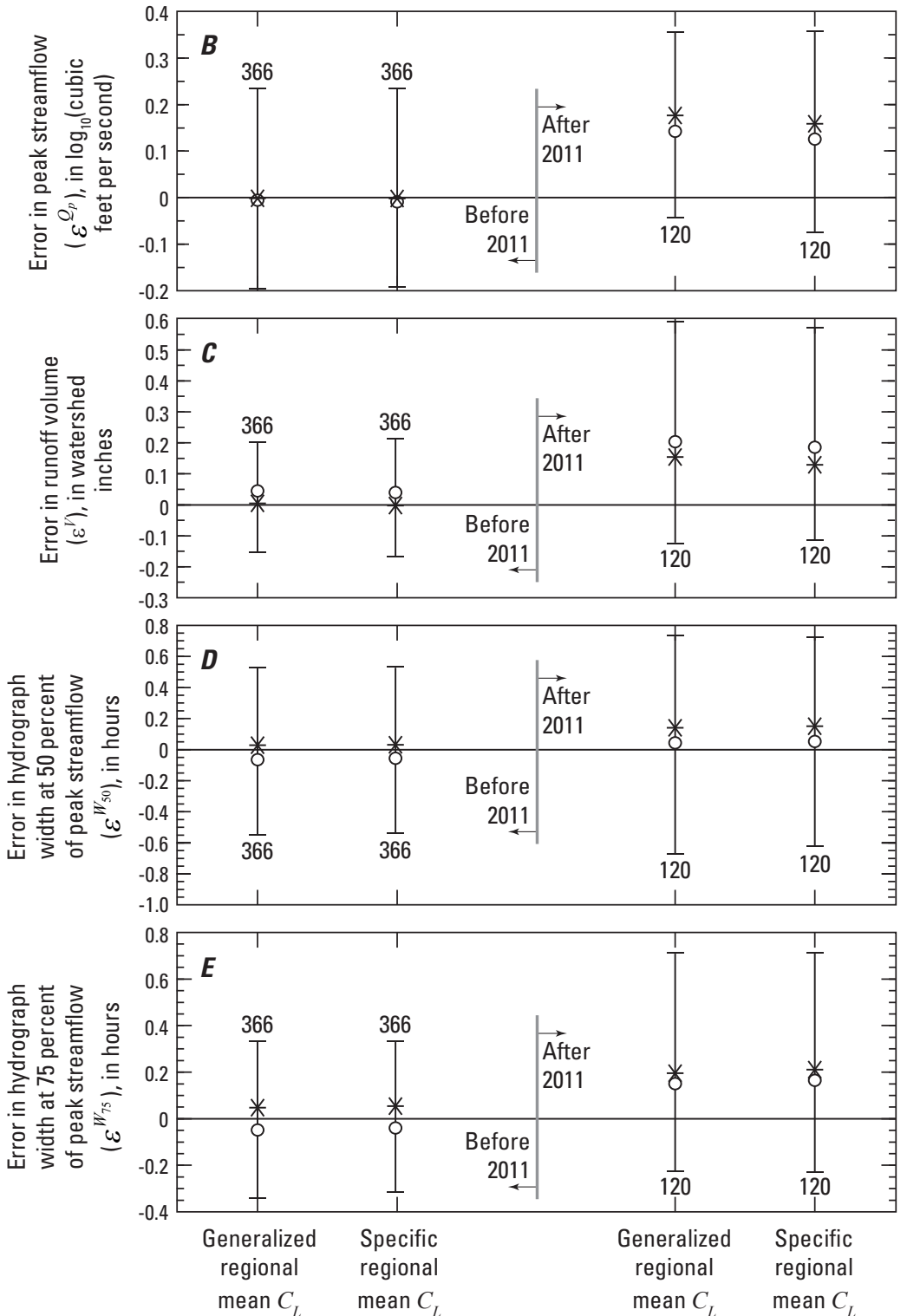

Figure 9. Whisker diagrams showing distribution of error statistics for both of the constant loss $\left(C_{L}\right)$ models for storms before 2011 (primary dataset) and after 2011 (verification dataset) from numerical values listed in tables 5 and 6 . 


\section{Comparison with Previous Studies}

The dimensionless GUH developed for Missouri is shown in figure $10 \mathrm{~A}$ with the previous unit hydrograph for Missouri from Becker (1990). The Becker (1990) unit hydrograph was made dimensionless in the $\mathrm{x}$-axis (horizontal direction) by dividing time by the basin lag time $\left(T_{L a g}\right)$; however, the coordinates from the dimensionless unit hydrograph indicate that the peak streamflow $\left(Q / Q_{p}=1\right)$ occurred when $T / T_{\text {Lag }}=0.95$. Therefore, the time values along the abscissa of Becker's dimensionless unit hydrograph were divided by 0.95 to make the dimensionless ratio $T / T_{p}$. The full range of computed shape factors, $K$, from 1.7 to 4.4 (table 3 ) are shown in figure $10 \mathrm{~A}$, along with the median value of 3.3 .

The variable shape factor is what gives the GUH great flexibility for application in Missouri. Rather than a single dimensionless unit hydrograph for all urban basins in Missouri (as was done for urban and rural basins in Becker [1990]), the GUH becomes basin specific based on the regressed values of $q_{p}$ and $T_{p}$ and the resultant $K$. The clear relations between the observed and fitted values of $q_{p}$ (fig. 7) and $T_{p}$ (fig. 8) imply that runoff hydrographs computed using the GUH will reasonably match the true observed runoff hydrograph. Becker (1990) showed the range of data used to develop the single dimensionless unit hydrograph (see fig. 4 in Becker [1990]); the GUH provides the full range of data, dependent on the computed values of $q_{p}$ and $T_{p}$ and the resultant $K$ (fig. 10), rather than a single dimensionless curve.

The dimensionless GUH developed for Missouri is shown in figure $10 B$ with other dimensionless unit hydrographs developed in other studies by the USGS (Stricker and Sauer, 1982; Inman, 1987; Bohman, 1990, 1992; Mason and Bales, 1996; Weaver, 2003) and the Natural Resources Conservation Service (2014b). All except the NRCS curve are made dimensionless using the basin lag, $T_{L a g}$, so the time values along the abscissa of the various dimensionless unit hydrographs were divided by the $T / T_{L a g}$ value at which the $Q / Q_{p}=1$, as was done with Becker's (1990) curve in figure 10A. The range of shape factors in Missouri encompasses most of the various other dimensionless unit hydrographs including the NRCS curve, except for part of the recession side of the hydrograph (fig. 10B).

The median basin-specific $K$ also is within the range of $K$ values developed for Texas, which are based on basin urbanization, with 5.2 for undeveloped basins and 2.9 for fully developed (Asquith and others, 2005, p. 31; fig. 10A). These values further bracket the equivalent $K$ value of 3.77 for a GUH equivalent to the NRCS (Natural Resources Conservation Service, 2014b) dimensionless hydrograph (Haan and others, 1994, p. 79). Thus, it can be concluded that the range of shapes (not necessarily peak or time to peak) of the GUH for this study is congruent with prior research even outside

Table 6. Common summary statistics for five forms of error in comparisons of observed and modeled runoff hydrographs for storms after 2011 on the 39 streamgages in urban areas in and adjacent to Missouri, using a modeled excess rainfall hyetograph and regressed gamma unit hydrograph parameters.

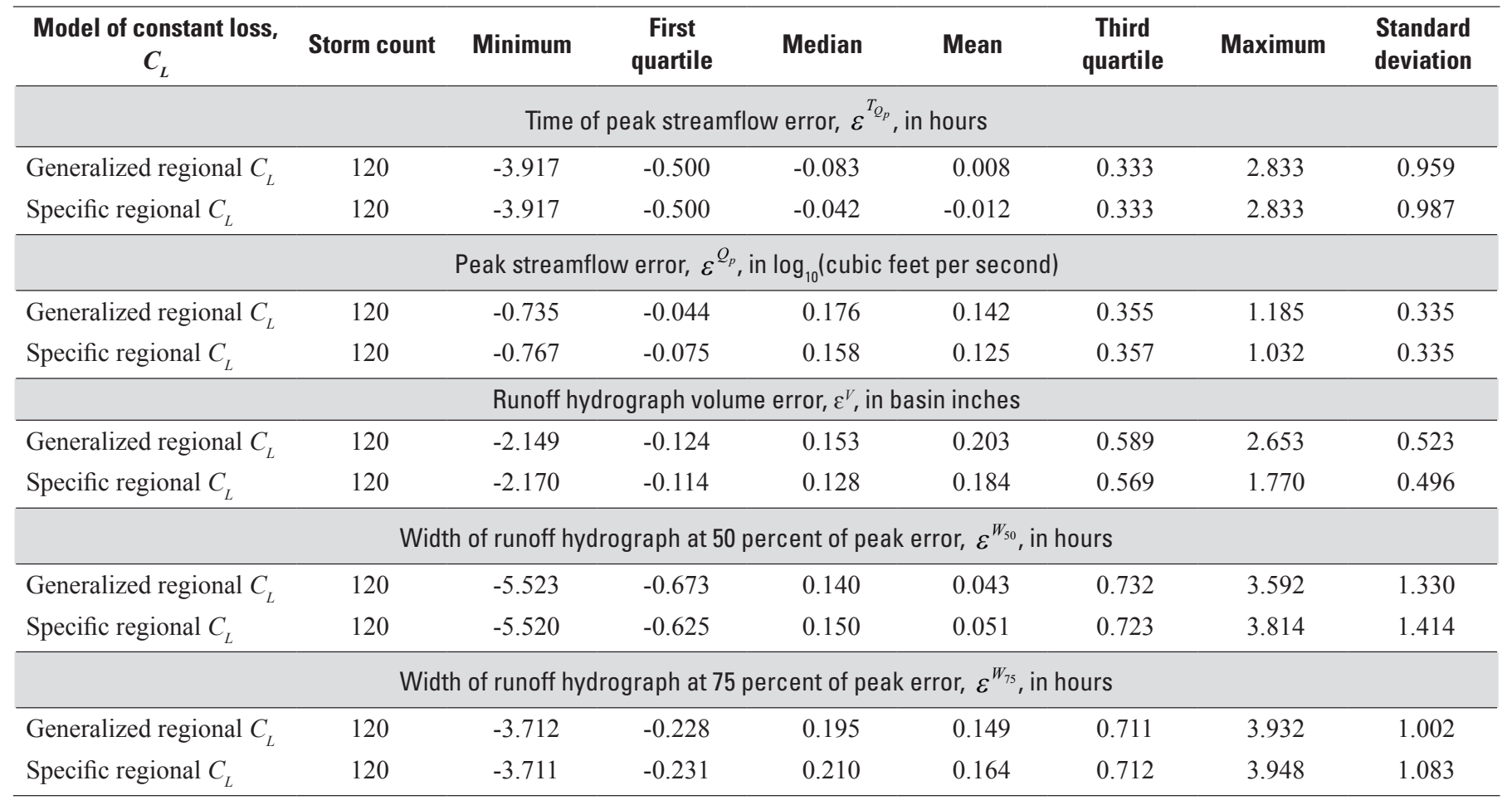


the study area (Asquith and Roussel, 2007; Asquith and others, 2005).

\section{Example Application of Methods}

The following examples demonstrate the steps required for estimating the various parameters necessary for a unit hydrograph using the various regression equations presented in the preceding sections. The ranges of data used for the rainfall and basin-specific independent variables (table 7) serve as the general limitations in the overall application of the GUH to urban basins in Missouri. The steps to develop the GUH parameters will be demonstrated first; then the steps to estimate the $I_{A}$ and develop an effective rainfall hyetograph from a total rainfall hyetograph will be demonstrated; finally, the GUH will be applied to the effective rainfall hyetograph to develop a runoff hydrograph. A spreadsheet to assist with these series of computations is provided as digital media with this report (http://pubs.usgs.gov/sir/2014/5193/downloads/ UnitHydrographProcessingTemplate.xlsx). The site used for these examples, the streamgage at Coldwater Creek near Black Jack, Mo. (site 18; figs. 1, 3; table 1), will be treated as an ungaged site for the purposes of demonstrating the steps, using the storm of June 26, 2000. The total rainfall hyetograph was developed using the techniques detailed in appendix 3 . The boxed symbols for $q_{p}, T_{p}$, and $K$ represent final values.

\section{Gamma Unit Hydrograph Parameter Determination Example}

Step 1, Estimate the GUH basin-depth peak streamflow $\left(q_{p}\right)$.- The relation developed for use in estimating the $q_{p}$ requires the drainage area, the main-channel slope (based on the 10- and 85-percent length method), the composite $C N$ computed based on land use and soil types in the basin, and the percent of the basin area in storage. These values are shown in table 1 for the Coldwater Creek near Black Jack, Mo., streamgage (site 18). Equation 7, developed for estimating $q_{p}$, is applied as follows:

$$
\begin{gathered}
q_{p}=0.0560(\text { DRNAREA })^{-0.2857}(\text { CSL1085LFP })^{0.3269} \times \\
(10)^{0.0106(C N)-0.0914(\text { ASTORAGE })} \\
\text { or } \\
q_{p}=0.0560(40.36)^{-0.2857}(5.51)^{0.3269}(10)^{0.0106(79)-0.0914(0.78)} \\
q_{p}=0.1984 \text { basin inches per hour. }
\end{gathered}
$$

This $q_{p}$ is regarded as the "true" basin-depth peak streamflow, which subsequent steps will seek to preserve.
Step 2, Estimate the GUH time to peak $\left(T_{p}\right)$.- Equation 8, developed for estimating $T_{p}$ requires the basin drainage area in square miles, the percent of the basin area in storage, and the composite $C N$ computed based on land use and soil types in the basin. Again, drawing from table 1, the equation is applied as follows:

$$
\begin{gathered}
T_{p}=4.7555(\text { DRNAREA })^{0.4336}(10)^{0.0983(\text { ASTORAGE })-0.0133(C N)} \\
\text { or } \\
T_{p}=4.7555(40.36)^{0.4336}(10)^{0.0983(0.78)-0.0133(79)}=2.511 \text { hours }
\end{gathered}
$$

Step 3, Round $T_{p}$ to the nearest 5-minute time step.Determine an integer value, $\delta$, where $\delta=T_{p} \times 60 / 5$. The value of $T_{p}$ from step 2 yields $\delta=30.1$, which would be rounded to 30 ; therefore, $T_{p}=2.500$ hours. This value of $T_{p}$ is regarded as the time to peak streamflow of the GUH.

Step 4, Determine the GUH shape factor (K).-The $K$ can be computed from the value of $q_{p}$ from step 1 and the rounded value of $T_{p}$ from step 3, combined with equation 4 with $V=1$, or

$$
V=q_{p} T_{p} \Gamma(K)\left(\frac{\mathrm{e}^{(1)}}{K}\right)^{K}
$$

or

$$
1=0.1984 \times 2.500 \Gamma(K)\left(\frac{\mathrm{e}^{(1)}}{K}\right)^{K}
$$

This equation is solved using a numerical root solver (such as Microsoft ${ }^{\circledR}$ Excel; appendix 1), and yields $K=1.70$.

Using the rounded value of $T_{p}$ from step 3 adjusts the shape of the GUH so that $q_{p}$ is maintained as the basindepth peak streamflow that occurs at $T_{p}$, which is a time that is consistent with the 5-minute increment of the GUH. These three parameters define the 5-minute GUH for the streamgage at Coldwater Creek near Black Jack, Mo. (site 18; figs. 1, 3; table 1). If a hydrograph with a time step other than a 5-minute unit hydrograph is desired, the equation for $\delta$ in step 3 should be modified accordingly. For example, $\delta=T_{p} \times 60 / 15$ for a 15 -minute hydrograph, and $\delta$ should be rounded to the nearest integer to preserve $T_{p}$ as the time to peak streamflow of the GUH. 


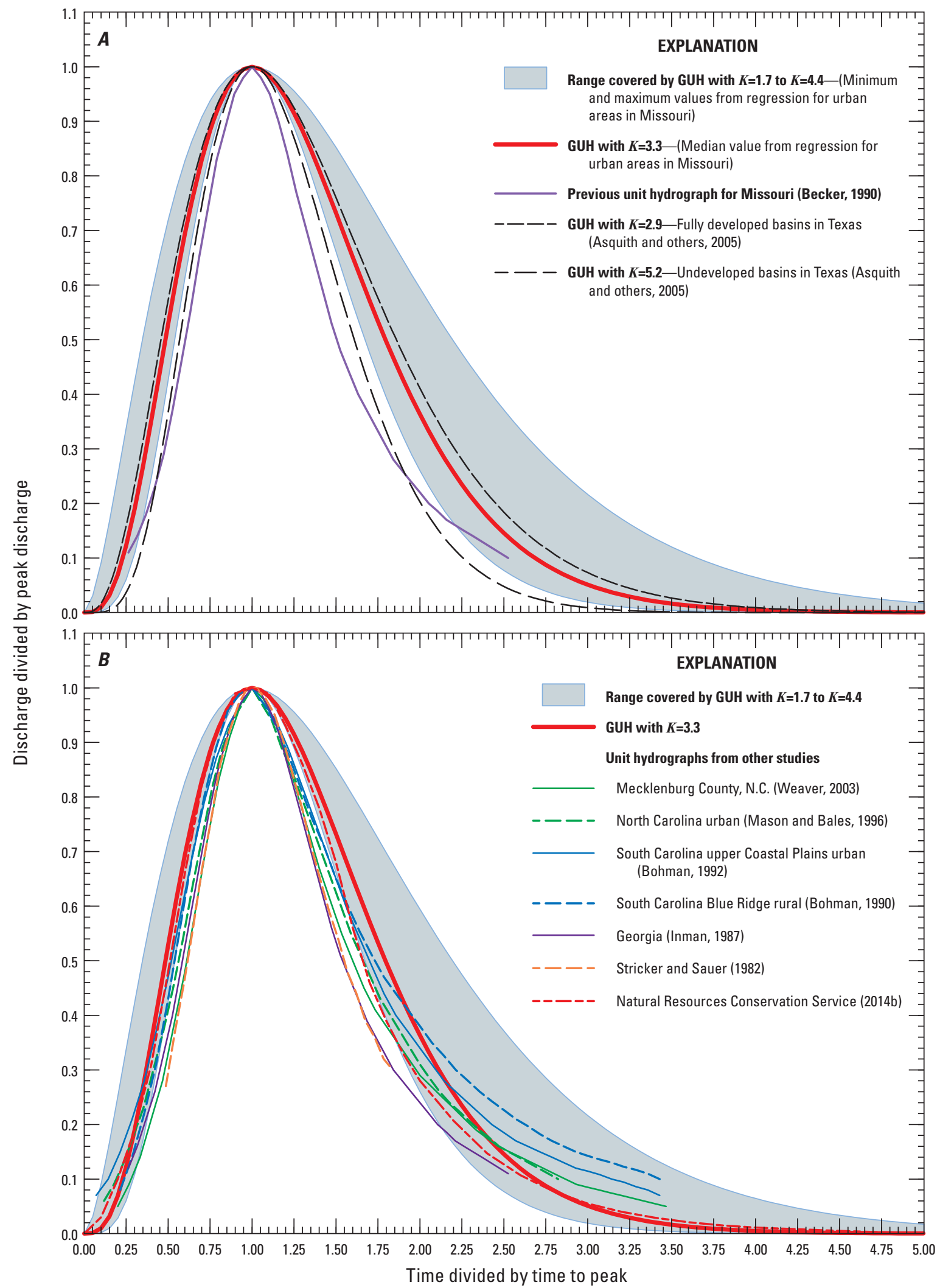

Figure 10. Shape of the dimensionless gamma unit hydrograph (GUH) for selected shape parameter $(K)$ values along with $A$, the previous dimensionless unit hydrograph developed for Missouri by Becker (1990) and $B$, dimensionless unit hydrographs developed in various other studies. 
Table 7. Range of basin- and rainfall-characteristic values used to develop selected basin-loss and gamma unit hydrograph regression equations from streamgages in urban areas in and adjacent to Missouri.

[abbreviations for basin characteristics follow naming conventions by U.S. Geological Survey StreamStats Web site (http://streamstatsags.cr.usgs.gov/ss_defs/ basin_char_defs.aspx); GIS, geographic information system; $\mathrm{mi}^{2}$, square miles; NLCD, National Land Cover Dataset; NRCS CN, Natural Resources Conservation Service curve number; dim., dimensionless]

\begin{tabular}{|c|c|c|c|c|c|c|c|c|c|}
\hline Statistic & $\begin{array}{c}\text { GIS } \\
\text { drainage } \\
\text { area } \\
\text { DRNAREA } \\
\left(\mathrm{mi}^{2}\right)\end{array}$ & $\begin{array}{l}\text { Impervious } \\
\text { area from } \\
\text { NLCD } 2001 \\
\text { IMPNLCD01 } \\
\text { (percent) }\end{array}$ & $\begin{array}{l}\text { Elevation change } \\
\text { between } 10 \text { and } \\
85 \text { percent along } \\
\text { main channel } \\
\text { CSL1085LFP } \\
\text { (feet/mile) }\end{array}$ & $\begin{array}{c}\text { Area of } \\
\text { storage } \\
\text { ASTORAGE } \\
\text { (percent) }\end{array}$ & $\begin{array}{c}\text { Streamflow } \\
\text { variability } \\
\text { index } \\
\text { STREAM_VAR } \\
\text { (dim.) }\end{array}$ & $\begin{array}{l}\text { Composite } \\
\text { NRCS CN } \\
\text { (dim.) }\end{array}$ & $\begin{array}{c}\text { Total rain } \\
\text { in storm } \\
\text { RAIN }_{\text {Storm }} \\
\text { (inches) }^{\text {inton }}\end{array}$ & $\begin{array}{l}\text { 5-day } \\
\text { antecedent } \\
\text { rainfall } \\
\text { RAIN }_{\text {5-day }} \\
\text { (inches) }\end{array}$ & $\begin{array}{l}\text { 14-day } \\
\text { antecedent } \\
\text { rainfall } \\
\text { RAIN }_{14-\text { day }} \\
\text { (inches) }\end{array}$ \\
\hline Minimum & 0.78 & 3.72 & 5.51 & 0.00 & 0.521 & 67 & 0.05 & 0.00 & 0.00 \\
\hline Maximum & 75.2 & 46.55 & 126.38 & 2.84 & 0.829 & 90 & 5.89 & 4.44 & 8.55 \\
\hline
\end{tabular}

\section{Effective Rainfall Hyetograph Development Example}

Step 1, Estimate the initial abstraction $\left(I_{A}\right)$.- The relation developed for use in estimating the $I_{A}$ depends on the low-flow region (figs. 1, 3). The streamgage at Coldwater Creek near Black Jack, Mo. (site 18), is in low-flow region 1 (figs. 1, 3), so equation 5 will be used to estimate the $I_{A}$. Equation 5 requires the total rainfall in the storm in question, the 14-day antecedent rainfall in the area, the composite $C N$ computed based on land use and soil types in the basin, and the percent impervious area of the basin. The $C N$ is known from the previous example; the percent impervious area can be drawn from table 1; the total rainfall in the storm was obtained from the NEXRAD hyetograph data, and is shown in table 8; and the 14-day antecedent rainfall in the area was obtained from the daily rainfall data from NCDC at http://www.ncdc. noaa.gov/cdo-web/. Equation 5, developed for estimating the $I_{A}$ in low-flow region 1, is applied as follows:

$$
\begin{gathered}
I_{A 1}=52.626\left(\frac{\operatorname{RAIN}_{\text {Storm }}}{\operatorname{RAIN}_{14-\text { day }}}\right)^{0.6743}(10)^{-0.0242(C N)-0.0090(\text { IMPNLCD } 01)} \\
I_{A 1}=52.626\left(\frac{1.00}{6.50}\right)^{0.6743}(10)^{-0.0242(79)-0.0090(40.97)} \\
I_{A 1}=0.078 \text { basin inches. }
\end{gathered}
$$

Step 2, Choose a value of constant loss $\left(C_{L}\right)$. - The $C_{L}$ was shown to be equally well estimated by a generalized regional mean or a specific regional mean value. These values for the streamgage at Coldwater Creek near Black Jack, Mo. (station number 06936475, site 18; table 1), are 0.20 and 0.17 inches per hour, respectively (St. Louis, Mo., Missouri River side [station number starts with "069"]; table 2). The specific regional mean value of 0.17 inches per hour will be used in this example (table 8). For use in the 5-minute hyetograph, this value must be converted from a rate in inches per hour to the equivalent rate in inches per 5-minute increment, or $0.17 / 60 \times 5=0.01416 \overline{6}$.

Step 3, Apply the $I_{A}$ and $C_{L}$ to the total rainfall hyetograph. - The total accumulated rainfall is used to determine the point at which the $I_{A}$ has been fulfilled and the $C_{L}$ begins (observation 3 in table 8 ). The effective rainfall is the total rainfall minus the $I_{A}$ minus the $C_{L}$, as shown in table 8 , subject to the following constraints:

- If the total rainfall hyetograph has no rainfall in a particular time interval, the cumulative $I_{A}$ and $C_{L}$ are held constant until the next interval for which the total rainfall hyetograph has a nonzero value (see observation 9 in table 8); and

- The $C_{L}$ cannot be greater than the total rainfall available in a given time interval. For example, see observation 14 in table 8 , with a total rainfall value of 0.010 inches for that interval; the $C_{L}$ is 0.014 inches per 5-minute interval, but only 0.010 is accumulated for that interval because that is all that is available from the total rainfall hyetograph.

Step 4, Determine the effective rainfall from the cumulative effective rainfall. - All of the computations in step 3 use the cumulative values. The incremental effective rainfall (the effective rainfall hyetograph) is determined by subtracting the accumulated effective rainfall for a given interval by the accumulated effective rainfall from the previous interval (table 8). 
Table 8. Example application of the method to convert a total rainfall hyetograph to an effective rainfall hyetograph for U.S. Geological Survey streamgage Coldwater Creek near Black Jack, Missouri (site 18; fig. 1).

[cells with blue highlight indicate nonzero values of rain in the hyetograph]

\begin{tabular}{|c|c|c|c|c|c|c|c|}
\hline \multirow[b]{2}{*}{ Observation } & \multirow{2}{*}{$\begin{array}{c}\text { Time } \\
\text { (hours) }\end{array}$} & \multirow{2}{*}{$\begin{array}{l}\text { Total rain } \\
\text { hyetograph } \\
\text { (inches) }\end{array}$} & \multicolumn{4}{|c|}{ Cumulative values } & \multirow{2}{*}{$\begin{array}{l}\text { Effective rain } \\
\text { hyetograph } \\
\text { (inches) }\end{array}$} \\
\hline & & & $\begin{array}{l}\text { Total rain } \\
\text { (inches) }\end{array}$ & $\begin{array}{c}\text { Initial abstraction, } I_{A} \\
\text { (inches) }\end{array}$ & $\begin{array}{c}\text { Constant loss, } C_{L} \\
\text { (inches) }\end{array}$ & $\begin{array}{l}\text { Effective rain } \\
\text { (inches) }\end{array}$ & \\
\hline 1 & 0.000 & 0.000 & 0.000 & 0.000 & 0.000 & 0.000 & 0.000 \\
\hline 2 & 0.083 & 0.060 & 0.060 & 0.060 & 0.000 & 0.000 & 0.000 \\
\hline 3 & 0.167 & 0.160 & 0.220 & ${ }^{\mathrm{a}} 0.078$ & ${ }^{\mathrm{a}} 0.014$ & ${ }^{\mathrm{a}} 0.128$ & 0.128 \\
\hline 4 & 0.250 & 0.160 & 0.380 & 0.078 & 0.028 & 0.274 & 0.146 \\
\hline 6 & 0.417 & 0.120 & 0.620 & 0.078 & 0.057 & 0.485 & 0.106 \\
\hline 7 & 0.500 & 0.100 & 0.720 & 0.078 & 0.071 & 0.571 & 0.086 \\
\hline 8 & 0.583 & 0.020 & 0.740 & 0.078 & 0.085 & 0.577 & 0.006 \\
\hline 9 & 0.667 & 0.000 & 0.740 & 0.078 & 0.085 & 0.577 & 0.000 \\
\hline 10 & 0.750 & 0.020 & 0.760 & 0.078 & 0.099 & 0.583 & 0.006 \\
\hline 14 & 1.083 & 0.010 & 0.800 & 0.078 & 0.123 & 0.599 & 0.000 \\
\hline 15 & 1.167 & 0.030 & 0.830 & 0.078 & 0.137 & 0.614 & 0.016 \\
\hline 16 & 1.250 & 0.020 & 0.850 & 0.078 & 0.152 & 0.620 & 0.006 \\
\hline 17 & 1.333 & 0.020 & 0.870 & 0.078 & 0.166 & 0.626 & 0.006 \\
\hline 18 & 1.417 & 0.020 & 0.890 & 0.078 & 0.180 & 0.632 & 0.006 \\
\hline 19 & 1.500 & 0.030 & 0.920 & 0.078 & 0.194 & 0.648 & 0.016 \\
\hline 20 & 1.583 & 0.010 & 0.930 & 0.078 & 0.204 & 0.648 & 0.000 \\
\hline 21 & 1.667 & 0.000 & 0.930 & 0.078 & 0.204 & 0.648 & 0.000 \\
\hline 22 & 1.750 & 0.030 & 0.960 & 0.078 & 0.218 & 0.664 & 0.016 \\
\hline 23 & 1.833 & 0.000 & 0.960 & 0.078 & 0.218 & 0.664 & 0.000 \\
\hline 30 & 2.417 & 0.000 & 0.970 & 0.078 & 0.228 & 0.664 & 0.000 \\
\hline 31 & 2.500 & 0.000 & 0.970 & 0.078 & 0.228 & 0.664 & 0.000 \\
\hline 32 & 2.583 & 0.000 & 0.970 & 0.078 & 0.228 & 0.664 & 0.000 \\
\hline 33 & 2.667 & 0.000 & 0.970 & 0.078 & 0.228 & 0.664 & 0.000 \\
\hline 34 & 2.750 & 0.000 & 0.970 & 0.078 & 0.228 & 0.664 & 0.000 \\
\hline 35 & 2.833 & 0.000 & 0.970 & 0.078 & 0.228 & 0.664 & 0.000 \\
\hline 36 & 2.917 & 0.000 & 0.970 & 0.078 & 0.228 & 0.664 & 0.000 \\
\hline 37 & 3.000 & 0.000 & 0.970 & 0.078 & 0.228 & 0.664 & 0.000 \\
\hline 38 & 3.083 & 0.000 & 0.970 & 0.078 & 0.228 & 0.664 & 0.000 \\
\hline 39 & 3.167 & 0.030 & 1.000 & 0.078 & 0.242 & 0.679 & 0.016 \\
\hline 40 & 3.250 & 0.000 & 1.000 & 0.078 & 0.242 & 0.679 & 0.000 \\
\hline 41 & 3.333 & 0.000 & 1.000 & 0.078 & 0.242 & 0.679 & 0.000 \\
\hline 42 & 3.417 & 0.000 & 1.000 & 0.078 & 0.242 & 0.679 & 0.000 \\
\hline 43 & 3.500 & 0.000 & 1.000 & 0.078 & 0.242 & 0.679 & 0.000 \\
\hline
\end{tabular}

${ }^{a}$ The point at which the total initial abstraction is reached and constant loss begins. 
The total rainfall hyetograph indicated a total of 1.0 inch of rainfall in the storm (as used for step 1). The effective rainfall hyetograph indicated a total of 0.679 inch. An example of a total and effective rainfall hyetograph is shown in figure $5 \mathrm{~A}$, in the upper left corner of the graph.

\section{Example Application of the Gamma Unit Hydrograph to the Effective Rainfall Hyetograph}

Computing the runoff hydrograph from the effective rainfall hyetograph and the GUH requires the process of convolution (eq. 1). Part of the process (for 8 increments of rainfall) will be shown here for demonstration purposes, but the process can be addressed with a single set of (albeit potentially long and complex) equations; the provided spreadsheet (http://pubs.usgs.gov/sir/2014/5193/downloads/UnitHydrogr aphProcessingTemplate.xlsx) will convolute a rainfall hyetograph of up to 120 increments without the multiple columns of data shown for this example.

Step 1, Use the GUH parameters to develop the dimensionless GUH for the basin.-Using the value of $T_{p}$ computed in the first part of the example, determine a series of $t / T_{p}$ values for the time increment of interest ( 5 minutes, in this case). Then, using the $q_{p}$ and $K$ values determined in the first part of the example, use equation 2 to determine the $q(t) / q_{p}$ series for the respective $t / T_{p}$ values.

Step 2, Determine the 5-minute GUH for the basin.Multiply the $t / T_{p}$ values by $T_{p}$, and the $q(t) / q_{p}$ values by $Q_{p}$ (utilizing the relation between $q_{p}$ and $Q_{p}$ from eq. 3 ). This will provide the 5-minute GUH, because 5 minutes was used for the time increment in step 1.

Step 3, Convolve the effective rainfall hyetograph with the 5-minute GUH.-Convolve the effective rainfall by multiplying the 5-minute unit hydrograph ordinates by each effective rainfall increment but delay the start time for that increment to the time increment of that effective rainfall (see Chow and others [1988] for a complete demonstration of the convolution process). This process is shown for 8 of the 40 increments of effective rainfall listed in table 9, but the process holds for all effective rainfall increments. For example, for the first seven time values $(0.0000,0.0833,0.1667,0.2500$, $0.333,0.4167$, and 0.500$)$, the first 5-minute unit hydrograph ordinate value after "Start" (81.8) is multiplied by the effective rainfall values corresponding to the time values and equals $0.0,0.0,10.5,11.9,8.7,8.7$, and 7.0 , respectively, under the "Convolution process" columns in table 9.
Step 4, Sum the convolved values to obtain the runoff hydrograph. - The column labeled "Convolved runoff hydrograph" in table 9 contains the summation of the convolved values, including the increments not shown.

\section{Method for Estimating Peak Streamflow from Rainfall for Urban Basins in Missouri}

Occasionally, only $Q_{p}$ is desired to solve a particular hydraulic design question, and the specifics of the hydrograph shape are not needed. Southard (2010) provides a method by which $Q_{p}$ can be estimated for urban basins in Missouri for a specific annual exceedance probability or recurrence interval, but occasionally $Q_{p}$ for a given rainfall event or a design rainfall is desired independent of the frequency. The rainfallrunoff pairs from the storm-specific GUH analysis were further analyzed to develop an equation for the estimation of $Q_{p}$ based on a quantity of rainfall on the basin and other basin characteristics.

The equation developed for this study for the estimation of the peak streamflow for an event $\left(\hat{Q}_{p}\right)$ computed using OLS regression, is

$\hat{Q}_{p}=5.0933\left(\operatorname{RAIN}_{\mathrm{Cent}}\right)^{0.9519}(\text { DRNAREA })^{0.5212}(10)^{0.0222(C N)}$

where

$\hat{Q}_{p} \quad$ is the estimated peak streamflow from a given rainfall amount, in cubic feet per second;

RAIN $_{\text {Cent }}$ is the total rainfall at the basin centroid from NEXRAD, in inches;

DRNAREA is the basin drainage area, in square miles; and

$C N$ is the composite NRCS curve number computed based on land use and soil types in the basin (appendix 2).

Equation 10 has 398 degrees of freedom, a residual standard error of about $0.240 \log _{10}$ (cubic feet per second), and an $\operatorname{Adj}-R^{2}$ of 0.795 . The relation between the storm-specific $Q_{p}^{\text {obs }}$ and $\hat{Q}_{p}$ from equation 10 is shown in figure 11 . Numerous basin characteristics were utilized during the development of equation 10 , but most were statistically insignificant. 


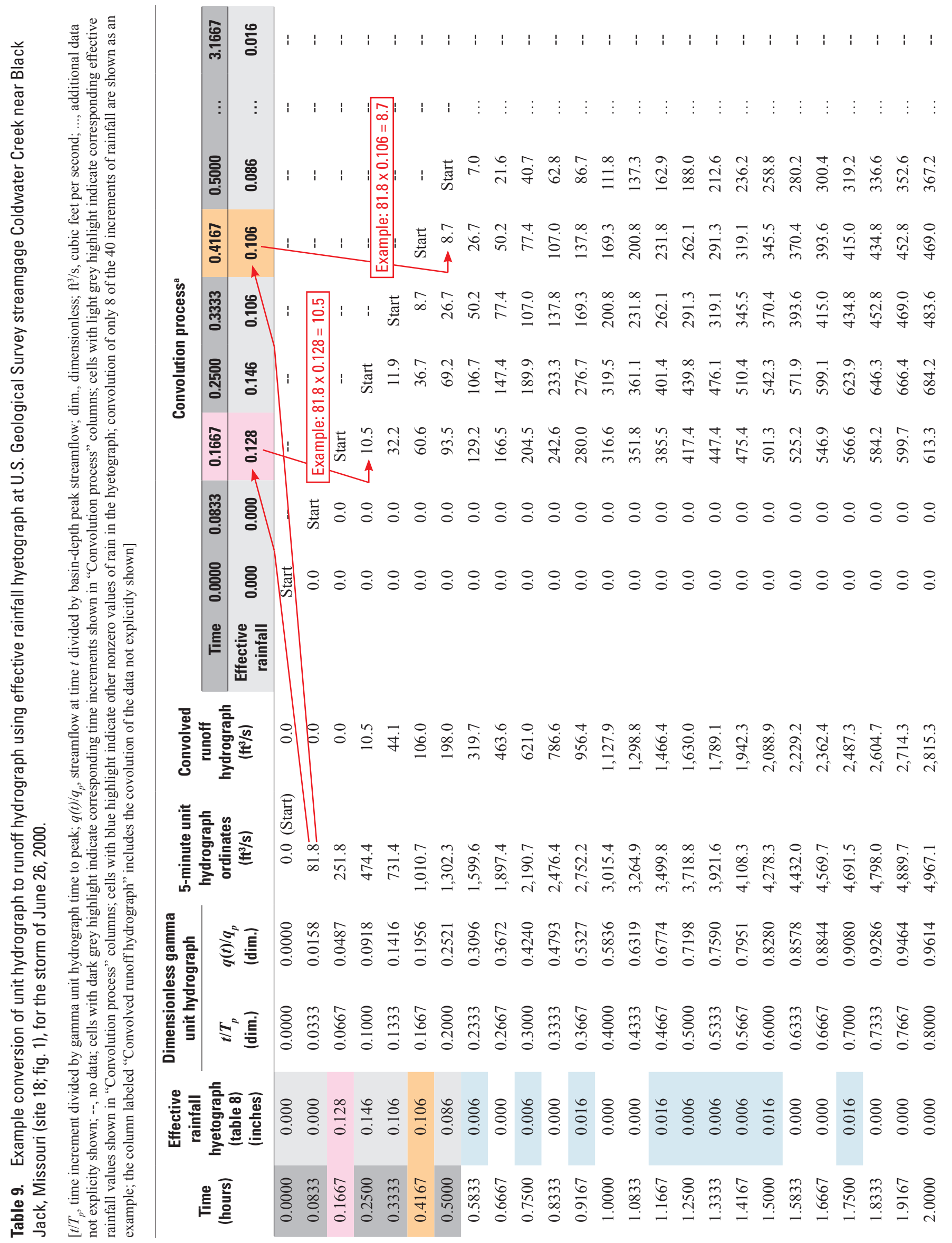




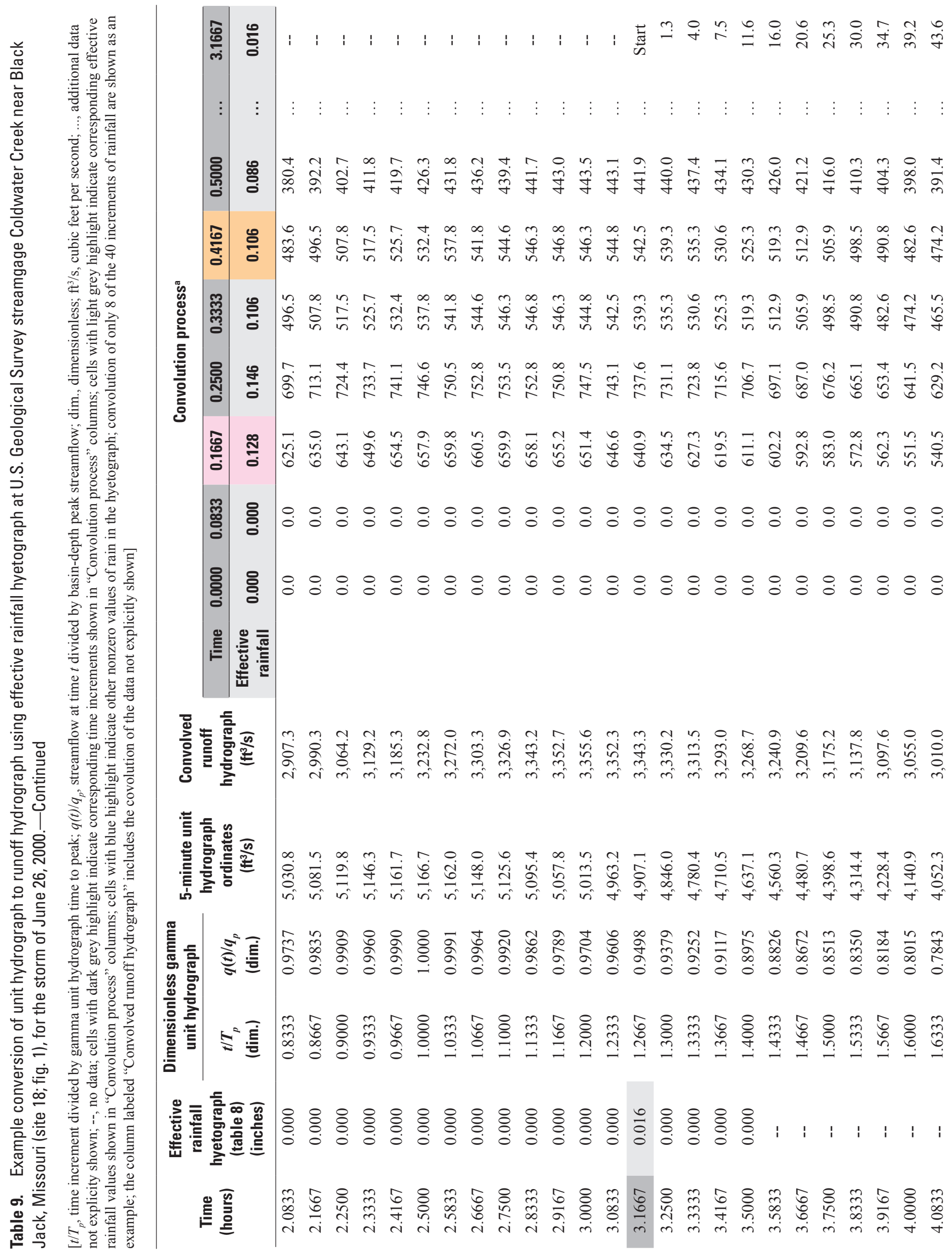




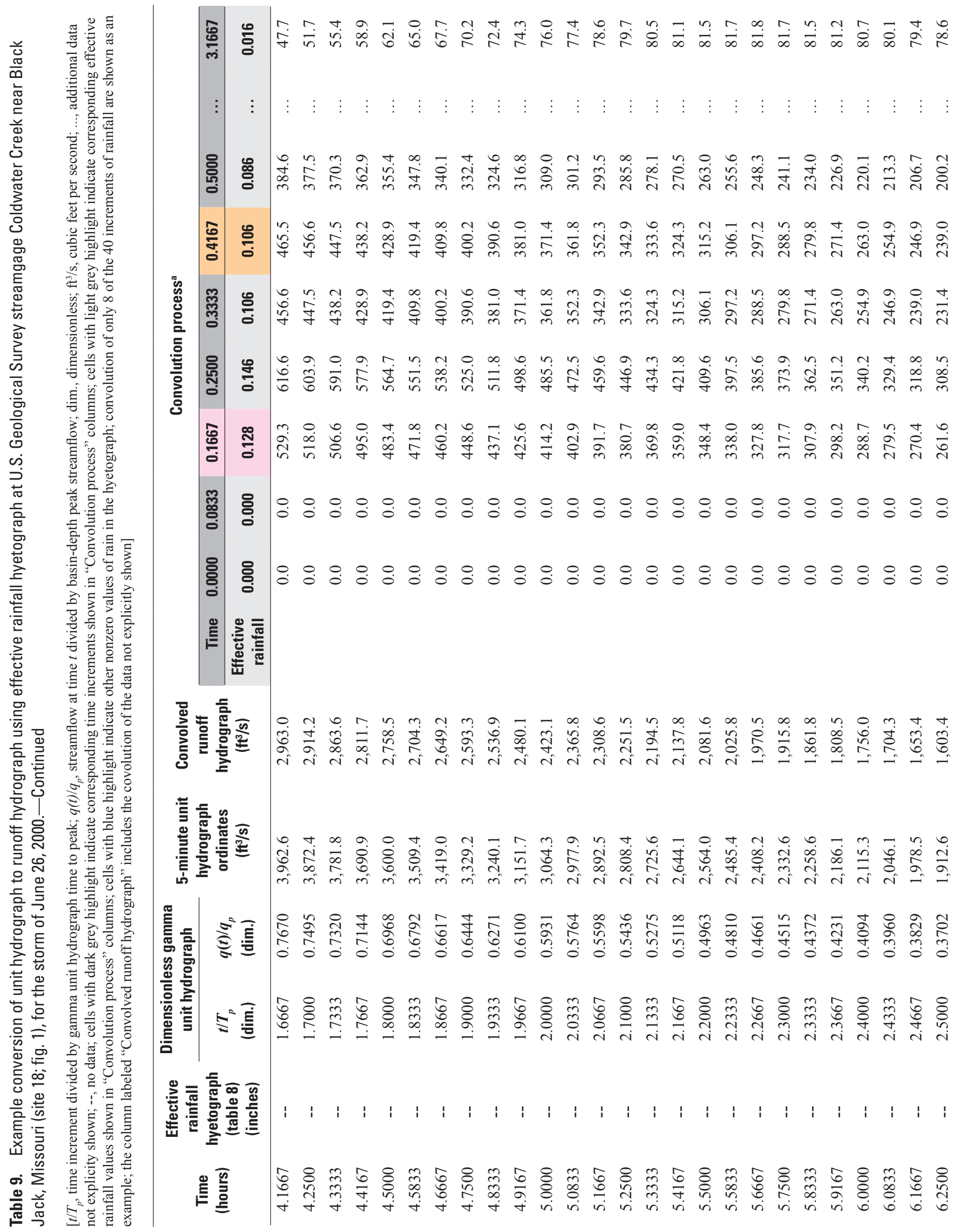




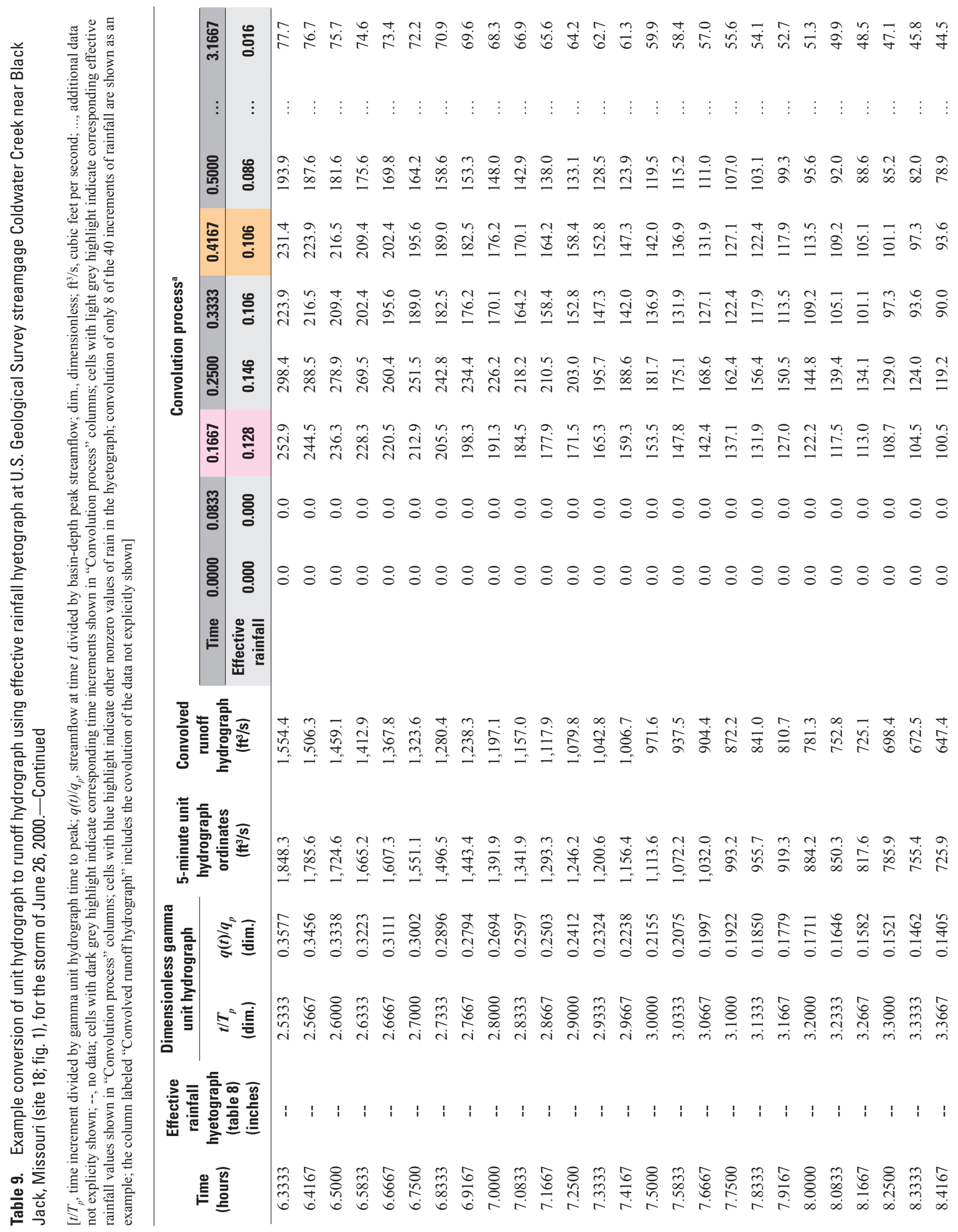




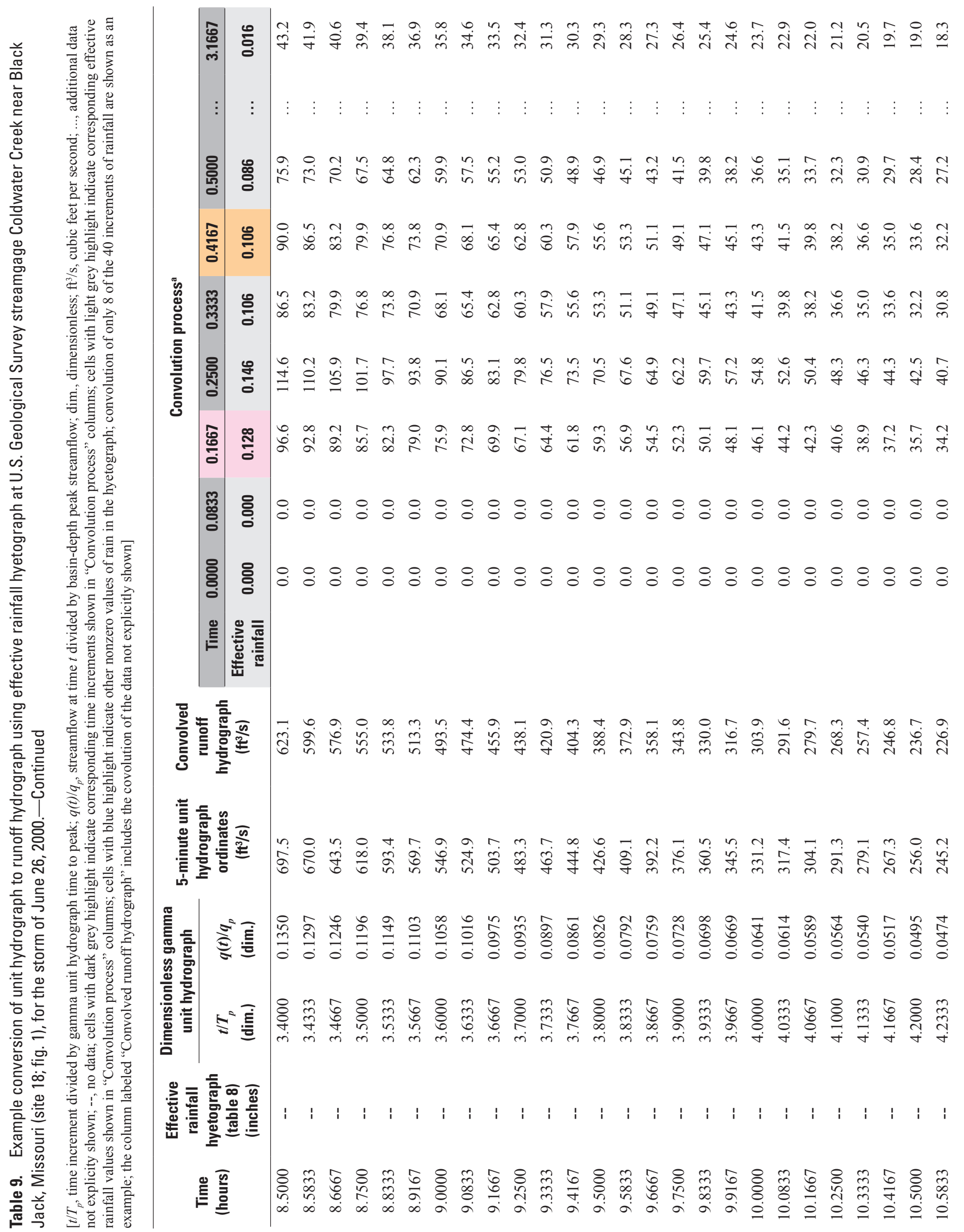




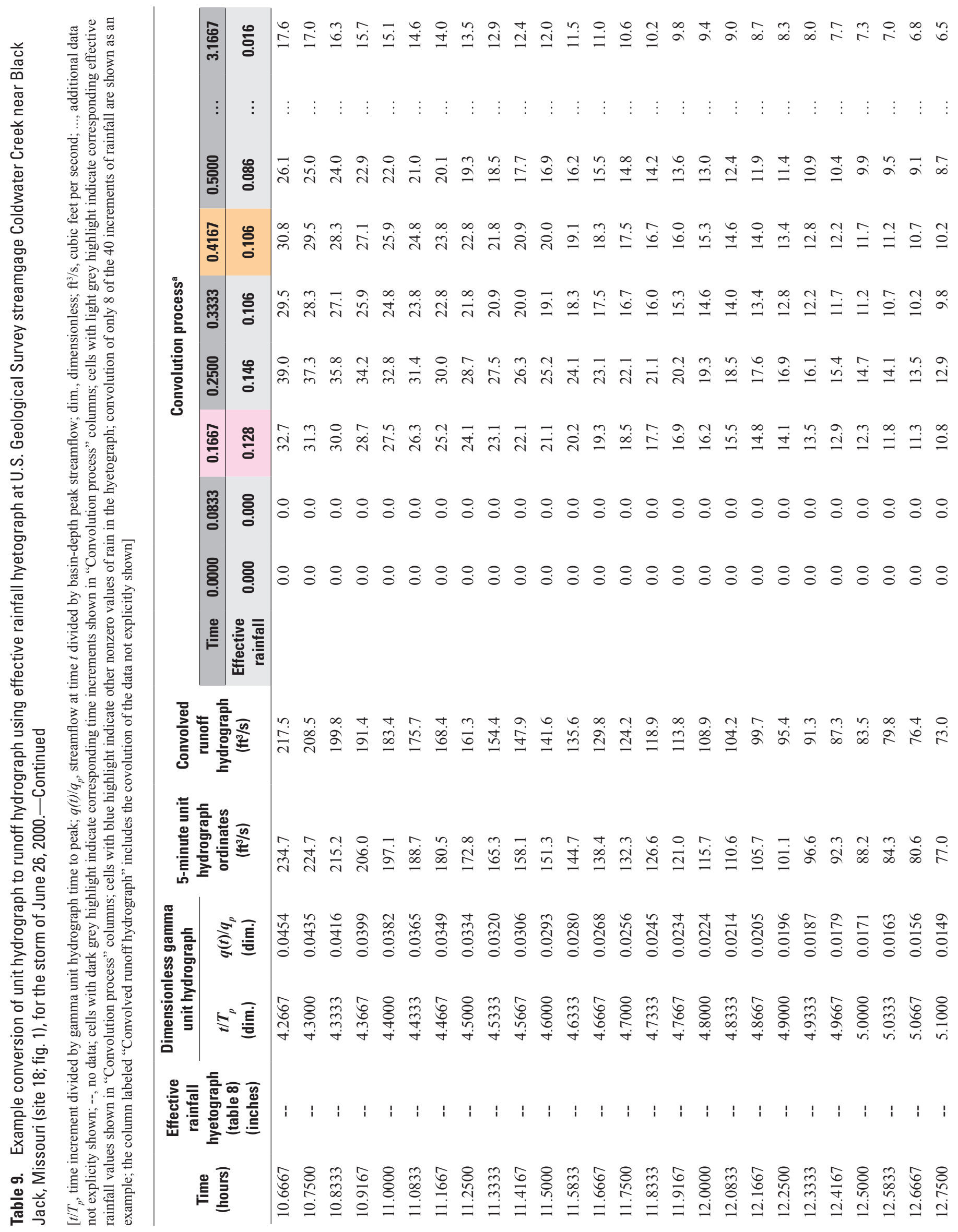




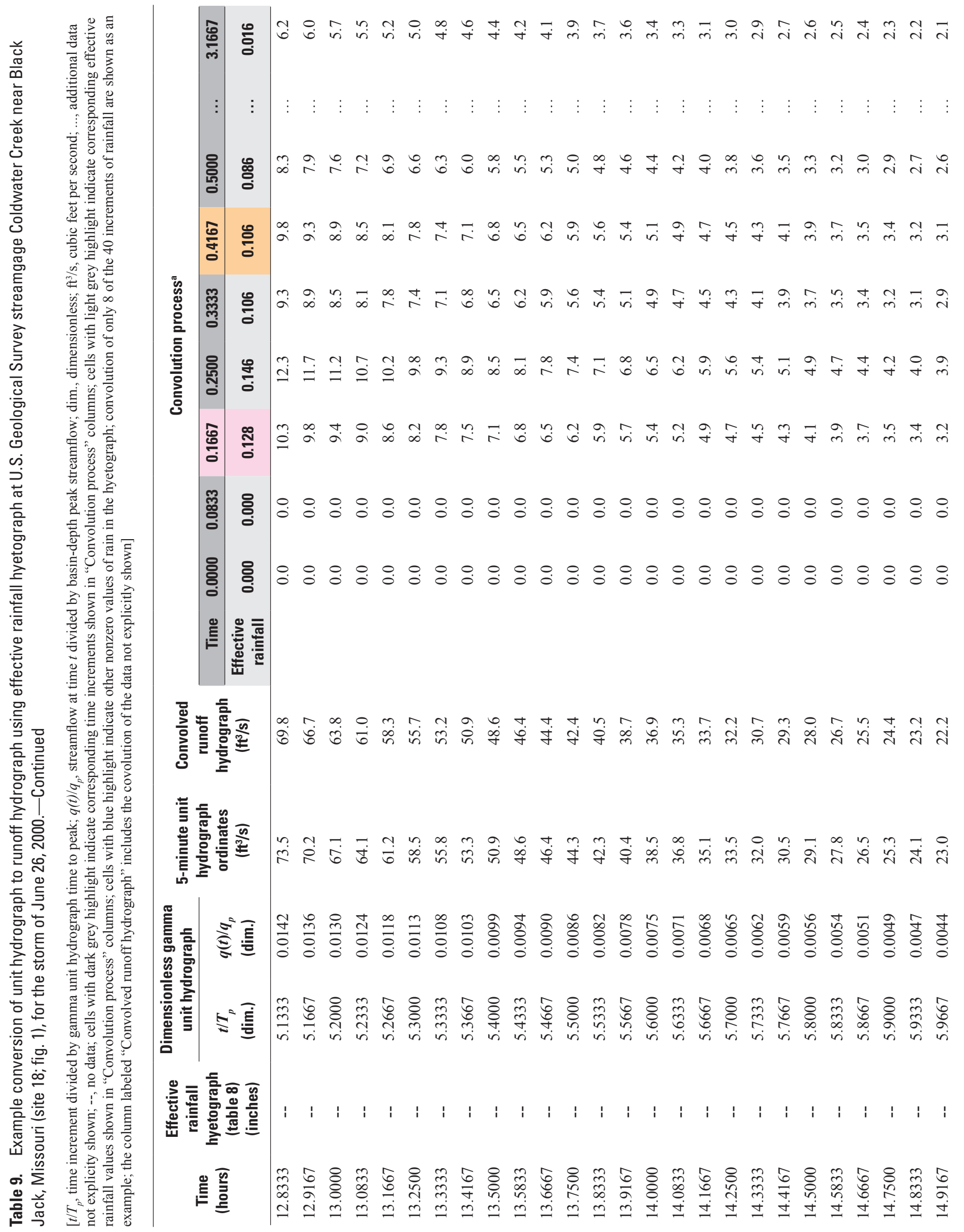




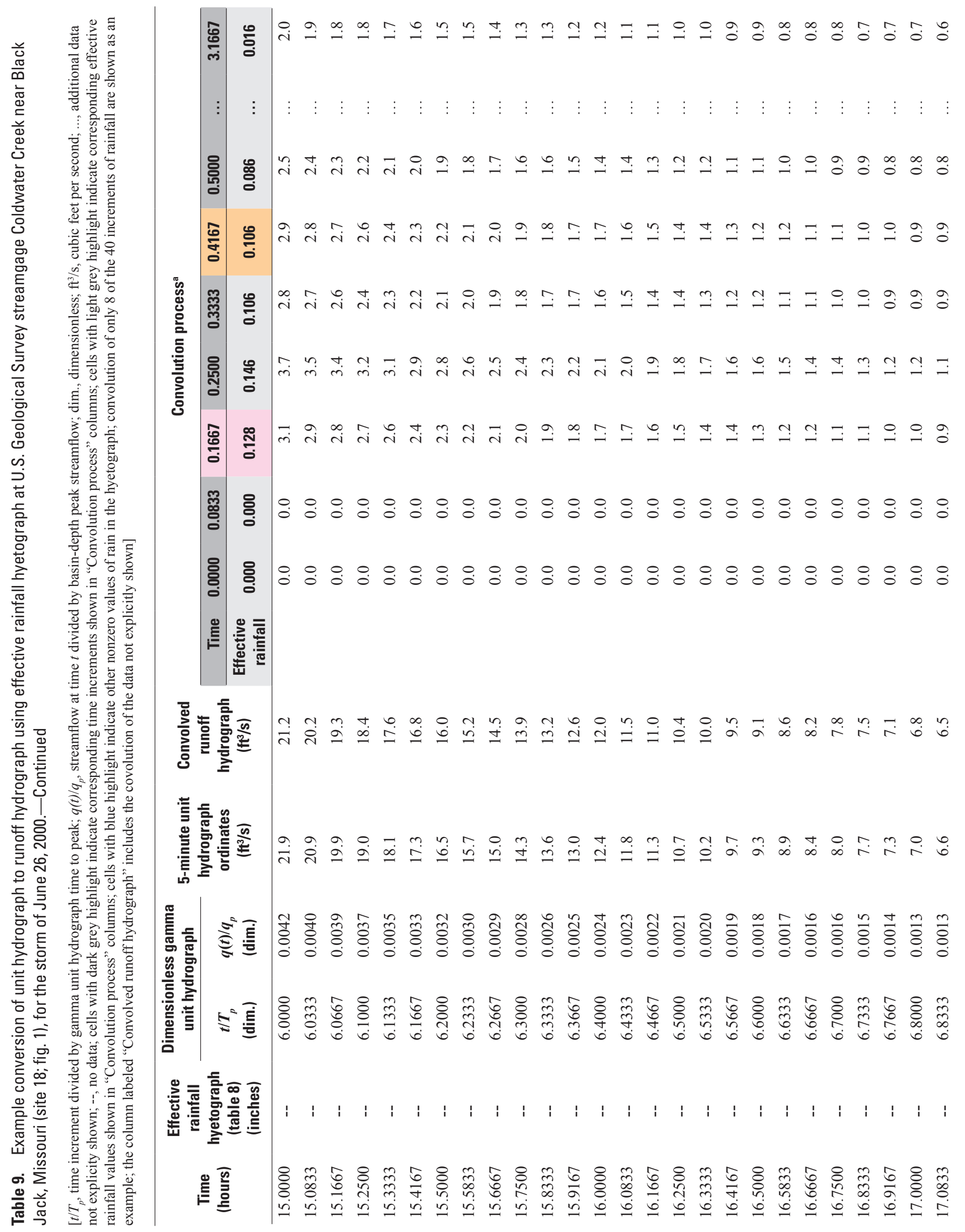




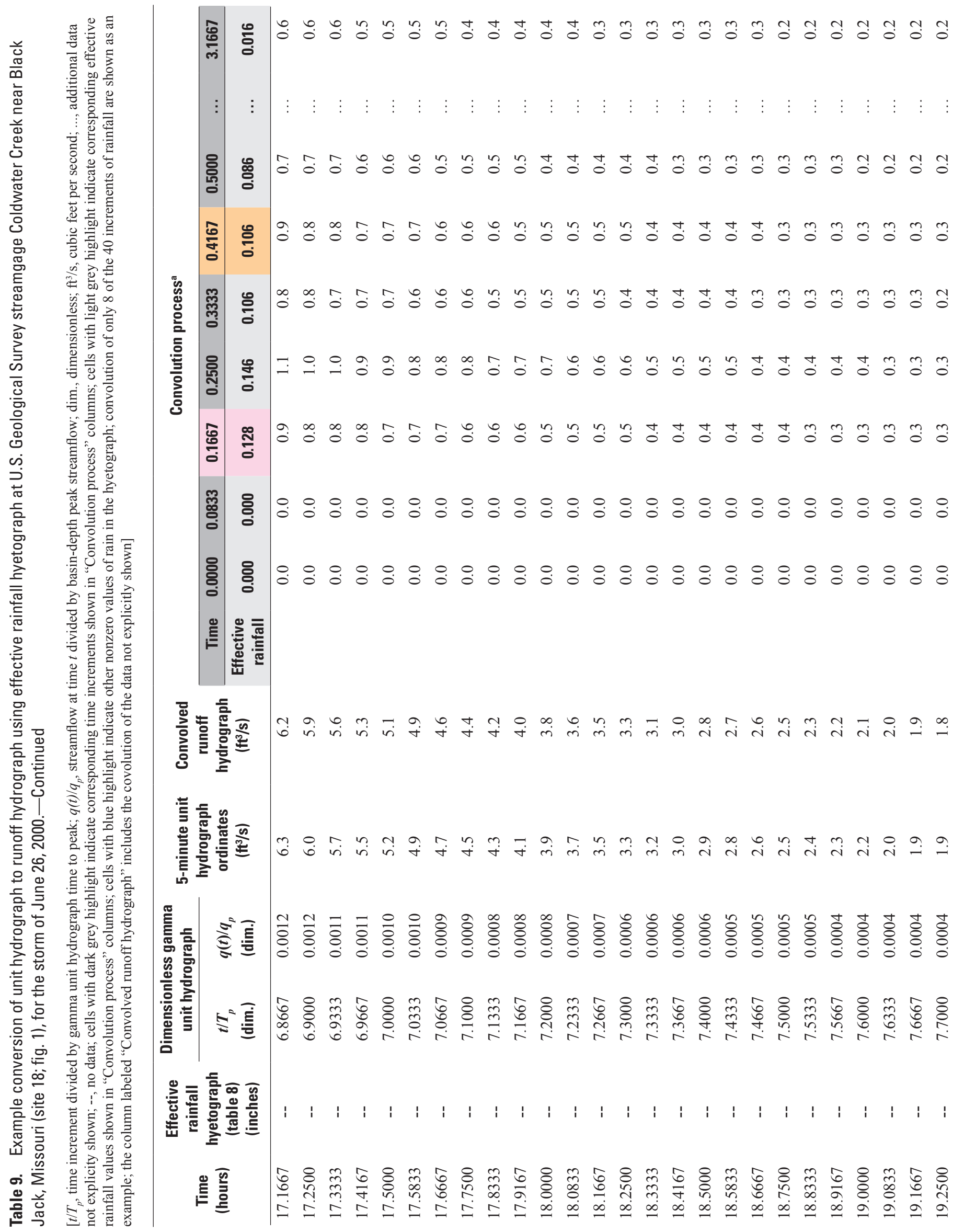




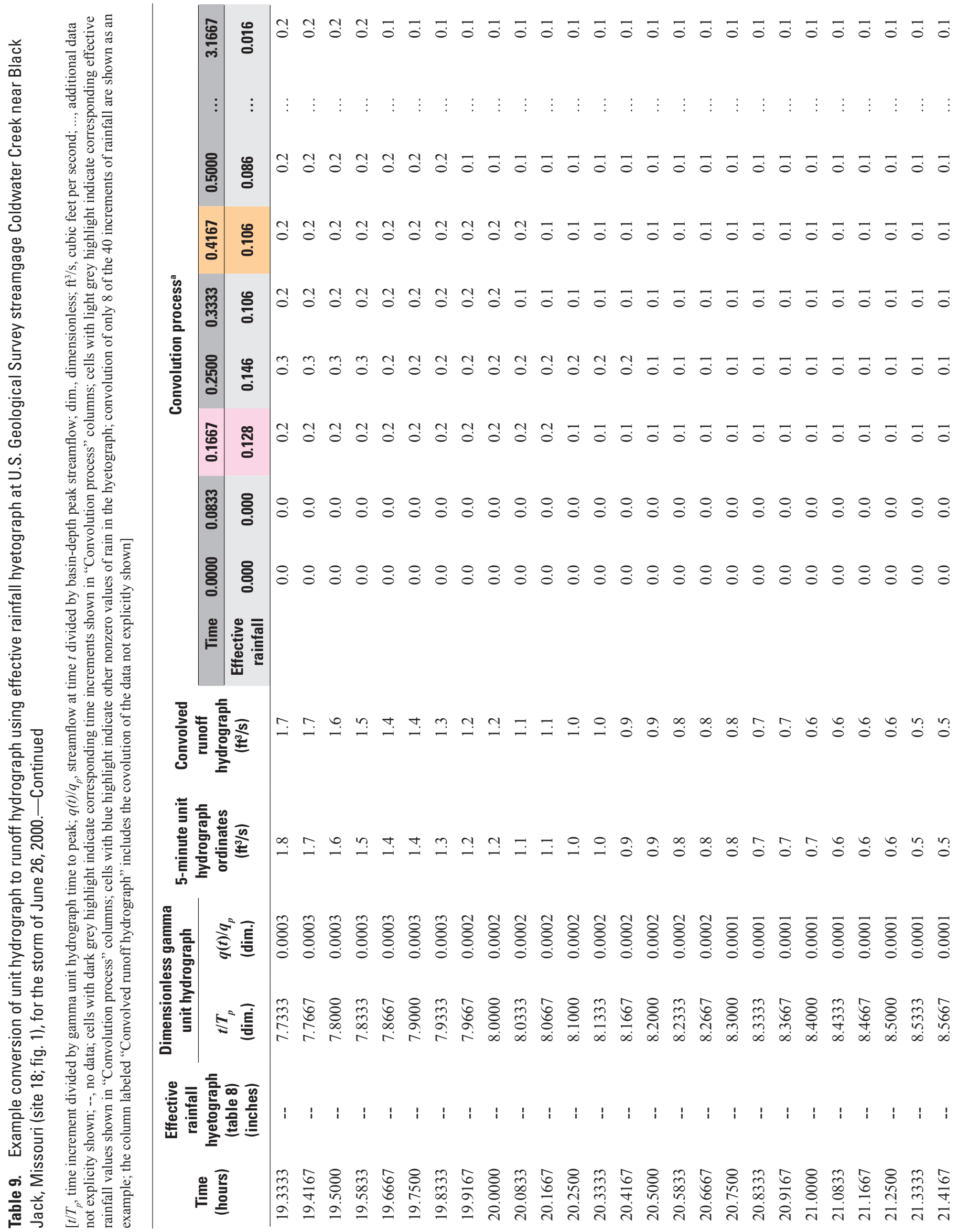




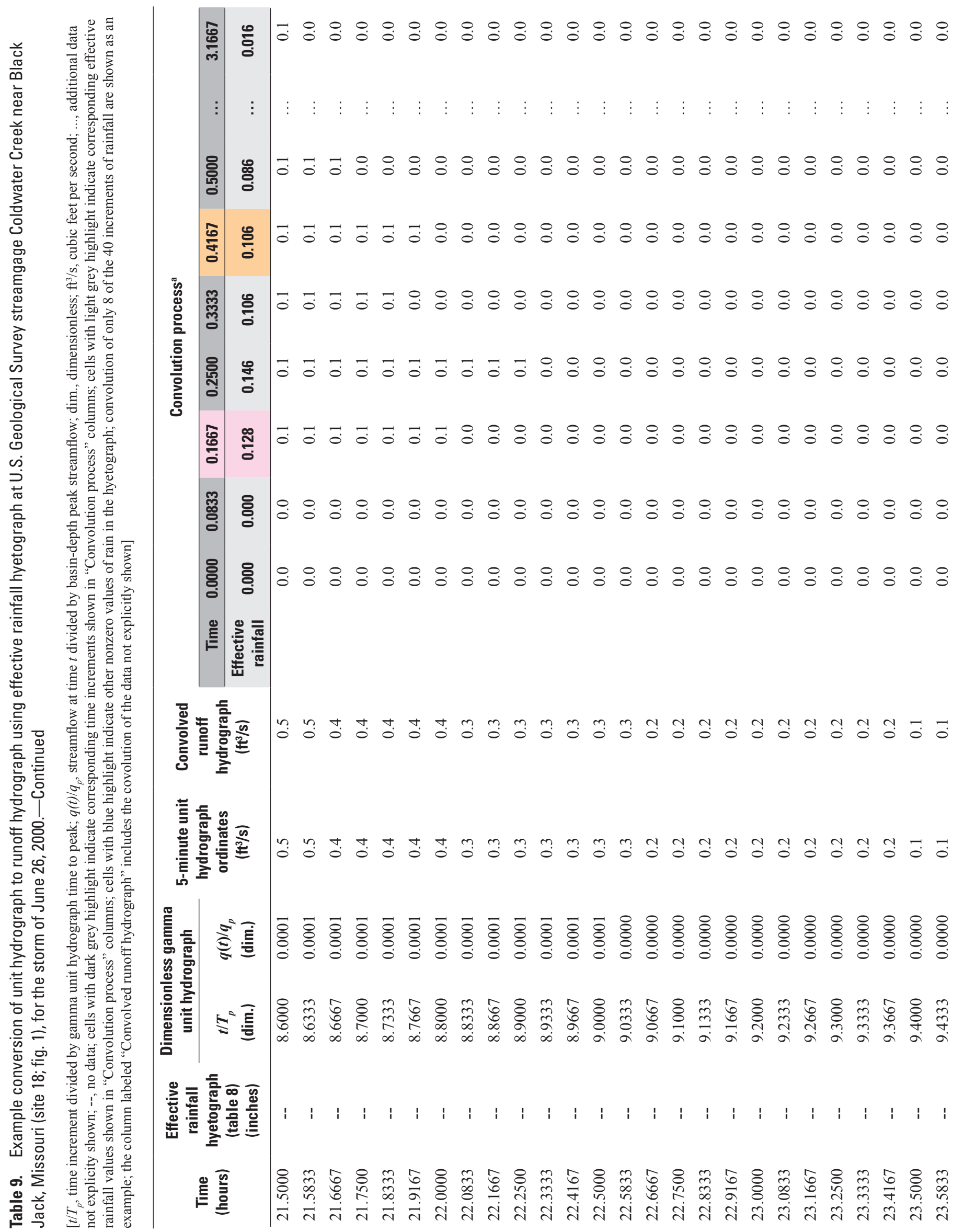




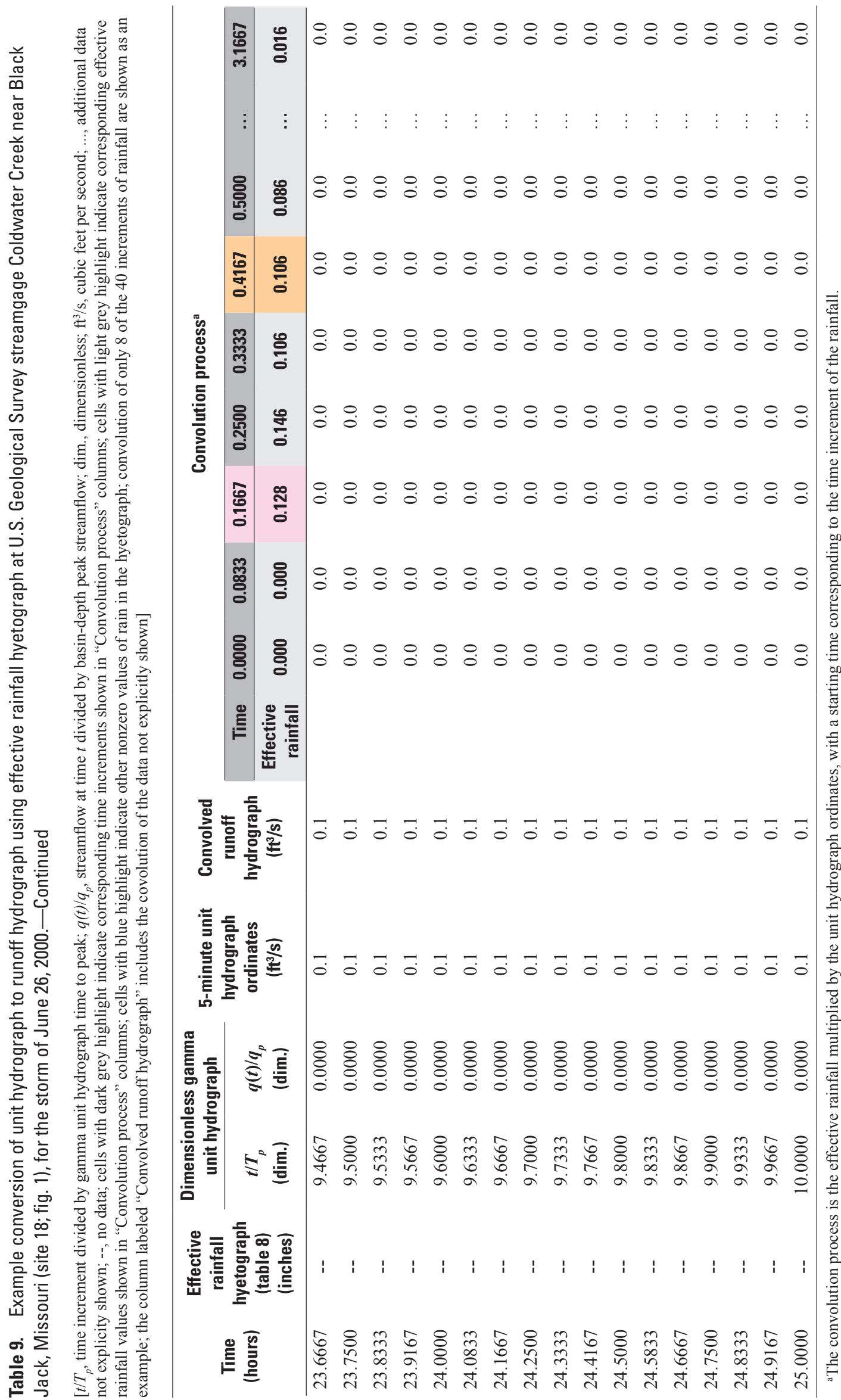


The rainfall at the basin centroid, RAIN $_{\text {Cent }}$ is intended to be a representation of the rainfall on the entire basin, and can be determined from the available NEXRAD DSP or NTP data or estimated from a design storm equation. The basin centroid is used rather than any other point (such as the basin outlet) to account for potential spatial variability of rainfall over the basin. To use the NEXRAD data, the approximate time of the end of the rainfall event is needed, and the radar sweep associated with this time is retrieved from the NCDC NEXRAD Data Archive, Inventory and Access Web site at http://www.ncdc.noaa.gov/nexradinv/, and viewed using the NCDC Weather and Climate Toolkit at http://www.ncdc.noaa. gov/oa/wct (see appendix 3 for more details). The value in the radar bin that contains the centroid of the basin is used as RAIN $_{\text {Cent }}$; however, the user again is cautioned that the coarse data resolution of the NTP dataset may over- or underestimate the rainfall on the basin.

\section{Methods for Estimating Flood Volume for Urban Basins in Missouri}

Flood volume also is a useful parameter in the design of conveyance works for flood flows, enabling a project to be designed to contain the flow volume from a specified event. The rainfall-runoff pairs from the storm-specific GUH analysis were further analyzed to develop an equation for the estimation of $V$ based upon a quantity of rainfall on the basin.

The equation developed for this study for the estimation of the flood volume for an event $(\hat{V})$ computed using OLS regression, is

$$
\hat{V}=0.0994\left(\operatorname{RAIN}_{\text {Cent }}\right)^{1.1109}(10)^{0.8621 \text { (STREAM_VAR) }}
$$

where

$\hat{V} \quad \begin{gathered}\text { is the estimated flood volume from a given } \\ \text { rainfall amount, in basin inches; } \\ \text { is the total rainfall at the basin centroid from } \\ \text { RAIN }\end{gathered}$
$\begin{gathered}\text { NEXRAD, in inches; and } \\ \text { STREAM_VAR }\end{gathered}$
$\begin{aligned} & \text { is the streamflow variability index as } \\ & \text { determined in the low-flow study by } \\ & \text { Southard (2013). }\end{aligned}$

Equation 11 has 405 degrees of freedom, a residual standard error of about $0.240 \log _{10}$ (basin inch), and an Adj- $R^{2}$ of 0.701 . The relation between the storm-specific $V^{\text {obs }}$ and $\hat{V}$ from equation 11 is shown in figure 12. Numerous basin characteristics were utilized during the development of equation 11, but most were statistically insignificant.

As with the estimation of peak streamflow, the rainfall at the basin centroid, RAIN ${ }_{\text {Cent }}$, can be determined from the available NEXRAD DSP or NTP data (with the caveats noted earlier in the "Methods for Estimating Peak Streamflow from Rainfall for Urban Basins in Missouri" section), or can be estimated from a design storm equation. If the total flood volume for a given basin is desired, the value obtained from equation 11 should be multiplied by the basin drainage area, resulting in a flood volume value expressed in square mileinches; this value would need to be converted to the desired final units, such as acre-feet or cubic feet.

\section{Summary and Conclusions}

Streamflow statistics are used by government agencies, engineers, scientists, and environmental groups for purposes of water management, permitting, and design. Streamflow data collected at streamflow-gaging stations (streamgages) inherently reflect unique characteristics of the basin upstream, including peak magnitude, the time to peak, flow volume, and base flow. These components can be defined for a basin to develop a unit hydrograph, the runoff hydrograph that results from a unit pulse of excess rainfall uniformly distributed over the basin at a constant rate for a specific duration; however, estimation of a runoff hydrograph by the unit hydrograph method requires a method to convert a total rainfall hyetograph into an appropriate excess rainfall hyetograph that represents the rainfall that runs off from the basin. Therefore, the U.S. Geological Survey (USGS), in cooperation with the Metropolitan Sewer District of St. Louis (MSD) in 2011, examined streamflow data and basin characteristics to develop an initial abstraction $\left(I_{A}\right)$ and constant loss $\left(C_{L}\right)$ model (or " $I_{A}-C_{L}$ model," a time-distributed basin-loss model) and unit hydrograph for urban areas in Missouri. Methods to determine peak streamflow and flood volume for a given rainfall event also were developed. This report is intended to supersede previous USGS urban unit hydrograph reports for Missouri.

The gamma unit hydrograph (GUH) has been shown in prior studies for various areas of the United States to attain a shape that mimics the general shape of many observed runoff hydrographs with three parameters. Two GUH parameters that are shown to be related to physical characteristics of the basin are basin-depth peak streamflow $\left(q_{p}\right)$ in inches over the basin per hour (basin inches per hour) and time to peak $\left(T_{p}\right)$ in hours. The third parameter is a shape parameter $(K)$ that is dependent on $q_{p}$ and $T_{p}$. Expression and analysis of unit hydrographs in terms of $q_{p}$ and $T_{p}$ are important because the magnitude and timing of peak streamflow $\left(Q_{p}\right)$ in cubic feet per second are critical for many designs.

To provide continuity with the recently updated urban flood-frequency equations for Missouri, a similar list of basins was used for this study. A final list of 39 streamgages in urban areas in and adjacent to Missouri was selected using three fundamental criteria: (1) urbanization with development resulting in an increase in impervious area, but relatively stable during the data analysis period; (2) no major diversions into or out of the basin upstream from the streamgage; and (3) minimal storage effects from retention, detention structures, or road crossings. Streamgages with more recent data records were 


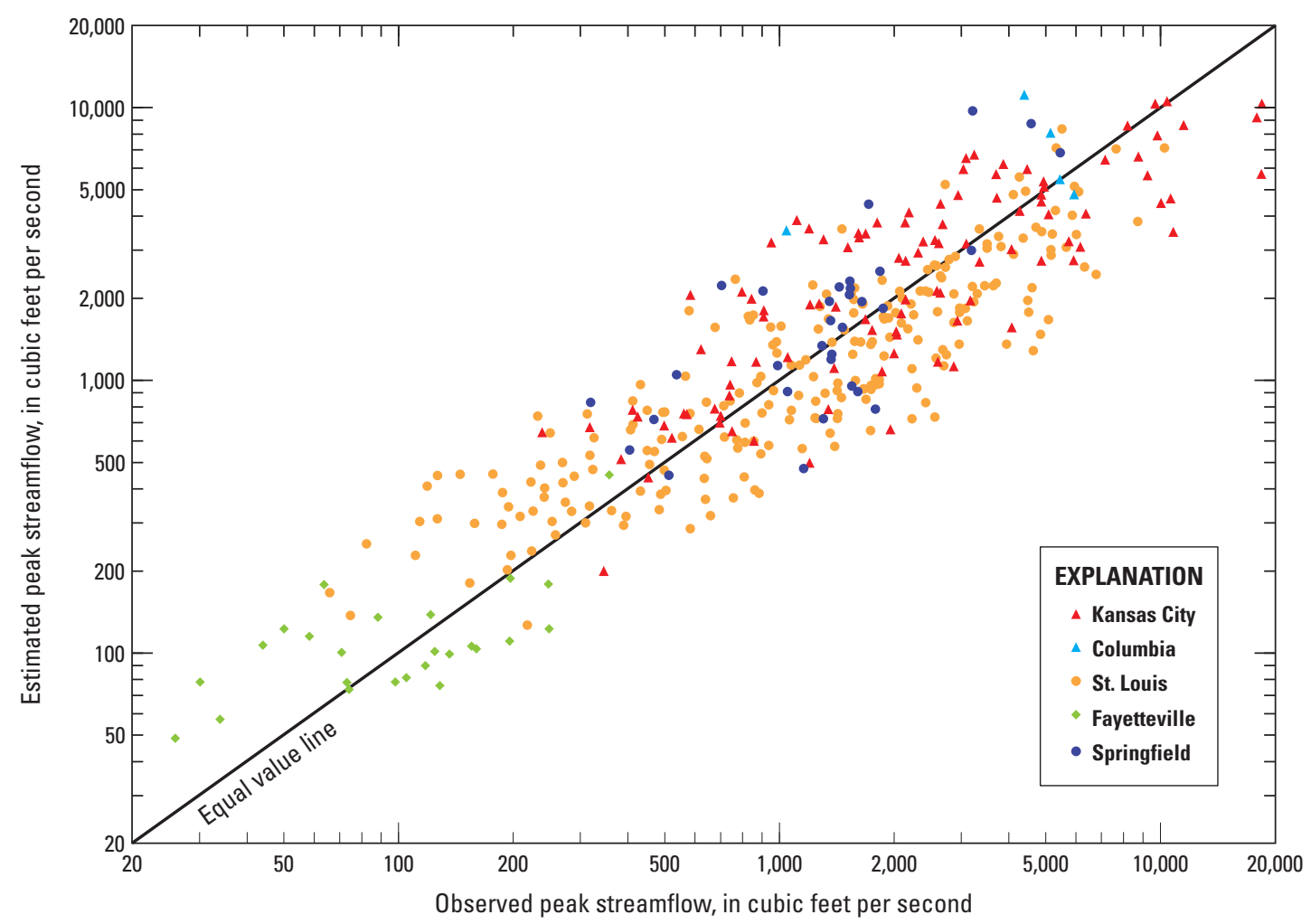

Figure 11. Comparison of observed $\left(Q_{p}^{\text {obs }}\right)$ and estimated $\left(\hat{Q}_{p}\right)$ peak streamflow from the peak streamflow regression equation for streamgages in urban areas in and adjacent to Missouri.

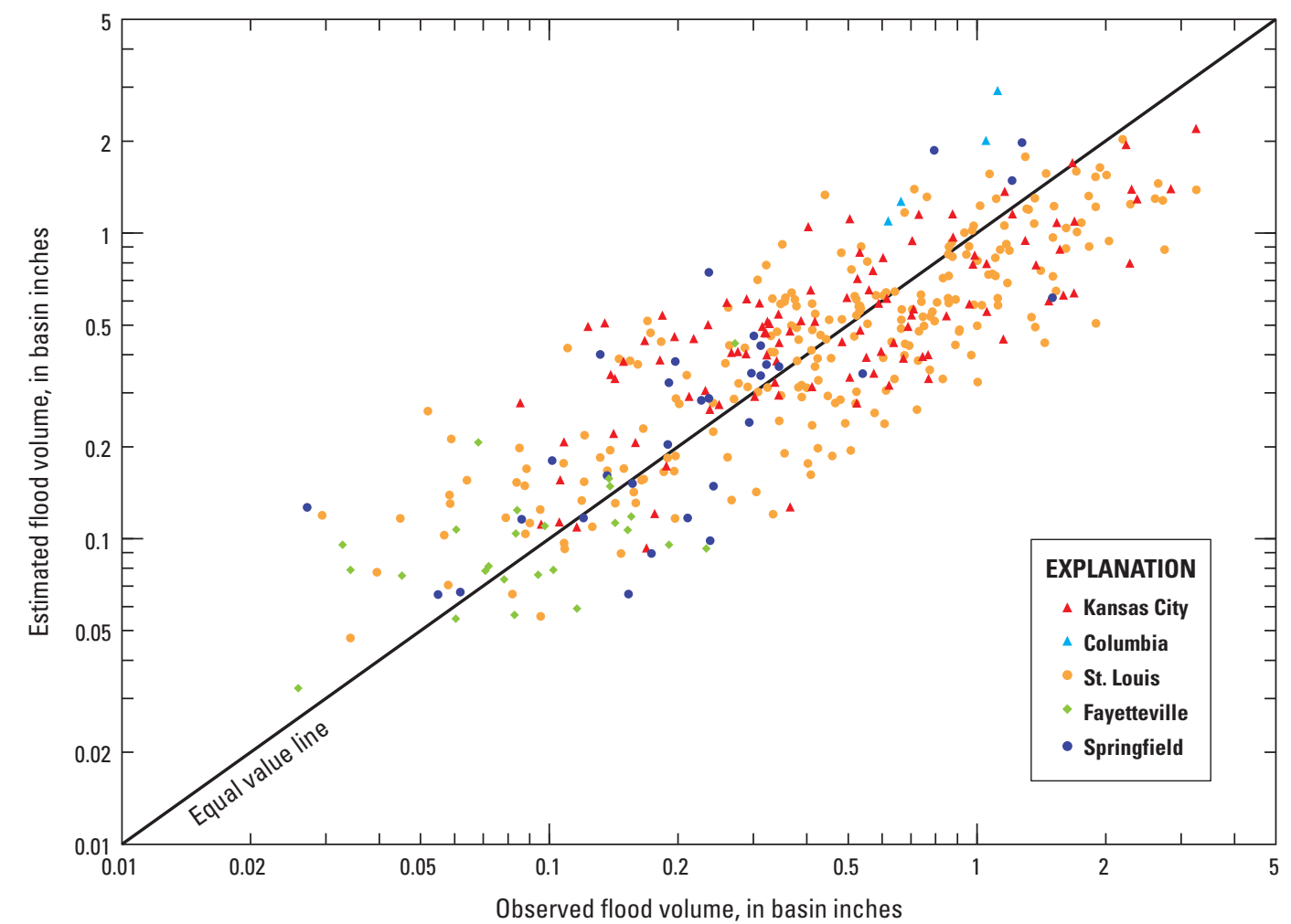

Figure 12. Comparison of observed ( $V^{\text {obs }}$ ) and estimated $(\hat{V})$ flood volume from the flood volume regression equation for streamgages in urban areas in and adjacent to Missouri. 
used for this study to utilize rainfall data from the next generation weather radar (NEXRAD) network maintained by the National Oceanic and Atmospheric Administration's National Weather Service, the Federal Aviation Administration, and the U.S. Air Force.

Several distinct basin characteristics were evaluated as predictor variables for estimation of peak streamflow and flood volume, as well as the estimation parameters for the GUH and the $I_{A}-C_{L}$ model. The basin characteristics were selected for use on the basis of their theoretical relation to flow, results from previous studies, and the ability to measure the basin characteristic using digital datasets and geographic information system technology. The key basin characteristics determined or computed for each of the 39 basins were drainage area; percent impervious area; main-channel slope based on the 10- and 85-percent length method; percentage of the basin area in storage (lakes, ponds, reservoirs, wetlands); the composite Natural Resources Conservation Service curve number $(C N)$ estimated from a combination of the soil type data and land-use characteristics; and the streamflow variability index developed for the recently completed study of low-flow regression in Missouri.

Characteristics of spatial and temporal rainfall distribution came from NEXRAD radar data. Procedures were developed to convert the variable radar sweep rate into a 5-minute total rainfall hyetograph using data from the radar bin at the centroid of a given basin. The NEXRAD data are of two spatial resolutions; the Level III Digital Precipitation Array (DPA) data are displayed on the 4- by 4-kilometer Hydrologic Rainfall Analysis Project grid, whereas the Level III Storm Total Precipitation (NTP) and the Level III Digital Storm Product (DSP) data are displayed on a 2-kilometer by 1-degree polar grid centered on the radar of interest. Additional characteristics determined for each storm on the basin included the 5-day and 14-day antecedent rainfall, estimated from the mean of daily rainfall values from various rain gages in the area.

The total rainfall hyetograph must be converted into an appropriate excess rainfall hyetograph by means of a basinloss model that is consistent with the hypothesized processes that prevent rainfall from becoming runoff. For this study, an $I_{A}-C_{L}$ model was developed. Initial abstraction is the capacity of a basin to store or "abstract" an absolute depth of rainfall near the beginning of a storm, such that depths of rainfall less than this value do not produce runoff. Constant loss is the capacity of a basin to remove rainfall at some constant rate after the $I_{A}$ amount is satisfied, and is analogous (but not equal) to an infiltration rate. A primary dataset of observed rainfall and runoff events through December 2010 for the basins upstream from the 39 streamgages was iteratively analyzed to compute the optimal storm-specific $\left(^{4}\right)$ parameter values for ${ }^{4} I_{A}$ and ${ }^{4} C_{L}$, as well as storm-specific values for the GUH parameters of ${ }^{\iota} q_{p},{ }^{\iota} T_{p}$, and ${ }^{\iota} K$. The optimal values resulted in an approximate match between the volume of the excess rainfall hyetograph and the observed runoff hydrograph, as well as an approximate match between the peak streamflow value, the time interval of the peak, the shape, and the appearance of the observed and modeled hydrographs. These methods successfully processed 440 storms.

Initial attempts to develop equations for $I_{A}$ from basinaverage values of the storm-specific ${ }^{4} I_{A}$ values were unsuccessful, and were independent of any storm-specific or antecedent rainfall terms; however, using the standard deviation of NEXRAD rainfall data for storms after 2008 (the DSP data, which has a higher spatial resolution), 89 storms were isolated as being reasonably uniformly distributed over the various basins in the study. The ${ }^{4} I_{A}$ values from these storms were analyzed against various basin and rainfall characteristics to develop an equation to estimate $I_{A}$ based on low-flow region by ordinary least-squares (OLS) regression. The equation for low-flow region 1 had an adjusted $R$-squared (Adj- $R^{2}$ ) of 0.604 and a residual standard error of about $0.252 \log _{10}$ (basin inch), whereas the equation for low-flow region $2 \mathrm{had}$ an $\mathrm{Adj}-R^{2}$ of 0.710 and a residual standard error of about $0.249 \log _{10}$ (basin inch). Although the $I_{A}$ equation was developed from a limited subset of the ${ }^{4} I_{A}$ values, the equation is eminently useful for prediction, recognizing the fundamental condition of uniform distribution of rainfall over the basin inherent in unit hydrograph theory.

Because it is analogous to infiltration, $C_{L}$ was assumed to not be as variable as $I_{A}$ across the basins in a particular urban area. Analyses with the overall mean and median of the stormspecific ${ }^{4} C_{L}$ values, a regression equation of the basin-mean $C_{L}$ values, and a regression tree model of the $C_{L}$ values indicated that the overall mean $C_{L}$ value of 0.240 basin inches per hour did no worse than any of the other values at predicting the $C_{L}$ of a basin. The storm-specific ${ }^{4} C_{L}$ values were further examined for possible regional trends, and generalized regions were established based on similar topography, geology, and soil types. Each urban area also was examined separately in a specific regionalization, with St. Louis ultimately being divided based on the low-flow regions, using the divide between the Missouri and Mississippi Rivers. Although there is no substantial difference between the topography, geology, and soils of the St. Louis area, a difference was noted in the specific regional mean $C_{L}$ value.

The storm-specific values of the basin-depth peak streamflow $\left({ }^{\natural} q_{p}\right)$ and time to peak $\left({ }^{\natural} T_{p}\right)$ were averaged for each basin to find a basin-average $q_{p}$ and $T_{p}$, which were subsequently used to determine a basin-specific value of $K$ for each basin. The basin-average $q_{p}$ values were analyzed against various basin characteristics to develop an equation for the estimation of $q_{p}$ with an Adj- $R^{2}$ of 0.887 using weighted least-squares (WLS) regression. The normalized number of storms in each basin was used as the weighting factor. Similarly, the basin-average $T_{p}$ values were analyzed against various basin characteristics to develop an equation for the estimation of $T_{p}$ with an Adj- $R^{2}$ of 0.900 using WLS regression. A regression was not developed for $K$ because it is computed from the values of $q_{p}$ and $T_{p}$ and the gamma hydrograph equation with a unit volume.

Two levels of testing were used in this study. First, a runoff hydrograph generated using a known excess rainfall 
hyetograph and the regressed GUH parameters of $q_{p}$ and $T_{p}$ was compared to the observed runoff hydrograph to test the validity of the GUH regressions. The error between the modeled and observed peak streamflow, time of peak streamflow, runoff volume, and hydrograph width at 50 and 75 percent of the peak streamflow were used as metrics in this test. Although the minimum and maximum errors occasionally were large, the interquartile range (third-quartile minus first-quartile) was substantially smaller than the range spanned by the minimum and maximum values, which indicates most of the errors have much smaller variation, and the minimum and maximum values may be extreme outliers. The central tendency of the regressed errors for peak streamflow and runoff hydrograph volume were both approximately zero, which implies a generally unbiased estimation of these values. The mean and median of the regressed time to peak streamflow were both small but greater than zero, which implies that the regressions create a hydrograph that has a peak that is later in time (by 10 minutes, on average) than observed. The mean and median of the regressed widths of the runoff hydrograph at 50 and 75 percent were less than zero, which implies that the gamma unit hydrograph tends to slightly underestimate these widths compared to the observed hydrograph width.

The second level of testing was to generate a runoff hydrograph using an excess rainfall hyetograph developed from the total rainfall hyetograph and the regressed $I_{A}$ and the two variations of the $C_{L}$ value (generalized regional mean and specific regional mean) combined with the regressed GUH parameters. The generated runoff hydrograph was compared to the observed runoff hydrograph to test the validity of the combined $I_{A}, C_{L}$, and GUH regressions. Both forms of the basin-loss model worked equally well to model the observed runoff hydrograph based on the error analysis, and neither model seems to make a consistently superior approximation. If these methods are used in an urban area in Missouri other than those examined in this study, the user is advised to consider using the generalized regional values. If these methods are used in an urban area that is a subbasin of one of the basins in this study, the user is advised to consider using the specific regional values.

The combined $I_{A}, C_{L}$, and GUH regressions were further validated using a verification dataset of several storms available after the start of the project in early 2011. The verification dataset indicates that both forms of the basin-loss model worked equally well to model the observed runoff hydrograph based on the error analysis; however, the verification dataset errors consistently are higher than the errors from the primary dataset of before-2011 storms for the peak streamflow, runoff volume, and hydrograph widths at 50 and 75 percent of peak streamflow. The interquartile range is slightly larger for the verification dataset for almost all of the errors.

Overall, the regressed dimensionless GUH compares well with previous urban unit hydrograph studies in Missouri and elsewhere in the United States. The range of shape factors in Missouri encompasses the various dimensionless unit hydrographs from other studies, except for part of the recession side of the hydrograph. The median basin-specific $K$ also is within the range of $K$ values developed for Texas. Thus, it can be concluded that the range of shapes (not necessarily peak or time to peak) of the GUH for this study is congruent with that from some prior research even outside the study area.

The rainfall-runoff pairs from the storm-specific GUH analysis were further analyzed against various basin and rainfall characteristics to develop an equation to estimate the peak streamflow and flood volume based on a quantity of rainfall on the basin. An equation for the estimation of the peak streamflow for an event $\left(\hat{Q}_{p}\right.$ ) was computed using OLS regression, and has an $\mathrm{Adj}-R^{2}$ of 0.795 with a residual standard error of $0.240 \log _{10}$ (cubic feet per second). An equation for the estimation of the flood volume for an event $(\hat{V})$ was computed using OLS regression, and has an Adj- $R^{2}$ of 0.701 , with a residual standard error of $0.240 \log _{10}$ (basin inch).

\section{References Cited}

Abramowitz, Milton, and Stegun, I.A., 1964 [reprinted 1972], Handbook of mathematical functions: National Bureau of Standards Applied Mathematics Series, v. 55, 1,046 p.

Asquith, W.H., and Roussel, M.C., 2007, An initial-abstraction, constant-loss Model for unit hydrograph modeling for applicable watersheds in Texas: U.S. Geological Survey Scientific Investigations Report 2007-5243, 82 p. [Also available at $h t t p: / / p u b s . u s g s . g o v /$ sir/2007/5243.]

Asquith, W.H., Bumgarner, J.R., and Fahlquist, L.S., 2003, A triangular model of dimensionless runoff producing rainfall hyetographs in Texas: Journal American Water Resources Association, v. 39, no. 4, p. 911-921.

Asquith, W.H., Cleveland, T.G., and Roussel, M.C., 2011, A method for estimating peak and time of peak streamflow from excess rainfall for 10- to 640-acre watersheds in the Houston, Texas, metropolitan area: U.S. Geological Survey Scientific Investigations Report 2011-5104, 41 p. [Also available at $h t t p: / / p u b s . u s g s . g o v / s i r / 2011 / 5104$.

Asquith, W.H., Roussel, M.C., Thompson, D.B., Cleveland, T.G., and Fang, Xing, 2004, Summary of dimensionless Texas hyetographs and distribution of storm depth developed for Texas Department of Transportation Research Project 0-4194: Lubbock, Texas Tech Center for Multidisciplinary Research in Transportation, Texas Tech University, Texas Department of Transportation Research Report 0-4194-4, 68 p.

Asquith, W.H., Roussel, M.C., Thompson, D.B., Cleveland, T.G., and Fang, Xing, 2005, Unit hydrograph estimation for applicable Texas watersheds: Lubbock, Texas Tech Center for Multidisciplinary Research in Transportation, Texas Tech University, Texas Department of Transportation Research Report 0-4193-4, 71 p. 
Becker, L.D., 1986, Techniques for estimating flood-peak discharges from urban basins in Missouri; U.S. Geological Survey Water-Resources Investigations Report 86-4322, $38 \mathrm{p}$.

Becker, L.D., 1990, Simulation of flood hydrographs for small basins in Missouri: U.S. Geological Survey WaterResources Investigations Report 90-4045, 40 p.

Becker, L.D., and Alexander, T.W., 1983, Floods in Kansas City, Missouri and vicinity, August 12-13, 1982:

U.S. Geological Survey Water-Resources Investigations Report 83-4141, 35 p.

Bohman, L.R., 1990, Determination of flood hydrographs for streams in South Carolina, Volume 1-Simulation of flood hydrographs for rural watersheds in South Carolina: U.S. Geological Survey Water-Resources Investigations Report 89-4087, 53 p.

Bohman, L.R., 1992, Determination of flood hydrographs for streams in South Carolina, Volume 2-Estimation of peakdischarge frequency, runoff volumes, and flood hydrographs for urban watersheds: U.S. Geological Survey WaterResources Investigations Report 92-4040, 79 p.

Chow, V.T., Maidment, D.R., and Mays, L.W., 1988, Applied hydrology: New York, McGraw-Hill, 572 p.

Cleveland, T.G., He, Xin, Asquith, W.H., Fang, Xing, and Thompson, D.B., 2006, Instantaneous unit hydrograph selection for rainfall-runoff modeling of small watersheds in north and south central Texas: Journal of Irrigation and Drainage Engineering, v. 132, p. 479-485.

Crum, T.D., and Alberty, R.L., 1993, The WSR-88D and WSR-88D Operation Support Facility: Bulletin of the American Meteorological Society, v. 74, no. 9, p. $1669-1687$.

Dillow, J.J.A., 1998, Technique for simulating peak-flow hydrographs in Maryland: U.S. Geological Survey WaterResources Investigations Report 97-4279, 39 p.

Faraway, J.J., 2006, Extending the linear model with R-Generalized linear, mixed effects and nonparametric regression models: Boca Raton, Fla., Chapman and Hall/CRC, 301 p.

Feaster, T.D., and Guimaraes, W.B., 2004, Estimating the magnitude and frequency of floods in small urban streams in South Carolina, 2001: U.S. Geological Survey Scientific Investigations Report 2004-5030, 68 p.

Feaster, T.D., Westcott, N.E., Hudson, R.J.M., Conrads, P.A., and Bradley, P.M., 2012, Comparison of TOPMODEL streamflow simulations using NEXRAD-based and measured rainfall data, McTier Creek watershed, South Carolina: U.S. Geological Survey Scientific Investigations Report 2012-5120, 33 p.
Haan, C.T., Barfield, B.J., and Hayes, J.C., 1994, Design hydrology and sedimentology for small catchments: San Diego, Academic Press, 588 p.

Helsel, D.R. and Hirsch, R.M., 2002, Statistical methods in water resources: U.S. Geological Survey Techniques of Water-Resources Investigations, book 4, chapter A3, 522 p.

Hjelmfelt, A.T., Jr., and Cassidy, J.J., 1975, Hydrology for engineers and planners: Ames, Iowa, Iowa State University Press, $210 \mathrm{p}$.

Inman, E.J., 1987, Simulation of flood hydrographs for Georgia streams: U.S. Geological Survey Water-Supply Paper $2317,26 \mathrm{p}$.

Jayakrishnan, R., Srinivasan, R., and Arnold, J.G., 2004, Comparison of raingage and WSR-88D Stage III precipitation data over the Texas-Gulf Basin: Journal of Hydrology, v. 292 , p. $135-152$.

Mason, R.R., Jr., and Bales, J.D., 1996, Estimating flood hydrographs for urban basins in North Carolina: U.S. Geological Survey Water-Resources Investigations Report 96-4085, 19 p.

Missouri Climate Center, 2014, Climate of Missouri: Columbia, Missouri, University of Missouri, accessed May 2014 at http://climate.missouri.edu/climate.php.

Multi-Resolution Land Characteristics Consortium, 2014, National Land Cover Dataset 2001: accessed June 2014 at http://www.mrlc.gov/index.php.

National Oceanic and Atmospheric Administration, 2006a, Federal Meteorological Handbook No. 11, Part C-WSR88D products and algorithms: U.S. Department of Commerce, Washington D.C., FCM-H11C-2006, accessed August 2014 at $h t t p: / / w w w . o f c m . g o v / f m h 11 / f m h 11 . h t m$.

National Oceanic and Atmospheric Administration, 2006b, Federal Meteorological Handbook No. 11, Part DWSR-88D unit description and operational applications: Washington D.C., U.S. Department of Commerce, FCM-

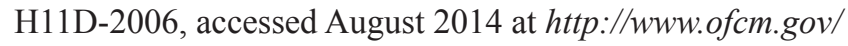
fmh11/fmh11.htm.

National Oceanic and Atmospheric Administration, 2011, Federal Meteorological Handbook No. 11, Part A-System concepts, responsibilities, and procedures: Washington D.C., U.S. Department of Commerce, FCM-H11A-2011, accessed August 2014 at http://www.ofcm.gov/fmh11/fmh11.htm.

National Oceanic and Atmospheric Administration, 2014a, NWS WSR-88D Level III data collection and distribution network information: National Weather Service Radar Operations Center, accessed May 2014 at http://www.roc. noaa.gov/WSR88D/Level_III/Level3Info.aspx. 
National Oceanic and Atmospheric Administration, 2014b, National Climatic Data Center, Climatic Data Online: accessed September 2014 at $h t t p: / / w w w . n c d c . n o a a . g o v / c d o-$ web/.

Natural Resources Conservation Service, 2014a, Geospatial data gateway: U.S. Department of Agriculture, accessed April 2014 at http://datagateway.nrcs.usda.gov.

Natural Resources Conservation Service, 2014b, Hydrographs, chap. 16 of Natural Resources Conservation Service, National Engineering Handbook-Part 630, Hydrology: accessed June 2014 at http://www.nrcs.usda.gov/Internet/ FSE_DOCUMENTS/stelprdb1043095.pdf.

O'Donnell, T., 1960, Instantaneous unit hydrograph derivation by harmonic analysis: Commission of Surface Waters, International Association of Scientific Hydrology Publication 51, p. 546-557.

Rutledge, A.T., 1998, Computer programs for describing the recession of groundwater discharge and for estimating mean ground-water recharge and discharge from streamflow records - update: U.S. Geological Survey Water-Resources Investigations Report 98-4148, 43 p.

Southard, R.E., 2010, Estimating the magnitude and frequency of floods in urban basins in Missouri: U.S. Geological Survey Scientific Investigations Report 2010-5073, 27 p.

Southard, R.E., 2013, Computed statistics at streamgages, and methods for estimating low-flow frequency statistics and development of regional regression equations for estimating low-flow frequency statistics at ungaged locations in Missouri: U.S. Geological Survey Scientific Investigations Report 2013-5090, 28 p. [Also available at http://pubs.usgs. gov/sir/2013/5090/.]
Stricker, V.A., and Sauer, V.B., 1982, Techniques for estimating flood hydrographs for ungaged urban watersheds: U.S. Geological Survey Open-File Report 82-365, 24 p.

U.S. Geological Survey, 2014, National Water Information System: U.S. Geological Survey, accessed October 2, 2014, at http://waterdata.usgs.gov/nwis/sw.

Weaver, J.C., 2003, Methods for estimating peak discharges and unit hydrographs for streams in the City of Charlotte and Mecklenburg County, North Carolina: U.S. Geological Survey Water-Resources Investigations Report 03-4108, $50 \mathrm{p}$.

Westcott, N.E., Knapp, H.V., and Hilberg, S.D., 2008, Comparison of gage and multisensory precipitation estimates over a range of spatial and temporal scales in the Midwestern United States: Journal of Hydrology, v. 351, p. 1-12.

Williams-Sether, T., Asquith, W.H., Thompson, D.B., Cleveland, T.G., and Fang, Xing, 2004, Empirical, dimensionless, cumulative-rainfall hyetographs developed from 1959-86 storm data for selected small watersheds in Texas: U.S. Geological Survey Scientific Investigations Report 2004-5075, 125 p. [Also available at http://pubs.usgs.gov/ $\operatorname{sir} / 2004 / 5075 /$.

Young, C.B., and Brunsell, N.A., 2008, Evaluating NEXRAD estimates for the Missouri River Basin-Analysis using daily raingauge data: Journal of Hydrologic Engineering, v. 13 , no. 7 , p. $549-553$. 

Appendixes 


\section{Appendix 1. Procedure for Determining Shape Parameter Using the Numerical Root Solver in Microsoft ${ }^{\circledR}$ Excel}

As stated in the main body of the report, the shape parameter $(K)$ of the gamma unit hydrograph $(\mathrm{GUH})$ must be determined using a numerical root solver of equation 4 with the volume, $V=1$. This appendix provides the step-by-step procedure to accomplish this using the Solver.xlam routine in Microsoft $\mathrm{f}^{\circledR}$ Excel. Full details of this powerful routine are available in the Help menu of Microsoft ${ }^{\circledR}$ Excel, but in summary:

"Solver is part of a suite of commands sometimes called 'what-if analysis' tools. With Solver, you can find an optimal (maximum or minimum) value for a formula in one cell—called the objective cell-subject to constraints, or limits, on the values of other formula cells on a worksheet. Solver works with a group of cells, called decision variables or simply variable cells, that participate in computing the formulas in the objective and constraint cells. Solver adjusts the values in the decision variable cells to satisfy the limits on constraint cells and produce the result you want for the objective cell" $\left(\right.$ Microsoft $^{\mathbb{R}}$, 2014).

A template to perform various steps in the development of the unit hydrograph is provided (http://pubs.usgs.gov/ sir/2014/5193/downloads/UnitHydrographProcessing Template.xlsx), and contains the various objective and variable cells needed to calculate $K$; however, the basic steps are as follows:

1. In an empty cell, enter the time to peak of the GUH $\left(T_{p}\right)$ computed from equation 8 in the report.

2. In another empty cell, enter the basin-depth peak streamflow $\left(q_{p}\right)$ computed from equation 7 in the report.

3. In another empty cell, enter a preliminary value for $K$. This can be any value, because it will be the variable cell used in the Solver routine, but to start, enter the median value of $K=3.3$ for urban areas in Missouri.

4. Rewriting equation 4 for the determination of gamma hydrograph volume with $V=1$ and solving for $q_{p}$ gives

$$
\begin{gathered}
V=1=q_{p} T_{p} \Gamma(K)\left(\frac{e^{(1)}}{K}\right)^{K} \\
\text { or } \\
q_{p}=\frac{1}{T_{p} \Gamma(K)\left(\frac{e^{(1)}}{K}\right)^{K}}
\end{gathered}
$$

Enter this equation into another empty cell near the cell containing the $q_{p}$ from equation 7 (step 2). In Microsoft ${ }^{\mathbb{Q}}$ Excel, this will look like:

$$
=1 /\left(\boldsymbol{T}_{p}^{*} \operatorname{EXP}(\operatorname{GAMMALN}(\boldsymbol{K}))^{*}(\operatorname{EXP}(1) / \boldsymbol{K})^{\wedge} \boldsymbol{K}\right)
$$

where $\boldsymbol{T}_{p}$ and $\boldsymbol{K}$ are pointers to the corresponding cells containing these values.

5. In an adjacent cell, compute the difference between the $q_{p}$ value determined from equation 7 and the $q_{p}$ value determined from the equation entered in step 4 . This will become the objective cell.

6. On the Data tab, in the Analysis group, click Solver (as shown).

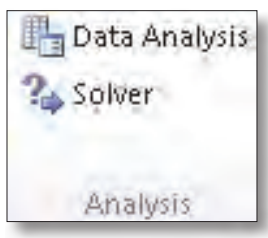

Note: if the Solver command or the Analysis group is not available, the Solver Add-in program needs to be loaded.

7. In the Set Objective: box, enter the cell reference for the objective cell (the cell containing the difference from step 5).

8. To make the difference between the $q_{p}$ values in the objective cell equal to zero, select the radio button by Value Of:, and type " 0 " in the box.

9. In the By Changing Variable Cells: box, enter the cell reference for the variable cell containing $K$ from step 3 .

10. No constraints are required, so leave the Subject to the Constraints: box blank. The checkbox for Make Unconstrained Variables Non-Negative can be checked.

11. Ensure the GRG Nonlinear solving method is selected from the Select a Solving Method: pull-down menu. No additional options are necessary.

12. Click Solve and do one of the following:

a. To keep the new value of $K$, click Keep Solver Solution in the Solver Results dialog box.

b. To restore the original value of $K$ (from before you clicked Solve), click Restore Original Values.

Following these steps, $K$ should adjust such that the difference in the objective cell is 0 , and the computed value of $q_{p}$ from step 4 equals the $q_{p}$ computed by equation 7 in step 2 .

\section{Reference Cited}

Microsoft $^{\circledR}$, 2014, Microsoft ${ }^{\circledR}$ Excel Help: accessed August 18, 2014. 


\section{Appendix 2. Methods Used to Estimate Basin Composite Curve Number}

The procedures used to develop the basin composite curve number $(C N)$ are explained in this appendix. The process included the intersection of two digital data layers in a geographic information system (GIS) and combined with data about runoff $C N \mathrm{~s}$ for various soil types and conditions from the Natural Resources Conservation Service (NRCS), National Engineering Handbook (NEH) Part 630, Chapter 9, Hydrologic Soil-Cover Complexes (Natural Resources Conservation Service, 2014).

The first data layer was the land use and land coverage (LULC) classification data layer available as part of the 2001 National Land Cover Dataset (NLCD) from the Multi-Resolution Land Characteristics Consortium (2014), and is summarized in table 2-1 for the classifications present in urban areas in Missouri. The other data layer was the hydrologic soil group classification code layer available from the NRCS Soil Survey Geographic (SSURGO) Database (Natural Resources Conservation Service, 2014a), which consists of polygons with one of the four soil group codes (A, B, C, or D) that corresponds to the surface soils in the area. The soil group codes were transferred from letters to numerals (" 10 " for A, " 20 " for B, " 30 " for C, " 40 " for $\mathrm{D}$, and " 99 " for unknown), and the two layers were intersected to form a single layer consisting of polygons with unique, combined soil group and LULC codes. For example, a polygon code of "2022" would represent a low intensity developed area (LULC 22) in soil type B (“20").

Chapter 9 of NEH Part 630 (Natural Resources Conservation Service, 2014) was used to assign a runoff $C N$ for each of the unique soil group and LULC codes developed. Chapter 9 of NEH Part 630 is diverse and thorough, providing runoff $C N$ s for a wide variety of land use types, subtypes and hydrologic conditions. For example, in the table for agricultural land, the cover type can be fallow, row crops, small grain crops, or several other types; row crops are further described by the cover treatment of straight row, contoured, contoured and terraced, or combinations of these three; each of these in turn can have a "poor" or "good" hydrologic condition. Given the wide variety of choices and the lack of direct correlation between the LULC codes and the various hydrologic soilcover complexes, some interpretation and simplification was required. A matrix of the runoff $C N$ for each soil type and LULC combination is shown in table 2-2. The three LULC codes for forest $(41,42$, and 43; table $2-1)$ were combined because table 9-1 of NEH Part 630 (Natural Resources
Conservation Service, 2014) does not break forested area into different distinct types, and rather uses the single category "woods" (table 2-2). Furthermore, chapter 9 of NEH Part 630 (Natural Resources Conservation Service, 2014) does not have $C N$ s for water or wetlands, so the three distinct LULC codes (codes 11, 90, and 95; table 2-1) were represented as highly impervious areas, using the $C N \mathrm{~s}$ for paved parking lots and roofs (table 2-2). There were a few areas where the SSURGO data did not indicate a soil group code. A visual examination of these areas in the SSURGO overlain on the LULC indicated that most of these areas were either bodies of water or one of the "developed" LULC codes (codes 21-24; table 2-2). These polygons were assigned a combined soil group and LULC code of "9999" and were subsequently assigned a $\mathrm{CN}$ of 93 as an approximate average of the various $C N \mathrm{~s}$ associated with developed land for the other soil group and LULC codes in table 2-2 .

As indicated in table 2-2, the hydrologic condition generally was assumed to be "good" because of the well-established nature of the development in most of the urban basins examined in Missouri. The "good" hydrologic condition implies the conditions encourage average or better than average infiltration and decrease runoff. If the methods of this report are used to establish the $C N$ for an ungaged basin, the user can refine the runoff $C N$ based on known conditions in the basin. The digital data layer from which the $C N \mathrm{~s}$ were determined for this report is included as a digital attachment (http://pubs.usgs. gov/sir/2014/5193/downloads/soil_lulc_mo.zip) for use with ungaged basins.

The $C N$ for a given soil group type and LULC code was multiplied by the percentage area of the polygon type in the basin. The sum of the products of the $C N$ and percentages resulted in the average $C N$ for the basin shown as the "Composite NRCS CN" in table 1 in the main body of the report.

\section{Reference Cited}

Natural Resources Conservation Service, 2014, Hydrologic soil-cover complexes, chap. 9 of Natural Resources Conservation Service, National Engineering Handbook-Part 630, Hydrology: accessed June 2014 at http://www.nrcs.usda. gov/Internet/FSE_DOCUMENTS/stelprdb1043088.pdf. 
Table 2-1. Land use and land cover classifications and descriptions used to develop runoff curve numbers for streamgages in urban areas in and adjacent to Missouri, from the National Land Cover Dataset (Multi-Resolution Land Characteristics Consortium, 2014).

[LULC, land use and land cover]

\begin{tabular}{cc}
\hline LULC code & Description \\
\hline 11 & Open water-All areas of open water, generally with less than 25 percent cover or vegetation or soil. \\
21 & $\begin{array}{l}\text { Developed, open space _-Includes areas with a mixture of some constructed materials, but mostly vegetation in the form of } \\
\text { lawn grasses. Impervious surfaces account for less than } 20 \text { percent of total cover. These areas most commonly include } \\
\text { large-lot single-family housing units, parks, golf courses, and vegetation planted in developed settings for recreation, } \\
\text { erosion control, or aesthetic purposes. }\end{array}$
\end{tabular}

22 Developed, low intensity - Includes areas with a mixture of constructed materials and vegetation. Impervious surfaces account for 20-49 percent of total cover. These areas most commonly include single-family housing units.

23 Developed, medium intensity - Includes areas with a mixture of constructed materials and vegetation. Impervious surfaces account for 50-79 percent of the total cover. These areas most commonly include single-family housing units.

24 Developed, high intensity - Includes highly developed areas where people reside or work in high numbers. Examples include apartment complexes, row houses, and commercial/industrial. Impervious surfaces account for 80-100 percent of the total cover.

31 Barren land (rock/sand/clay) — Barren areas of bedrock, desert pavement, scarps, talus, slides, volcanic material, glacial debris, sand dunes, strip mines, gravel pits, and other accumulations of earthen material. Generally, vegetation accounts for less than 15 percent of total cover.

41 Deciduous forest-Areas dominated by trees generally greater than 5 meters tall, and greater than 20 percent of total vegetation cover. More than 75 percent of the tree species shed foliage simultaneously in response to seasonal change.

42 Evergreen forest - Areas dominated by trees generally greater than 5 meters tall, and greater than 20 percent of total vegetation cover. More than 75 percent of the tree species maintain their leaves all year. Canopy is never without green foliage.

Mixed forest-Areas dominated by trees generally greater than 5 meters tall, and greater than 20 percent of total vegetation cover. Neither deciduous nor evergreen species are greater than 75 percent of total tree cover.

52 Shrub/scrub-Areas dominated by shrubs; less than 5 meters tall with shrub canopy typically greater than 20 percent of total vegetation. This class includes true shrubs, young trees in an early successional stage or trees stunted from environmental conditions.

71 Grassland/herbaceous-Areas dominated by grammanoid or herbaceous vegetation, generally greater than 80 percent of total vegetation. These areas are not subject to intensive management such as tilling, but can be utilized for grazing.

81 Pasture/hay_-Areas of grasses, legumes, or grass-legume mixtures planted for livestock grazing or the production of seed or hay crops, typically on a perennial cycle. Pasture/hay vegetation accounts for greater than 20 percent of total vegetation.

82 Cultivated crops-Areas used for the production of annual crops, such as corn, soybeans, vegetables, tobacco, and cotton, and also perennial woody crops such as orchards and vineyards. Crop vegetation accounts for greater than 20 percent of total vegetation. This class also includes all land being actively tilled.

90 Woody wetlands - Areas where forest or shrub land vegetation accounts for greater than 20 percent of vegetative cover and the soil or substrate is periodically saturated with or covered with water.

95 Emergent herbaceous wetlands - Areas where perennial herbaceous vegetation accounts for greater than 80 percent of vegetative cover and the soil or substrate is periodically saturated with or covered with water. 
Table 2-2. Runoff curve numbers for various land use and land cover classifications and soil group types for streamgages in urban areas in and adjacent to Missouri, from tables 9-1 and 9-5 of Chapter 9, National Engineering Handbook Part 630 (Natural Resources Conservation Service, 2014).

[LULC, land use and land cover]

\begin{tabular}{|c|c|c|c|c|c|c|}
\hline \multirow{3}{*}{$\begin{array}{l}\text { LULC code } \\
\text { (table 2-1) }\end{array}$} & \multirow{3}{*}{ Description $^{\mathrm{a}}$} & \multirow{3}{*}{ Source $^{b}$} & \multicolumn{4}{|c|}{ Runoff curve number for soil group } \\
\hline & & & A & B & C & D \\
\hline & & & “10" & “20" & “30" & “40” \\
\hline 21 & $\begin{array}{l}\text { Open space (lawns, parks, golf courses, cemeteries), good condition } \\
\text { (grass cover over } 75 \text { percent) }\end{array}$ & $9-5$ & 39 & 61 & 74 & 80 \\
\hline 22 & $\begin{array}{l}\text { Residential districts, } 1 / 3 \text { acre lot size (town houses), } 30 \text { percent } \\
\text { impervious }\end{array}$ & $9-5$ & 57 & 72 & 81 & 86 \\
\hline 23 & $\begin{array}{l}\text { Residential districts, } 1 / 8 \text { acre or less lot size (town houses), } \\
65 \text { percent impervious }\end{array}$ & $9-5$ & 77 & 85 & 90 & 92 \\
\hline 24 & Urban districts, commercial and business, 85 percent impervious & $9-5$ & 89 & 92 & 94 & 95 \\
\hline 31 & Streets and roads, gravel (including right-off-way) & $9-5$ & 76 & 85 & 89 & 91 \\
\hline ' $41,42,43$ & Woods, good hydrologic condition & $9-1$ & 30 & 55 & 70 & 77 \\
\hline 52 & $\begin{array}{l}\text { Brush—brush/forbs/grass mixture with brush the major element, } \\
\text { good hydrologic condition }\end{array}$ & $9-1$ & 30 & 48 & 65 & 73 \\
\hline 71 & $\begin{array}{l}\text { Pasture, grassland, or range - continuous forage for grazing, good } \\
\text { hydrologic condition }\end{array}$ & $9-1$ & 39 & 61 & 74 & 80 \\
\hline 81 & $\begin{array}{l}\text { Meadow—continuous grass, protected from grazing and generally } \\
\text { mowed for hay }\end{array}$ & $9-1$ & 30 & 58 & 71 & 78 \\
\hline 82 & $\begin{array}{l}\text { Row crops, (average value taken from "contoured cover treatment," } \\
\text { good hydrologic condition }\end{array}$ & $9-1$ & 65 & 75 & 82 & 86 \\
\hline $\mathrm{d} 11,90,95$ & $\begin{array}{l}\text { Paved parking lots, roofs, driveways, and so forth } \\
\text { (excluding right-of-way) }\end{array}$ & $9-5$ & 98 & 98 & 98 & 98 \\
\hline
\end{tabular}

${ }^{a}$ From table 9-1 or table 9-5 in Chapter 9, National Engineering Handbook Part 630 (Natural Resources Conservation Service, 2014).

bSource refers to table 9-1 or table 9-5 in Chapter 9, National Engineering Handbook Part 630 (Natural Resources Conservation Service, 2014).

'The three distinct LULC codes for forest were combined, because table 9-1 in Natural Resources Conservation Service (2014) did not distinguish.

${ }^{\mathrm{d}}$ The three distinct LULC codes for open water, woody wetlands, and emergent herbaceous wetlands were combined as essentially impervious, because none of the the tables in Chapter 9 of National Resource Conservation Service (2014c) provided curve numbers for these types. 


\section{Appendix 3. Procedure for Obtaining Rainfall Hyetograph and Other Rainfall- Related Values from NEXRAD Radar Data}

The procedure to develop a total rainfall hyetograph from either the next generation weather radar (NEXRAD) Level III Digital Precipitation Array (DPA) or Digital Storm Product (DSP) datasets from the National Climatic Data Center (NCDC) is demonstrated in this appendix. The DSP data also can be used to determine the centroid of the rainfall on the basin, as well as the average rainfall and the approximate standard deviation of the rainfall on the basin. Because of the coarse resolution of the DPA data, these additional rainfallrelated values are not as easily determined or not as useful in analysis, particularly for small basins. The links currently (2014) are functional - although some of the data links may change in the future, the procedure likely will remain the same. Tools or commands in Arc and ArcMap (Esri, 2014) are indicated with the Arial Bold font. Other computer commands (such as equations, filenames, field names, and entered data) are indicated with the Arial font.

\section{Obtaining the NEXRAD Data and Converting to a Table in Microsoft ${ }^{\circledR}$ Excel}

1. Delineate all basins of interest from a point of interest on the stream (the "station" on the stream). A geographic information system (GIS) shapefile is necessary for each basin and its associated station.

2. Find the centroid of each basin using the Data Management Tools>Features>Feature to Point tool. Merge the centroids with points of the stations for each basin using the Data Management Tools>General>Merge tool. Open the attribute table of the merged file, create a new field called Type, and manually input whether the point is a station or a centroid. Then, eliminate all fields except FID, Shape, the station number, the station name, and the new Type field.

3. Obtain the dates of storms for which rainfall data are desired, grouping the storms by area.

4. Go to the NCDC NEXRAD Data Archive, Inventory and Access Web site at http://www.ncdc.noaa.gov/nexradinv/.

5. Select the radar on the map closest to the area of interest.

6. Input the date of a particular storm of interest, and select L3 [DPA] - DIGITAL PRECIP ARRAY (ONE HOUR TOTAL) (PPS) (256 LEVEL / $230 \mathrm{KM}$ ) or, if available, L3 [DSP] - STORM TOTAL PRECIPITATION (PPS) (256 LEVEL / 230 KM), then select create Graph.
7. Isolate the time of the rainfall for the given runoff date based on when the radar is in "Precip Mode." Enter email address, and select order Data . If the rainfall carries over to the next day or is carried over from the previous day, order the data from the other days separately by repeating step 6 for each additional day.

8. Repeat steps 4-7 for all storm events of interest in step 3.

9. Open the email received from orders@noaa.gov, typically labeled HAS Data Request: HAS\# Completed, where "HAS\#" corresponds to the order number from the confirmation screen displayed when the order was placed. Open the link contained in the email message, following the ftp procedures that will allow download of all data on a day at once with a web browser. Create a directory for each radar and download the data into a new subfolder in the appropriate radar directory labeled with the date corresponding to the data being downloaded. The first four letters of the files indicate the radar for which the data were taken. Repeat for each email/date.

10. Download the National Oceanic and Atmospheric Administration's (NOAA's) Weather and Climate Toolkit at $h t t p: / / w w w . n c d c . n o a a . g o v / o a / w c t$. Once the toolkit is downloaded, open the toolkit.

11. In the toolkit, open the folder of the DPA or DSP data corresponding to a particular date. List the files, select all the files, and click Export

- Select Shapefile as the Output Format. Create a new folder named "Shapefile" within the folder of the opened DPA or DSP data and select that new folder as the output directory, and click Next

- Because there will be no variables to select, click Next

- Adjust the spatial extent to cover only the area of interest:

- If the viewer has already been set to cover the area of interest, select the checkboxes to Lock Spatial Extent to Viewer and Engage Spatial Filter; or

- Determine the area of interest by loading the basins of interest into ArcMap and finding the geographic coordinates of the corners of a rectangular boundary that completely covers the basins; enter these coordinates into the extent filter boxes; and then

- Click Next 
- Set the Minimum and Maximum values to NONE, and Category Overrides to RF, and click Next

- Because there are no shapefile export options to select, click Next.

- Select Start Export and wait for the export to finish.

- Once finished, click Done and repeat step 11 for each day of data obtained from the NCDC Web site.

12. To use the union tool in ArcMap and get output that keeps the timestamp, trim off everything in the name of each shapefile except the last 6 numbers (WARNING: By cutting off the beginning of the name of the shapefiles, you will lose the information containing the storm date on the files, but by keeping the data and shapefiles organized in a folder labeled with the date, you can keep track of which files belong to which date). To trim the names efficiently, complete the following steps:

- Select all of the files in the directory, hold the shift key and right click, and select Copy as path.

- Open Microsoft ${ }^{\circledR}$ Excel, and paste the copied list of files. A list of the names of all the files in the folder will appear with the full path.

- Insert a column to the left of the list, type mv in the first row of the new column and copy it down for the whole list.

- In the column to the right of the list type $=\operatorname{Right}(B 2,28)$, and in the next column to the right type $=\operatorname{Right}(B 2,10)$ and copy these down for the whole list. Highlight the two columns and copy them, then use the Paste Special... command to paste the values over the formulas in the highlighted columns. Delete the column with the long, full path name so that only the columns with mv, the full file name as it exists without the full path, and the shortened name of the timestamp remain. Save the file as a formatted text (space delimited) file labeled list.aml in the same directory as the shapefiles. This will save the name as list.aml.prn—remove the ".prn” from the end, making it list.aml.

- In Arc, type "cd", drag and drop the folder containing the shapefiles for a particular day, and press Enter. Type \& $\mathbf{r}$ list.aml and press Enter. Once this is finished running, the files will all be renamed with only the timestamp corresponding to the data.

13. Open ArcMap and pull in all the shapefiles for a particular day. Use the Analysis Tools>Overlay>Union tool to create a union of all the DPA or DSP shapefiles for a particular day. Label the union output file with the date corresponding to the DPA or DSP shapefiles. Repeat for each date.

14. In ArcMap, open the data layer with the basins, stations, and centroids. Use the Analysis

Tools>Overlay>Intersect tool to intersect the merged centroids and stations points (from step 2) with each of the union outputs. Label the intersect output file as the date corresponding to the union (which is the date corresponding to the DPA or DSP shapefiles).

15. Open the attribute table of the intersect file created in step 14 , and export it to a text file (*.txt) in the directory where the intersect file was stored. Open this text file in Microsoft $^{\circledR}$ Excel, using a comma delimiter. WARNING: Don't simply open the *.dbf file (which can be opened in Microsoft $^{\circledR}$ Excel) because all of the data may not be there.

16. Transpose, sort, and organize the data in each Microsoft $\mathrm{f}^{\circledR}$ Excel workbook by performing the following steps (the provided template [http://pubs.usgs.gov/sir/2014/5193/ downloads/RainShapefileTemplate.xlsx] does this automatically, except the final step below).

- The data in the value* column gives the DPA or DSP rainfall information, and the FID_* column titles associate the rainfall value with a time; therefore, link the rainfall information with the time information by moving (or otherwise associating) the FID_* column titles to the rainfall value data (the template does this by indirect reference from the "Transposed" worksheet to the "Template" worksheet). WARNING: the first FID_* column likely contains a piece of the date and not the time; make sure that the value* data line up with an appropriate FID_* time column title.

- The FID_* column contains the time associated with the data (FID_hhmmss). Isolate the time by hour and minute and have it ready for subsequent calculations, using the $=\operatorname{Mid}()$, =Right(), and $=\operatorname{Left}()$ functions to isolate the respective hour and minute, and use the $=$ Value() function to convert the values to a number.

- Remove all colorlnd* columns completely (the template does this by not referencing these rows in the "Template" worksheet).

- Enter the appropriate year, month, and day of the storm (from the file name) and copy it down throughout the data.

- The final product in each Microsoft ${ }^{\circledR}$ Excel workbook should contain a time series of data for each station (if precipitation occurred at the station during the time period) for a particular date. For multiple storms at multiple sites, it is recommended to use the template provided (http://pubs.usgs.gov/sir/2014/5193/ downloads/RainShapefileTemplate.xlsx) that performs these functions automatically. 
17. Combine the data where a particular storm occurred during multiple days.

18. Remove all extraneous data (such as data for a particular storm event if it is not of interest at a particular station).

19. If desired, the data can be organized by station (instead of by storm date), with each storm on a separate worksheet. The time of interest for each particular storm at a station can be highlighted and extraneous data before and after the time of interest can be removed.

\section{Obtaining Hyetograph from the NEXRAD Tabular Data in Microsoft ${ }^{\circledR}$ Excel}

The procedures to obtain a rainfall hyetograph are slightly different depending on the data source (DPA or DSP); although the DSP data represent the accumulated rainfall since the beginning of the precipitation event, the DPA data represent the accumulated rainfall during the previous hour, which changes how the data need to be extracted for a hyetograph. These procedures can be used to create a rainfall hyetograph from either the station or the centroid rainfall data, or both. A template to perform these steps is provided (http://pubs.usgs. gov/sir/2014/5193/downloads/UnitHydrographProcessing Template.xlsx). The time increment between radar sweeps varies between 4 and 5 minutes when the radar is in "Precip Mode," and it will be necessary to do some additional manipulation to the data to get a 5-minute hyetograph that corresponds to the 5-minute runoff data. It is important to recognize that the NEXRAD data are in Greenwich Mean Time (GMT) when attempting to correlate it with runoff data.

1. The first step is the same for either a DPA or DSP dataset: Convert the actual date and time of each storm to a running time of hours, starting with the hour (out of 24) the data begins. To do this, perform the following steps:

a. Create a time for each line in Julian serial format, using the $=$ Date( $)$ function summed with the Time() function.

b. At the top of the date column, create a cell that has only the date (not the time) of the first observation, using the $=$ Date () function.

c. Create another time column by subtracting the value in the cell from step (b) from the Julian date from step (a) and multiplying by 24 to convert the Julian serial day format to hours.

2. To obtain a rainfall hyetograph,

a. From DPA data:

- Create a One-Hour Previous time column, a Hyetograph column, and an Intermediate column.
- In the One-Hour Previous column, take the time step (in Julian serial format) and subtract 1 hour and add 1 second to it.

- In the Hyetograph column, subtract the value in the Intermediate column (explained in next step) from the DPA data for that time step. If the difference is less than zero, use zero as the value.

- In the Intermediate column, use the =Sumifs() function to sum the Hyetograph column from the previous hour (the One-Hour Previous column) up to, but not including, the current time step.

b. From DSP data, create a Hyetograph column, and subtract the previous line of DSP data from the current line. If the difference is less than zero, use zero as the value.

3. These procedures create a radar time-specific hyetograph, with variable time steps defined by the radar sweep times. To convert the radar hyetograph to a 5-minute rainfall hyetograph, use the $=$ Sumifs () function to group the radar Hyetograph column by 5 minutes in an additional column. The radar hyetograph can be converted to any desired increments (such as 15 or 30 minutes), but 5 minutes exclusively was used for this analysis.

\section{Obtaining Basin-Average Rainfall and Centroid of Rainfall-Digital Storm Product Data Only}

The DSP 5-minute rainfall hyetograph can be adjusted based on the basin-average rainfall. The incremental rainfall amounts can be multiplied by the ratio of the basin-average rainfall to the sum of the rainfall in the unadjusted hyetograph. This method conserves mass, such that the total volume of rainfall in each DSP cell in the basin (from the final radar sweep of a given storm) was equal to the volume under the scaled hyetograph. To obtain the basin-average rainfall (for DSP data only), complete the following steps:

1. Find the last time slot with rainfall from the radar rainfall hyetograph;

2. Pull the single DSP shapefile corresponding to the date and time of interest into ArcMap, along with a shapefile of the basin of interest; and

3. Clip the DSP shapefile to the basin shapefile using the Analysis Tools $>$ Extract $>$ Clip tool;

4. Calculate the areas of the newly clipped file using the Spatial Statistics Tools $>$ Utilities $>$ Calculate Areas tool;

5. Convert the areas from square meters to square miles with a unit conversion $\left(3.2808^{2} / 5280^{2}\right)$, and then weight those 
areas with the value corresponding to the area with the

Data Management Tools $>$ Fields $>$ Calculate Field tool;

6. Find the centroids of the specified areas with the Data Management Tools>Features $>$ Feature to Point tool; and

7. The sum of the weighted areas in the attribute table ( $F \_$Area field) divided by the area of the basin (in square miles) is the basin-average rainfall for a particular storm on a particular basin.

To obtain the centroid of the rainfall (for DSP data only):

8. Calculate the geographic mean of the points from step 6, with the new weighted areas as the Weight Field using the Spatial Statistics Tools>Measuring Geographic Distributions>Mean Center tool; and

9. The attribute table yields the geographic coordinates of the centroid of the rainfall for a particular storm on a particular basin.

\section{Obtaining Standard Deviation of Rainfall- Digital Storm Product Data Only}

Using the attribute table data computed in step 7 of the "Obtaining Basin-Average Rainfall and Centroid of RainfallDigital Storm Product Data Only," the values for each of the radial cells in the DSP data also are reported in the value field. The standard deviation of these values provides a qualitative sense of the standard deviation of the rainfall when one ignores the radial nature of the data from the radar (see fig. 3 in the report). This value is useful to determine the distribution of the rainfall on the basin: if the standard deviation is low, the rainfall values are relatively uniformly distributed across the basin, whereas if the standard deviation is high, the rainfall values are not uniformly distributed across the basin, or there may be a few radar bins with high or low outliers.

\section{Reference Cited}

Esri, 2014, ArcGIS, accessed September 23, 2014, at

http://www.esri.com/software/arcgis/. 
Publishing support provided by:

Rolla Publishing Service Center

For more information concerning this publication, contact: Director, Missouri Water Science Center

U.S. Geological Survey

1400 Independence Road, MS-100

Rolla, MO 65401

(573) 308-3667

Or visit the Missouri Water Science Center Web site at: http://mo.water.usgs.gov/ 

